\title{
Guía de Práctica Clínica Mexicana para el diagnóstico y tratamiento de la Enfermedad Pulmonar Obstructiva Crónica GUÍA MEXICANA DE EPOC, 2020 GMEPOC 2020
}

\author{
Mexican clinical practice guideline for diagnosis and \\ treatment of chronic obstructive pulmonary disease
}

\author{
Comité Ejecutivo y Grupo Nuclear
}

Juan Carlos Vázquez-García, ${ }^{1}$ Rafael de Jesús Hernández-Zenteno, ${ }_{1}^{1}$ José Rogelio Pérez-Padilla, María del Carmen Cano-Salas, ${ }^{1}$ Margarita Fernández-Vega, ${ }^{1}$ Jorge Salas-Hernández,

Marco Antonio Figueroa-Morales, ${ }^{2}$ Rosaura Esperanza Benítez-Pérez, Luis Adrián Rendón-Pérez, ${ }^{3}$ Jesús Vázquez-Cortés, ${ }^{4,5}$ Mayra Edith Mejía-Ávila, ${ }^{1,5}$ José Luis Mayorga-Butrón ${ }^{6,7}$

\section{Coautores}

Moisés Acuña-Kaldman, ${ }^{8}$ Rocío Barriga-Acevedo, ${ }^{9}$ Alma Rosa Bizarrón-Muro, ${ }^{10}$ Robert Camargo-Ángeles, ${ }_{11}^{11}$ Catalina Casillas-Suárez, ${ }^{12}$ Celia Oralia Castañeda-Hernández, ${ }^{13}$ Rafael Patricio Castañón-Rodríguez, ${ }_{1}$ Juan Francisco Castillo-Sánchez, ${ }^{14}$ Arturo Cortés-Télles, ${ }^{15}$ Jesús Javier Díaz-Castañón ${ }_{1}^{16}$ Abelardo Elizondo Ríos, ${ }^{3}$ María Guadalupe Espitia-Hernández, ${ }^{17}$ Martha Angélica García-Avilés, ${ }^{11}$ Rogelio García-Torrentera, ${ }^{1,18}$ Julio Edgardo González Aguirre, ${ }^{3}$ Fernando Carlos Guillén-Ortega, ${ }^{19}$ José Carlos Herrera-García, ${ }^{20}$ Marco Antonio Loustaunau-Andrade, ${ }^{21}$ Gerardo Ezequiel Magdaleno Maldonado, ${ }^{22}$ Luz Audina Mendoza Topete, ${ }^{23}$ José Padua-García, ${ }^{24}$ Andrés Palomar-Lever, ${ }^{24}$ Rafael Francisco Páramo-Arroyo, ${ }^{25}$ Saraí del Carmen Toral-Freyre, ${ }^{1,18}$ José Felipe Villegas-Elizondo, ${ }^{3}$ Edgar Gerardo Zozoaga-Velázquez ${ }^{26}$

${ }^{1}$ Instituto Nacional de Enfermedades Respiratorias. Tlalpan, Ciudad de México; ${ }^{2}$ Hospital General de Zona No. 76, IMSS, Estado de México; ${ }^{3}$ Hospital Universitario "Dr. José Eleuterio Gonzalez". Monterrey, Nuevo León; ${ }^{4}$ Hospital Ángeles Lomas. Huixquilucan, Estado de México; ${ }^{5}$ Sociedad Mexicana de Neumología y Cirugía de Tórax A.C. Benito Juárez, Ciudad de México; ${ }^{6}$ Instituto Nacional de Pediatría, Ciudad de México; ${ }^{7}$ Departamento de Posgrado, Facultad de Medicina, Universidad Nacional Autónoma de México, México; ${ }^{8} \mathrm{Hospital}$ General del

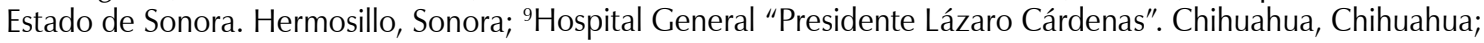

${ }^{10}$ Tepic, Nayarit; ${ }^{11}$ Centro Nacional de Programas Preventivos y Control de Enfermedades, CENAPRECE, Secretaría de Salud; ${ }^{12}$ Hospital General de México "Dr. Eduardo Liceaga". Cuauhtemoc, Ciudad de México; ${ }^{13}$ Instituto de Salud del Estado de México; ${ }^{14}$ Hospital Regional del ISSSSTE. Monterrey, Nuevo León; ${ }^{15}$ Mérida, Yucatán;

${ }^{16}$ Universidad Autónoma de Guadalajara. Guadalajara, Jalisco; ${ }^{17}$ Hospital Regional $1{ }^{\circ}$ de Octubre, ISSSTE, Ciudad de México; ${ }^{18}$ Asociación Mexicana de Terapia Respiratoria, A.C. Ciudad de México; ${ }^{19} \mathrm{Hospital}$ General Belisario Domínguez, ISSSTE, Tuxtla Gutiérrez, Chiapas; ${ }^{20} \mathrm{Hospital}$ Universitario de Puebla. Benemérita Universidad

Autónoma de Puebla. Puebla, Puebla; ${ }^{21}$ ISSSTECALI UABC. Mexicali, Baja California; ${ }^{22}$ Hospital Central Militar. Miguel Hidalgo, Ciudad de México; ${ }^{23}$ Centro Médico Nacional de Occidente, IMSS. Guadalajara, Jalisco;

${ }^{24}$ Centro Médico ABC. Álvaro Obregón, Ciudad de México; ${ }^{25}$ Hospital TEC 100, Universidad Anáhuac Querétaro. Querétaro, Querétaro; ${ }^{26}$ UMAE Hospital de Especialidades Número 1 Bajío, IMSS. León, Guanajuato. 


\section{Abreviaturas}

AGREE II = The Appraisal of Guidelines for Research \& Evaluation (por sus siglas en inglés) o Instrumento de Evaluación de Guías de Práctica Clínica (segunda versión).

$\mathrm{AV}=$ Apoyo ventilatorio (por sus siglas en inglés: VS, ventilatory support).

CAT $=$ Cuestionario de calidad de vida (COPD Assessment Test, por sus siglas en inglés).

$\mathrm{CEI}=$ corticosteroides inhalados.

COPD $=$ enfermedad pulmonar obstructiva crónica (Chronic Obstructive Pulmonary Disease, por sus siglas en inglés).

CENETEC $=$ Centro Nacional de Excelencia Tecnológica en Salud.

$\mathrm{CO}_{2}=$ dióxido de carbono.

$\mathrm{CPAP}=$ presión positiva continua en la vía aérea (Continuous Positive Airway Pressure, por sus siglas en inglés).

$\mathrm{CVL}=$ capacidad vital lenta

$\mathrm{DM}=$ diferencia de medias.

DLCO = difusión pulmonar de monóxido de carbono.

$\mathrm{EC}=$ ensayo(s) clínico(s).

$\mathrm{EPAP}=$ presión positiva espiratoria.

$E P O C=$ enfermedad pulmonar obstructiva crónica.

FVC = capacidad vital forzada (forced vital capacity, por sus siglas en inglés).

$\mathrm{FEV}_{1}=$ volumen espiratorio forzado en un segundo (por sus siglas en inglés: Forced Expiratory Volume).

GesEPOC = acrónimo para la Guía Española de la EPOC.

GMEPOC = Guía Mexicana de Enfermedad Pulmonar Obstructiva Crónica.

GPC = Guía de Práctica Clínica.

HFNC = terapia de oxígeno con flujo alto por puntas nasales (high flow nasal cannula, por sus siglas en inglés).

IC 95\% = intervalo de confianza de 95\%.

IDMp = inhalador de dosis medida presurizado.

Índice BODE = índice creado para el acrónimo Body mass index, Obstruction, Dyspnea and Exercise, por sus siglas en inglés.

IPAP = presión positiva inspiratoria.

IPDE4 = inhibidor de fosfodiesterasa 4.

IPS = inhalador de polvo seco.

$\mathrm{LABA}=\beta_{2}$-agonista de acción prolongada (long acting beta-agonist, por sus siglas en inglés).

LAMA = anticolinérgico de acción prolongada (long-acting muscarinic antagonist, por sus siglas en inglés).

$\mathrm{mMRC}=$ escala de disnea (modified Medical Research Council, por sus siglas en inglés).

$\mathrm{NE}=$ nivel de evidencia.

PCV 13 = vacuna polivalente conjugada de 13 polisacáridos.

$\mathrm{PICO} / \mathrm{PECO}$ = acrónimo para Patient, Intervention/Exposition, Comparison, Outcome, por sus siglas en inglés.

$\mathrm{PFR}=$ pruebas de función respiratoria.

pMDI = pressurized metered dose inhaler (por sus siglas en inglés) o inhalador de dosis medida presurizado.

PPSV 23 = vacuna de neumococo polivalente de 23 polisacáridos.

$\mathrm{OR}=$ razón de probabilidades (odds ratio, por sus siglas en inglés). 
$\mathrm{RP}=$ rehabilitación pulmonar.

$\mathrm{RR}=$ razón de riesgo (risk ratio, por sus siglas en inglés).

$\mathrm{RS}=$ revisión sistemática de la literatura.

$\mathrm{SABA}=\beta_{2}$-agonista de acción corta (short-acting beta-agonist, por sus siglas en inglés).

SAMA = anticolinérgico de acción corta (short-acting muscarinic antagonist, por sus siglas en inglés).

$\mathrm{SpO}_{2}=$ saturación de oxígeno por pulsometría .

SIGN = Scottish Intercollegiate Guidelines Network, por sus siglas en inglés.

$S G R Q=$ cuestionario respiratorio Saint George.

TRN = terapia de reemplazo de nicotina.

$\mathrm{UTI}=$ unidad de terapia intensiva.

$\mathrm{VMI}=$ ventilación mecánica invasiva .

$\mathrm{VMNI}=$ ventilación mecánica no invasiva.

$\mathrm{Vt}=$ volumen tidal o volumen corriente. 
Neumol Cir Torax. 2019; 78 (supl. 1): s1-s76

RESUMEN. Introducción: La enfermedad pulmonar obstructiva crónica (EPOC) es una de las principales causas de muerte en México y en el mundo. Pese a que en los últimos años se ha alcanzado un gran progreso en su manejo y tratamiento, esto también ha conllevado una mayor complejidad. En México, es fundamental el desarrollo de guías de práctica clínica (GPC) que estén basadas en estándares internacionales para establecer recomendaciones a todos los niveles de atención. Objetivos: El objetivo fue desarrollar una GPC con recomendaciones clínicas desarrolladas de forma sistematizada para asistir a la toma de decisiones, tanto de médicos de todos los niveles de atención, como de pacientes, cuidadores de pacientes y todos los elaboradores de políticas públicas involucrados en el manejo de pacientes con enfermedad pulmonar obstructiva crónica. Material y métodos: Este documento fue desarrollado por parte de la Sociedad Mexicana de Neumología y Cirugía de Tórax en cumplimiento con los estándares internacionales como los descritos por el Instituto de Medicina de los Estados Unidos (IOM, por sus siglas en inglés). Se integró un Grupo de Desarrollo de la Guía (GDG) de manera interdisciplinaria, considerando la participación de neumólogos y metodólogos con experiencia en revisiones sistemáticas de la literatura y el desarrollo de GPC. De forma sistematizada, se consensuaron los alcances, las preguntas clínicas y se evaluaron otras Guías Internacionales sobre el tema. Se evaluó críticamente la calidad metodológica de esas GPC. A través del abordaje ADAPTE, se transculturizó la GPC a nuestro país y, finalmente, utilizando metodología de consenso formal de expertos, se desarrollaron las recomendaciones clínicas. Resultados: Se consensuaron 40 preguntas estructuradas clínicamente relevantes para el diagnóstico y tratamiento, así como las recomendaciones clínicas pertinentes y su texto de soporte. Las recomendaciones abarcan preguntas sobre diagnóstico y tratamiento. Conclusión: Esta GPC pretende proveer recomendaciones clínicas para el diagnóstico y manejo terapéutico de los distintos estadios de la EPOC basadas en evidencia científica, que asisten en el proceso de toma de decisiones compartidas y que esperamos contribuyan a mejorar la calidad de la atención clínica en las pacientes con EPOC.

Palabras clave: Guías de Práctica Clínica, medicina basada en evidencia, enfermedad pulmonar obstructiva crónica.

ABSTRACT. Introduction: Chronic obstructive pulmonary disease (COPD) is one of the leading causes of the death in Mexico and worldwide. In recent years, great progress has been achieved in its management and treatment, which also entails greater complexity. In Mexico, the development of clinical practice guidelines (CPG) under international standards is essential to stablish recommendations at all levels of care. Objectives: This Clinical Practice Guideline provides systematically developed clinical recommendations to assist clinical decision makers involved in the management of patients with COPD. Material and methods: This document was developed by the Mexican Respiratory Society in compliance with international standards described by the IOM (Institute of Medicine). An interdisciplinary Guideline Development Group (GDG), considering experts in respiratory medicine and methodologists with experience in systematic reviews of the literature and CPG development. GDG agreed the scope of the guideline, the clinical questions list and made the critical appraisal of the current evidence with validated tools. We use ADAPTE approach to conduct the cross-cultural adaptation of several international guidelines in order to provide clinical recommendations suitable to our country. Results: The GDG agreed on 40 clinically relevant questions in order to develop clinical recommendations. The scientific evidence that answered each of these clinical questions was identified and critically evaluated, before being incorporated into the body of evidence of the guideline. The GDG agreed by means of the formal consensus technique modified panel Delphi, the final drafting of the clinical recommendations. Recommendations address important clinical gaps regarding diagnoses and treatment of COPD. Conclusion: This CPG intends to provide clinical recommendations for the diagnosis and management of patients with Chronic Obstructive Pulmonary Disease and to assist in the shared decision-making process. The GDG hopes that this guide will contribute to improve the quality of clinical care in patients with this illness.

Keywords: Clinical Practice Guidelines, evidence-based medicine, chronic obstructive pulmonary disease. 


\section{1: Introducción}

La enfermedad pulmonar obstructiva crónica (EPOC) es una de las principales causas de muerte en México y en el mundo. La carga a la salud de los mexicanos por esta enfermedad es mayor, no sólo en fatalidades, también en la discapacidad que produce, en la afectación en la calidad de vida de los pacientes y sus familiares y en los costos personales y al sistema de salud. En las últimas dos décadas se ha alcanzado un gran progreso en la incorporación de nuevos tratamientos y en el manejo integral de los enfermos, lo que conlleva también una mayor complejidad para la educación y la capacitación de los profesionales médicos y de los pacientes, así como para la toma de decisiones en las instituciones de salud.

A nivel global son cada vez más los esfuerzos que se hacen para generar recomendaciones clínicas basadas en la mayor evidencia científica para el diagnóstico y tratamiento de las principales enfermedades crónico-degenerativas, entre ellas la EPOC. Estas recomendaciones se agrupan en documentos oficiales denominados guías de práctica clínica (GPC) que suelen ser gestionadas y desarrolladas por organizaciones gubernamentales o no gubernamentales como las asociaciones médicas profesionales. A nivel internacional se han elaborado procedimientos y recomendaciones para generar guías bajo metodología estandarizada y validada. En este contexto, con la finalidad de evitar duplicidad de esfuerzos y hacer más eficiente el uso de recursos, se recomienda generar una GPC local y propia bajo un proceso de adaptación y transculturización de las principales guías internacionales. Este proceso toma en cuenta las diferencias culturales, el estado actual y la organización de los sistemas de salud, así como la disponibilidad de recursos de cada país. Además, se realiza bajo la opinión de expertos clínicos y de los pacientes, considerando sus valores y su propia idiosincrasia.

La inequidad de los sistemas de salud en México es una realidad insoslayable; claramente, existe menor disponibilidad de recursos y especialistas, en particular de la medicina respiratoria, fuera de las grandes ciudades y centros hospitalarios. Esto contrasta con una creciente mortalidad y prevalencia de las principales enfermedades respiratorias.

La Guía Mexicana de EPOC, GMEPOC nace como un esfuerzo de los autores y sus instituciones bajo la política y gestión financiera y administrativa de la Sociedad Mexicana de Neumología y Cirugía de Tórax, A.C. GMEPOC, 2020 es una GPC desarrollada bajo las recomendaciones metodológicas internacionales y adaptada a la realidad de la población y del sistema de salud de México. Su desarrollo, pero especialmente su implementación, contribuirá a disminuir la brecha en el diagnóstico y tratamiento de los pacientes con EPOC en las diferentes instituciones y en todos los niveles de atención.

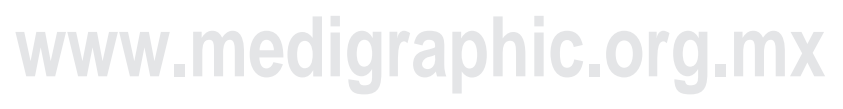




\section{2: La carga de EPOC en México}

El estudio sobre la Carga Mundial de Enfermedades (GBD, por sus siglas en inglés) de 2017 con información de enfermedades y factores de riesgo de 195 países y territorios a nivel global colocó a la enfermedad pulmonar obstructiva crónica (EPOC) como la cuarta causa de muerte general. En el año 2017, esta enfermedad fue responsable del $5.72 \%$ de todas las fatalidades, con más 3 millones de muertes en todo el mundo, ${ }^{1,2}$ y se predice que para 2020 será la tercera causa de muerte global y, que para el año 2030, alcanzará 4.5 millones de muertes. ${ }^{2}$ En México, durante el año 2017, se estimó que el $4.07 \%$ de todas las muertes, es decir, casi 29 mil fatalidades fueron por EPOC. ${ }^{1}$ En la última década en nuestro país, esta enfermedad ha fluctuado entre la cuarta y séptima causa de muerte de acuerdo con estadísticas oficiales.

En el contexto de las enfermedades crónico-degenerativas, está muy por debajo de las enfermedades cardiovasculares, la diabetes y el cáncer, pero muy cerca de las enfermedades cerebrovasculares y hepáticas. Los datos de mortalidad en México y en el mundo se deben interpretar con reserva, ya que las denominaciones de la enfermedad son aún muy variadas dentro de la Clasificación Internacional de Enfermedades (CIE); entre ellas, se incluyen: EPOC, enfisema, bronquitis crónica, asma, estado asmático y otras enfermedades obstructivas. La exactitud de los registros también podría verse afectada por la gran cantidad de subdiagnósticos y también por el error diagnóstico.

En México, la mortalidad por EPOC es menor al promedio mundial (4.07 versus $5.36 \%) .{ }^{1}$ Sin embargo, si se revisa a detalle la mortalidad para cada estado de la república, ésta fluctúa del 2.89\% (Baja California Sur) al 6.32\% (Aguascalientes), es decir, una diferencia de 2.24 veces dentro del territorio nacional. En la figura $1 A$ se muestra la mortalidad por estado. Si se observa el mapa geográfico, no parece existir un patrón territorial bien definido (figura 1B); más bien, las diferencias geográficas de mortalidad podrían estar influidas por factores de riesgo, como exposiciones, factores poblacionales y la calidad de los registros locales. En la figura 2 se muestra la mortalidad por sexo y por estado, sin que se observen diferencias extremas. Lo que sí resulta evidente e irrefutable es que la mortalidad ha sido creciente en todo el territorio y prácticamente se ha duplicado desde 1990 (figura 3).

En nuestro país, los datos de prevalencia de EPOC son todavía muy escasos. El estudio PLATINO, ${ }^{3}$ un estudio de base poblacional realizado en el área metropolitana de la Ciudad de México en sujetos de 40 años o más, mostró una prevalencia para la EPOC del $7.8 \%$, diagnóstico hecho con en el estándar de oro: la espirometría y su criterio de $\mathrm{FEV}_{1} / \mathrm{FVC}<0.70$. No obstante, esta encuesta demuestra ser de hace ya casi 20 años (realizada en 2002) y la definición puede incluir una proporción significativa de falsos positivos, particularmente en personas mayores a 60 años. Análisis más recientes de esta misma información estiman una prevalencia real cercana al $4 \%$, la segunda más baja conocida para una ciudad, al igual que la mortalidad, que podría sufrir las mismas diferencias significativas territoriales en nuestro país. ${ }^{4,5}$

El subdiagnóstico y el error diagnóstico de la EPOC son uno de los escenarios más desafiantes para México y el mundo. En el estudio PLATINO esto se evidenció cuando mostró que el $86 \%$ de las personas con EPOC no habían sido diagnosticadas (subdiagnóstico). Además, se encontró que aproximadamente la mitad de los individuos con diagnóstico previo de EPOC, bronquitis crónica o enfisema nunca se habían realizado una espirometría (error diagnóstico). ${ }^{6}$ El subdiagnóstico fue $>$ en el $85 \%$ de los casos con obstrucción al flujo aéreo de grado leve y moderado (GOLD 1 y 2), del $60 \%$ en casos graves (GOLD 3 ) y en el $25 \%$ de los casos muy graves (GOLD 4). La razón principal de esto se debe a que el diagnóstico de EPOC 


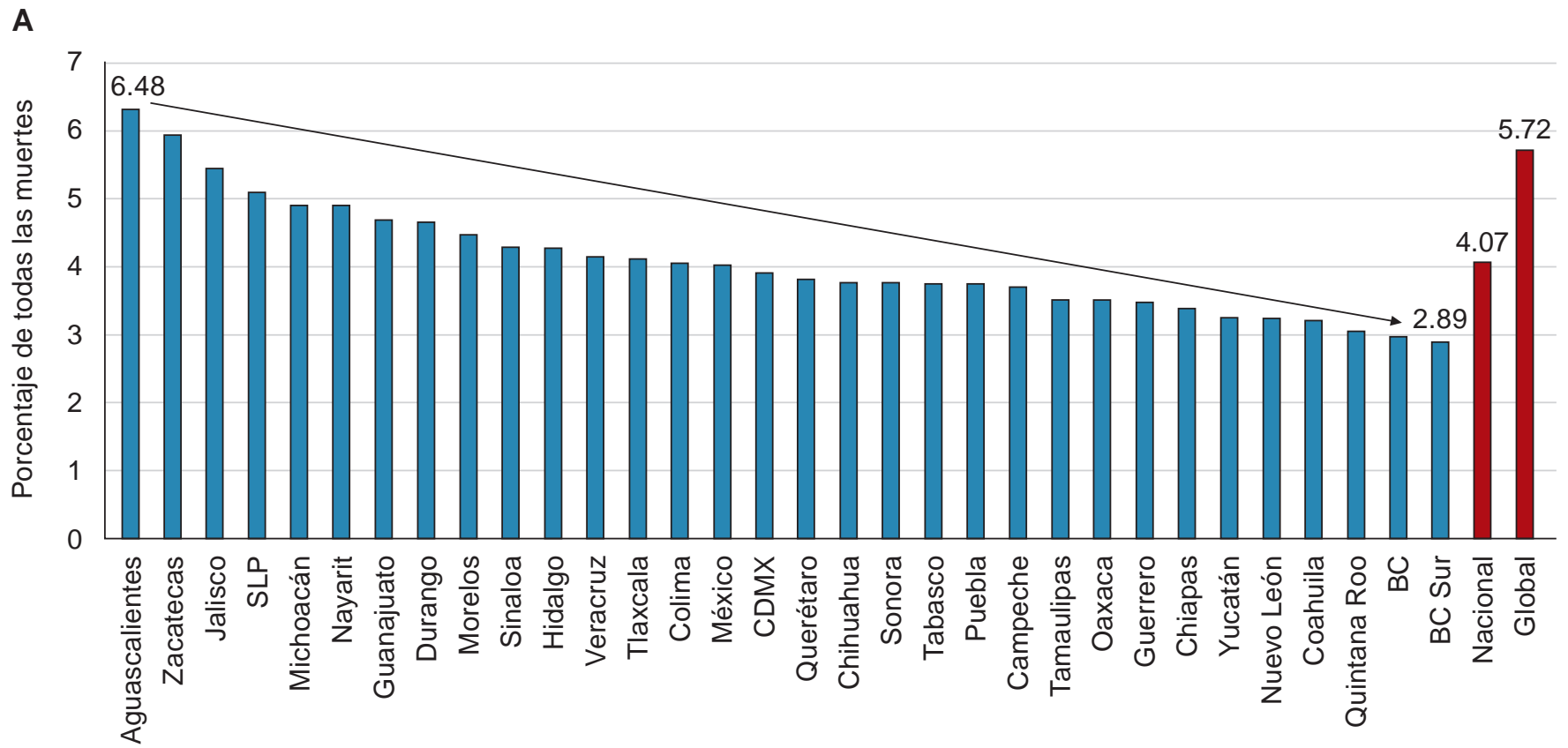

B

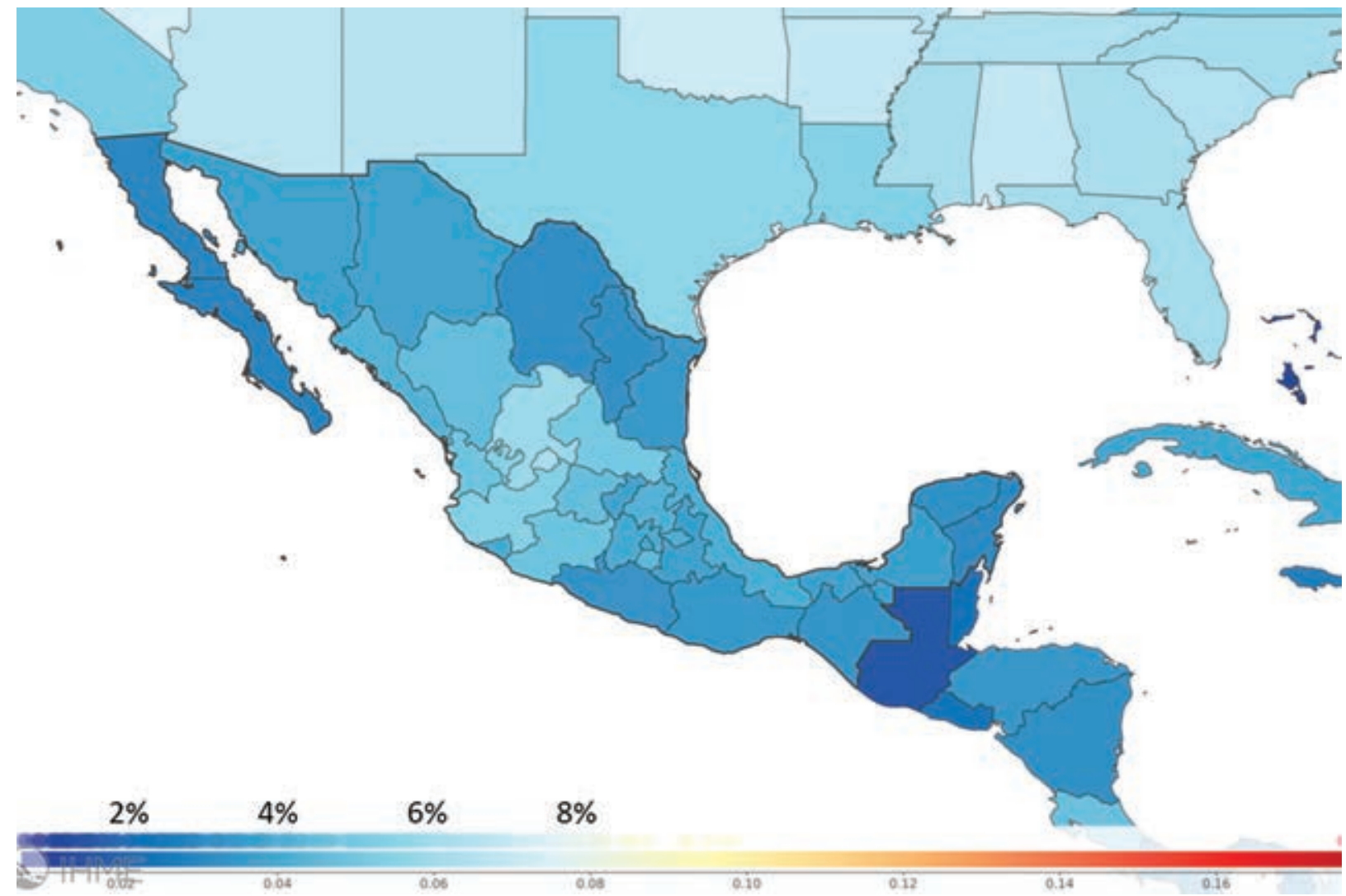

Figura 1: Mortalidad por EPOC en México, para ambos sexos y todas las edades, de acuerdo con el estudio de la Carga Mundial de las Enfermedades (GBD, 2017). En el panel superior (A) se grafica de forma descendente la mortalidad por Estado, como porciento del total de muertes anuales y se compara con el promedio nacional y el global. En el panel inferior (B) se muestra la misma información, pero de acuerdo al mapa territorial del país. 

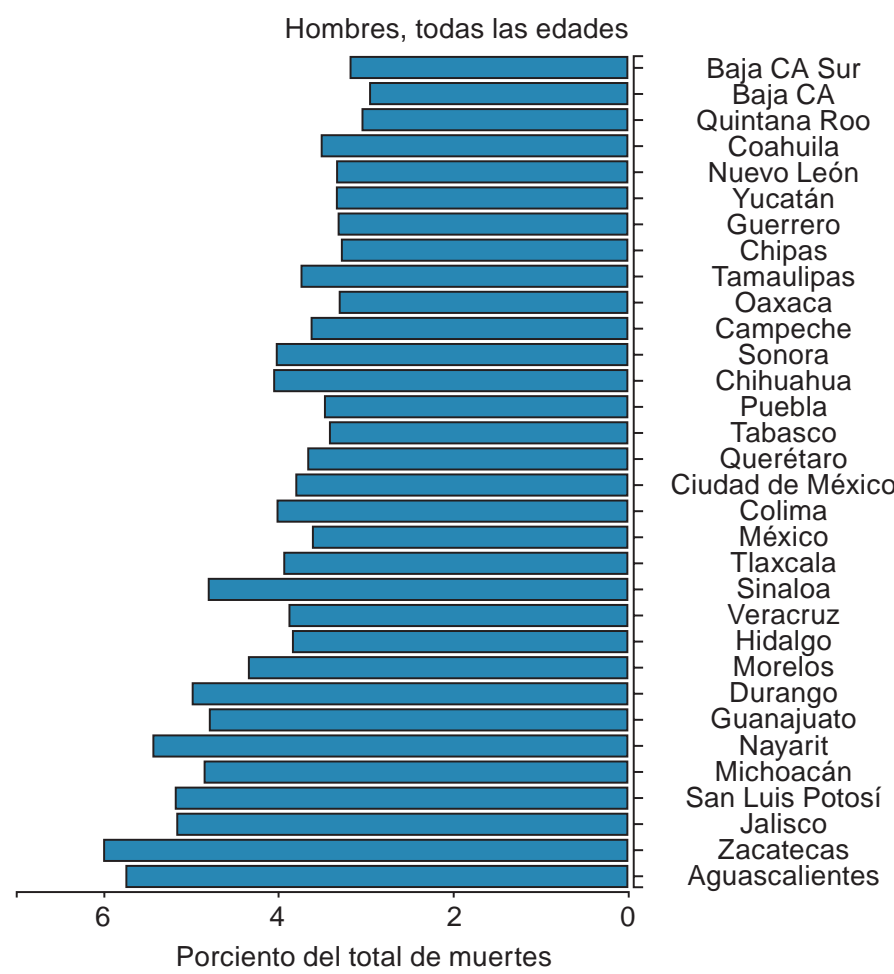

Mujeres, todas las edades

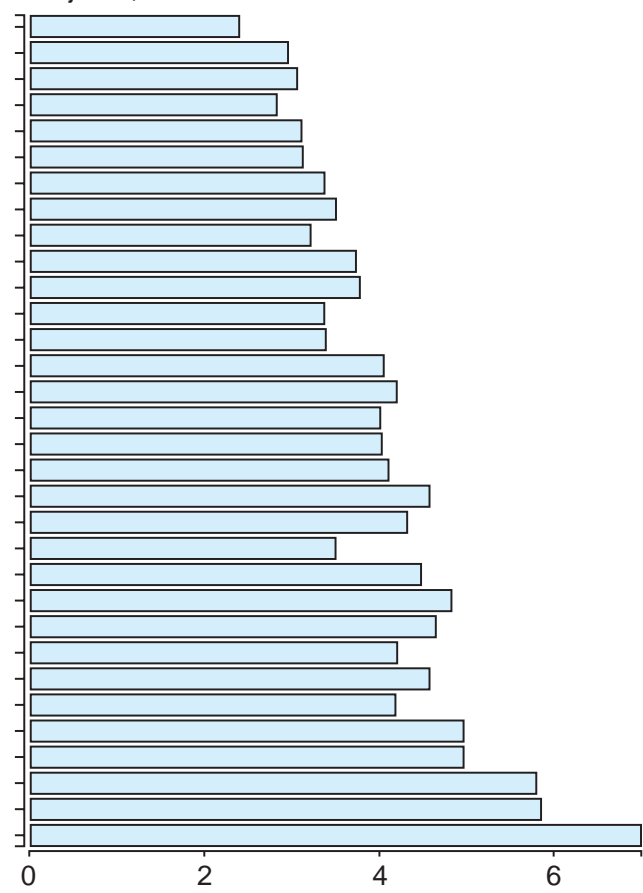

Porciento del total de muertes

Figura 2: Mortalidad por EPOC en México 2017, dividido por Estados, todas las edades y por sexo. Se muesra hombres en la columna izquierda y mujeres en la derecha de acuerdo con el estudio de la Carga Mundial de las Enfermedades (GBD, 2017).

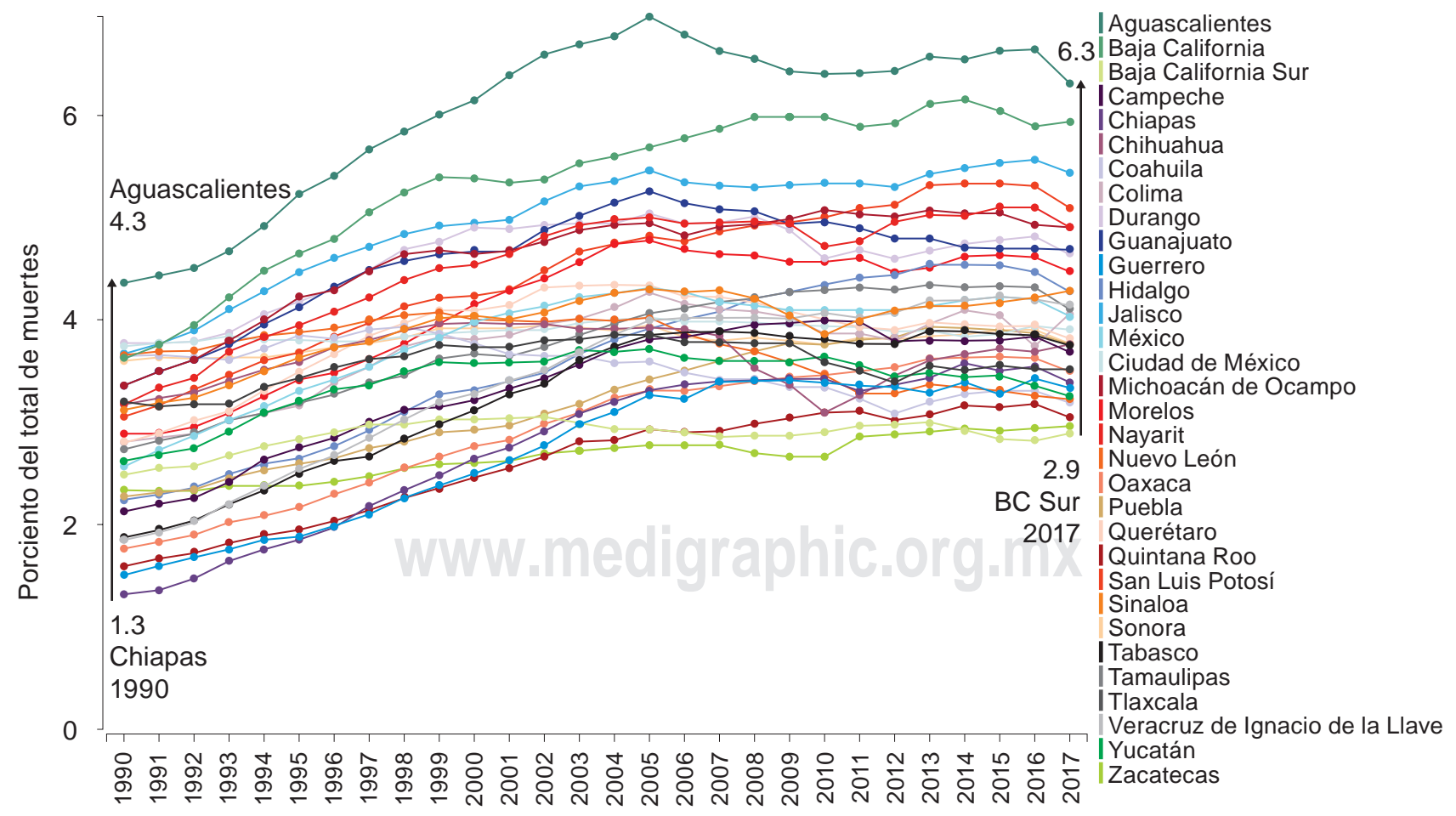

Año

Figura 3: Mortalidad por EPOC, como porcentaje de todas las muertes, en México de 1990 a 2017, de ambos sexos y todas las edades, y por Estado de la República de acuerdo con el estudio de la Carga Mundial de las Enfermedades (GBD, 2017). 
requiere confirmarse por medio de la espirometría —un método objetivo que demuestra la obstrucción del flujo del aire y que aún está escasamente disponible en muchos países- En un estudio reciente de 44 ciudades de 27 países, ${ }^{5}$ se encontró una frecuencia promedio de EPOC subdiagnosticada a nivel poblacional del $81.4 \%$ (50-98\%), incluyendo a la Ciudad de México con un $81.6 \%$.

Los factores de riesgo causal pueden explicar el comportamiento y la carga de EPOC en el presente y predecirán el futuro: el envejecimiento poblacional y los estilos de vida están estrechamente relacionados. El estudio GBD de 2017 estimó que la mortalidad por EPOC es atribuible en un $67 \%$ a las exposiciones nocivas del aire, donde $37 \%$ correspondió a tabaquismo, $14 \%$ a la exposición del humo de biomasa y $16 \%$ a la contaminación atmosférica (6\% partículas, $5 \%$ ozono y $5 \%$ contaminantes de ambiente ocupacional).

La morbilidad y los gastos que se derivan de las enfermedades respiratorias son enormes. Por ejemplo, se estimó por el Instituto Nacional de Salud Pública que el costo anual de las enfermedades relacionadas con el tabaquismo fue de $\$ 45$ mil millones de pesos; esto corresponde del 8 al 15\% del gasto en salud. Esto es una subestimación, ya que sólo se investigaron cuatro padecimientos: EPOC, cáncer pulmonar, enfermedad isquémica miocárdica y enfermedad cerebrovascular.7 En el Instituto Nacional de Enfermedades Respiratorias (INER), el gasto por EPOC fue de $\$ 52$ millones de pesos por 508 pacientes; esto da un promedio de $\$ 102,362$ pesos por paciente y los gastos de bolsillo de los pacientes son proporcionales a la gravedad de la enfermedad. Durante el año 2014, se estimaron de $\$ 1,116$ a 2,240 de dólares por año. ${ }^{8}$ En los Estados Unidos, se ha estimado un costo anual total de 36 mil millones de dólares para 13.7 millones de personas con EPOC. ${ }^{9}$

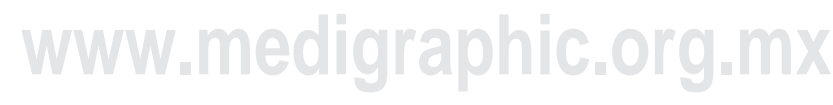




\section{3: La metodología de la Guía Mexicana de Enfermedad Pulmonar Obstructiva Crónica (GMEPOC)}

Actualmente, a nivel mundial existen numerosas iniciativas para proveer recomendaciones clínicas basadas en evidencia para el diagnóstico y manejo terapéutico de la EPOC..$^{10-14}$ No obstante, las diferencias culturales y la organización de los sistemas de salud de cada país hacen muy relevante la necesidad de desarrollar guías de práctica clínica (GPC) propias que tomen en cuenta la opinión de expertos clínicos y la de los pacientes, considerando tanto sus valores como su propia idiosincrasia.

La transculturización de las guías internacionales a nuestro medio contribuye a disminuir la duplicidad de esfuerzos y mejora la eficiencia del uso de recursos. Este proceso se debe realizar bajo un esquema estandarizado y validado a nivel internacional para proveer recomendaciones basadas en evidencia. La Red Internacional de Guías (Guidelines International Network o GIN, por sus siglas en inglés) ha desarrollado una serie de recomendaciones para llevar a cabo la transculturización de esos documentos, conocidas como metodología ADAPTE y descritas en detalle en un documento propio (manual ADAPTE).

\section{1: La metodología ADAPTE}

La metodología ADAPTE para los procesos de desarrollo y adaptación transcultural de las guías de práctica clínica se propuso en el año 2007. Ésta ha sido ampliamente aceptada y apoyada por las principales instituciones y agencias desarrolladoras de las GP. ${ }^{10}$ Para la adopción y transculturización de la GMEPOC, se llevó a cabo la evaluación de la calidad metodológica con la que las guías de referencia internacional fueron desarrolladas. Para esto, se usó el instrumento para la evaluación de las GPC conocido como AGREE II, el cual evalúa la calidad metodológica global de una GPC con base en la sistematización, el proceso de desarrollo metodológico y el reporte de la misma. ${ }^{11} E s t a$ evaluación es un proceso fundamental para la toma de decisiones, pues, de acuerdo con la puntuación AGREE II, es cómo se decide su calidad y, en consecuencia, si se incluye en el cuerpo de evidencia para el desarrollo de nuevas recomendaciones. No obstante, una puntuación baja no debe ser el único criterio para excluir un documento, ya que existen otros elementos a considerar en la evaluación de las recomendaciones. ${ }^{11}$

La fecha de publicación de la guía y períodos de tiempo cubiertos por la estrategia de búsqueda bibliográfica se revisan con el objetivo de incluir la mayor evidencia vigente. Si los expertos clínicos concluyen que la bibliografía no está actualizada, se deberá tomar la decisión sobre aceptar o no esa recomendación; toda decisión de este tipo debe registrarse y reportarse en el documento. Algunas recomendaciones pueden no afectarse por nueva evidencia y se podrán mantener a pesar de haber sido generadas años atrás. El contenido debe evaluarse cuidadosamente, a fin de identificar si las recomendaciones de las GPC, al ser adaptadas, proveen evidencia suficiente y pueden ser aplicables a nuestro medio; por lo tanto, es importante evaluar los niveles de evidencia asociados con cada recomendación. Además, la evaluación de la consistencia de la guía incluye: una estrategia de búsqueda y selección de la evidencia; consistencia entre la evidencia seleccionada y cómo los desarrolladores sintetizan, analizan y extraen esta evidencia, y la consistencia entre la interpretación de la evidencia y las recomendaciones. ${ }^{10}$

\section{2: Desarrollo de la GMEPOC}

Los pasos para el desarrollo de la GMEPOC se enumeran en la tabla 1. Una vez definido los procesos ejecutivos, administrativos y financieros dentro de la 
I. Selección del Grupo de Desarrollo de la Guía

1. Comité Ejecutivo para administración, contenido y finanzas (JCVG, MMA, LARP, JVC)

2. Grupo nuclear compuesto por nueve neumólogos, tres metodólogos y un coordinador general (JCVG)

3. Tres metodólogos involucrados en todo el proceso de desarrollo de la guía

4. Integración de un grupo ampliado con neumólogos representativos de las diferentes regiones del país e instituciones (IMSS, ISSSTE, SEDENA, medicina privada, otros). Además dos médicos generales de CENAPRECE, Secretaría de Salud

II. Elaboración del documento de enfoques (SCOPE)

III. Búsqueda de la literatura para guías de EPOC

IV. Evaluación de la calidad de las guías por instrumento AGREE II (2 evaluadores/guía)

V. El grupo nuclear define la guía GOLD como guía madre principal y de acuerdo al paso IV, cuatro más como guías principales

VI. Elaboración de preguntas clínicas clave a partir de las guías madre y método PICO

VII. Contestación de preguntas clave de acuerdo con guías madre y con asignación de nivel de evidencia y recomendación

VIII. Ajustes de textos mediante consenso formal, metodología Delphi modificada y técnica nominal

IX. Integración del texto de la guía con base en la preguntas clínicas, sus respuestas, nivel de evidencia científica y recomendación, seguido de una revisión de la literatura y análisis

X. Revisión amplia del texto final por expertos

XI. Edición y conclusión del documento final

EPOC = enfermedad pulmonar obstructiva crónica.

Sociedad Mexicana de Neumología y Cirugía de Tórax (SMNyCT), se estableció un Comité Ejecutivo y se procedió a definir un grupo nuclear (GN), compuesto por un grupo independiente de expertos clínicos de la SMNyCT, así como metodólogos de la Iberoamerican Agency for Development \& Assessment of Health Technologies (A2DAHT). Posteriormente, un segundo grupo se determinó como el grupo ampliado (GA) de desarrollo, compuesto por otro panel de expertos de la misma sociedad médica. Debido a que la guía tiene un enfoque en atención primaria, se incluyeron profesionales del Centro Nacional de Programas Preventivos y Control de Enfermedades (CENAPRECE) de la Secretaría de Salud Federal de México. A todos se les pidió participar tomando en consideración su estatus profesional, su conocimiento de las bases de investigación clínica y su compromiso intencional para el proceso de desarrollo sin conflictos de interés. EI GN de GMEPOC desarrolló el documento de alcances y enfoque (Scope) de la GPC (Anexo A). El alcance de la guía fueron pacientes adultos con diagnóstico de EPOC, incluyendo aquéllos expuestos a humo de tabaco y combustión de biomasa (humo de leña y otros biomateriales). La población excluida fueron pacientes con asma, tuberculosis, bronquiectasias y fibrosis quística. No se consideraron tópicos clínicos relacionados con cirugía en EPOC ni manejo de comorbilidades o deficiencia de alfa-1-antritripsina. Los escenarios clínicos donde se aplicaron las recomendaciones de esta GPC fueron los procesos de atención en el primer, segundo y tercer nivel; además, se incluyeron las condiciones clínicas de EPOC estable y exacerbación de la EPOC y sus consideraciones de diagnóstico y tratamiento. Para el diagnóstico, se incluyó el cuadro clínico, la espirometría y otras pruebas de laboratorio y gabinete, así como la formulación de diagnósticos diferenciales. El manejo de la EPOC estable incluyó: tratamiento farmacológico y no farmacológico para la cesación tabáquica; tratamiento farmacológico (broncodilatadores $\beta_{2}$-agonistas, anticolinérgicos, sus combinaciones, corticosteroides, metilxantinas, inhibidores de fosfodiesterasa y antibióticos); tratamiento no farmacológico (rehabilitación pulmonar, oxígeno suplementario y el empleo de inmunizaciones), y 
cuidados paliativos y apoyo al final de la vida. El tratamiento de la exacerbación de la EPOC abordó un plan de manejo domiciliario u hospitalario y criterios de referencia al especialista. El manejo ambulatorio también incluyó el empleo de broncodilatadores, antibióticos y corticosteroides sistémicos; en los casos de manejo hospitalario comprendió antibióticos y corticosteroides sistémicos, oxígeno suplementario y ventilación mecánica no invasiva e invasiva.

Una vez definido el documento de alcances, el GN planteó preguntas clínicas clave mediante el método PICO/PECO (Patient, Intervention/Exposition, Comparison, Outcome, por sus siglas en inglés). ${ }^{12}$ EI GN propuso la Global Initiative for Chronic Obstructive Lung Disease (GOLD, 2019), en su versión más actual, como la guía principal. ${ }^{2}$ Después de una búsqueda de la literatura enfocada en guías internacionales que tratan los temas expresados en el documento de alcances, se incluyeron las siguientes guías de diagnóstico y tratamiento para la EPOC: 1) Diagnóstico y tratamiento de la enfermedad pulmonar obstructiva crónica por el Centro Nacional de Excelencia Tecnológica en Salud de México (CENETEC);15 2) Chronic obstructive pulmonary disease (COPD) in over 16s: diagnosis and treatment, National Institute for Clinical Excellence (NICE);16 3) la Guía para la EPOC de la Asociación Latinoamericana de Tórax (ALAT);17 4) la Guía Española de la EPOC (GesEPOC);18 5) la guía Management of COPD exacerbations y la Prevention of COPD exacerbations, European Respiratory Society/American Thoracic Society (ERS/ATS), ${ }^{1920}$ y 6) la COPD-X Plan Australian and New Zealand guidelines for the management of Chronic Obstructive Pulmonary Disease. ${ }^{21}$

El GN analizó estas publicaciones y se eligieron para el análisis detallado de calidad. En caso de que hubiera más de una versión de una guía, se eligió únicamente la versión más actual. Cada una de estas guías se sometió a una evaluación detallada por dos expertos, para ello, se empleó el instrumento AGREE II (Appraisal of Guidelines for Research and Evaluation, por sus siglas en inglés)..$^{11}$ Se encontró buena concordancia entre las evaluaciones AGREE-II por guía, pero, en caso de discordancia, se discutió hasta llegar a un consenso con todo el GN (tabla 2).

En la GMEPOC se usó la estructura de preguntas clínicas clave y sus respuestas para formular recomendaciones y sugerencias clínicas. Esta GPC utiliza la escala de graduación de la evidencia de la Scottish Intercollegiate Guidelines Network (SIGN), la cual permite la revisión de la calidad de la evidencia (tabla 3) y la asignación de niveles de recomendación (tabla 4). Dichas escalas también son adoptadas por el Centro Nacional de Excelencia Tecnológica en Salud (CENETEC) de la Secretaría de Salud de México.

EI GN de la guía elaboró el texto de soporte de las preguntas clínicas y recomendaciones, en función de la evidencia encontrada en las guías de referencia, la seguridad de la recomendación, su costo y la preferencia del paciente, según la opinión de los expertos mexicanos. Para el consenso formal de expertos, los miembros del GDG evaluaron las recomendaciones clínicas a ser adaptadas por medio del panel Delphi modificado.

\section{3: Consenso formal, metodología Delphi modificada y técnica nominal}

Durante el proceso de desarrollo de una guía, se prefiere un método de consenso formal a uno informal. Las guías desarrolladas con métodos de consenso informales, por lo general, formulan recomendaciones sin considerar la evidencia científica y tienden a basarse en criterios escasamente definidos, además de no adoptar un consenso explicito. Por ello, resultan en guías que tienden a ser subjetivas y poco definidas. Los métodos para el desarrollo de consenso formal proveen una estructura al proceso de toma de decisiones de grupo, por ejemplo, al adoptar métodos de calificación para representar el grado respecto a las preguntas o problemas 


\section{Tabla 2: Porcentajes de acuerdo (AGREE II) con las guías de referencia internacional para GMEPOC.}

Guía

Global Initiative for Chronic Obstructive Lung Disease (GOLD) $)^{2}$

Diagnóstico y tratamiento de la EPOC (CENETEC) ${ }^{10}$

Chronic obstructive pulmonary disease (COPD) in over 16s: diagnosis and treatment (NICE) ${ }^{16}$

Guía Latinoamericana de EPOC (ALAT) ${ }^{17}$

Guías Españolas de la EPOC (GEsEPOC) ${ }^{18}$

Management of COPD exacerbations (ERS/ATS) ${ }^{19}$

Prevention of COPD exacerbations (ERS/ATS) ${ }^{20}$

COPD-X Plan Australian and New Zealand Guidelines for the management of COPD ${ }^{21}$
Porcentaje de acuerdo AGREE II (dos revisores)

EPOC = enfermedad pulmonar obstructiva crónica.

Tabla 3: Escala de graduación de la evidencia SIGN (Scottish Intercollegiate Guidelines Network).

Nivel de evidencia
$1++$
$1+$
$1-$
$2++$
$2+$
$2-$
3
4
Metaanálisis, RS de EC o EC con alto riesgo de sesgos babilidad de establecer una relación causal no sea causal
Estudios no analíticos como informes de casos y series de casos
Opinión de expertos

Abreviaturas: $\mathrm{RS}$ = revisión sistemática; $\mathrm{EC}$ = ensayos clínicos.

Metaanálisis de alta calidad, RS de EC o EC de alta calidad con muy poco riesgo de sesgo

Metaanálisis bien realizados, $\mathrm{RS}$ de $\mathrm{EC}$ o EC bien realizados con poco riesgo de sesgos

RS de alta calidad de estudios de cohortes o de casos y controles. Estudios de cohortes o de casos y controles con bajo riesgo de sesgo y con alta probabilidad de establecer una relación causal

Estudios de cohortes o de casos y controles bien realizados con bajo riesgo de sesgo y con una moderada pro-

Estudios de cohortes o de casos y controles con alto riesgo de sesgo y riesgo significativo de que la relación

Tabla 4: Niveles de evidencia propuestos por SIGN (Scottish Intercollegiate Guidelines Network).

Grado de recomendación

A

B

C

$\mathrm{D}$

\section{Interpretación}

Al menos un metaanálisis, RS o EC clasificado como 1++ y directamente aplicable a la población diana de la guía 0 un volumen de evidencia científica compuesto por estudios clasificados como 1+ y con gran consistencia entre ellos Volumen de evidencia científica compuesta por estudios clasificados como 2++, directamente aplicable a la población diana de la guía y que demuestran gran consistencia entre ellos, o evidencia científica extrapolada desde estudios clasificados como $1++$ o $1+$

Volumen de evidencia científica compuesta por estudios clasificados como $2+$ directamente aplicables a la población diana de la guía y que demuestren gran consistencia entre ellos, o evidencia científica extrapolada desde estudios clasificados como $2++$

Evidencia científica de nivel 3 o 4, o evidencia científica extrapolada desde estudios clasificados como $2+$ 
predefinidos. Hay varias ventajas en un grupo de decisión, a saber: existe un rango más amplio de conocimiento directo y experiencia; la interacción (anónima) entre los miembros estimula la consideración de un rango amplio de opciones y un debate que reta las ideas recibidas y estimula otras nuevas; las idiosincrasias son filtradas (aunque, en ocasiones, de forma errónea) y, en términos de influencia en el comportamiento de otros, el grupo en su conjunto puede llevar más carga de lo que sería para un solo individuo.

El abordaje por la técnica de grupo nominal (Nominal Group Technique [NGT]) modificado se usó similarmente al panel de método de consenso de la corporación RAND (Research And Development), que se utiliza extensamente en muchos procesos de desarrollo de GPC. ${ }^{14}$ Este abordaje es una alternativa al Delphi y a los métodos de consenso para desarrollo por medio de conferencias, pero, al mismo tiempo, constituye una técnica formal. El abordaje por la técnica de grupo nominal se ha usado antes con éxito, generalmente en el cuidado de la salud y en el desarrollo de guías clínicas.

\section{4: Panel Delphi modificado}

El método Delphi es un método predictor, interactivo y sistemático. Éste se basa en un panel de expertos independientes y en el principio de que las estimaciones de un grupo estructurado son más exactas que las individuales o que las de un grupo no estructurado. El panel mantiene el anonimato de los participantes y los expertos responden cuestionarios cuidadosamente seleccionados en una o más rondas. Tras cada ronda, un facilitador provee un resumen anónimo de las calificaciones de los expertos, así como las razones que dieron para los juicios establecidos. Finalmente, el proceso se detiene después de que un criterio se ha definido (por ejemplo, tras lograr un porcentaje de consenso); las puntuaciones de media o mediana del final de las rondas determinan los resultados. La identidad de los participantes no es revelada, aún después de completar el reporte final. Esto evita el efecto de dominio por autoridad o personalidad; asimismo, evita sesgos personales y minimiza el efecto de arrastre o efecto halo, permitiendo que todos expresen libremente sus opiniones y estimulando la crítica abierta y el análisis de errores tras la revisión de juicios establecidos. ${ }^{14}$

En la GMEPOC, cada pregunta, recomendación y textos de soporte fueron calificados por los miembros del panel. Para ello, se utilizó la escala de Likert con valores del 1 al 9 , donde 1 significa que los daños esperados sobrepasan a los beneficios esperados («totalmente en desacuerdo») y el 9 significa que los beneficios esperados sobrepasan a los riesgos esperados («totalmente de acuerdo»). Una calificación media de 5 puede significar que los daños y los beneficios son aproximadamente iguales o que el evaluador no puede hacer un juicio para el paciente descrito en la recomendación. Se estableció un mínimo de $70 \%$ como criterio de consenso y un promedio mayor a 7 para considerar finalizada la ronda para cada una de las recomendaciones. La retroalimentación del GA se estableció por argumentos basados en la experiencia clínica y se evaluó por el GN, con lo que se generaron las recomendaciones finales. Para esta guía, se empleó sólo una ronda de panel Delphi modificado.

EI GDG se reunió en dos ocasiones; de esta forma, se aseguró la diversidad y el acuerdo con las diferentes opiniones. En la primera reunión se revisó: el impacto y alcances de la guía; las herramientas y criterios utilizados para la selección de las GPC de referencia; la metodología de consenso, y la revisión de todas las preguntas en formato PICO/PECO, con la finalidad de eliminar aquéllas cuyos contenidos no fueran válidos para la realidad mexicana por no existir medicamentos o intervenciones, así como su correcta redacción en lenguaje español. La aprobación final se 
estableció por la técnica de consenso nominal y, finalmente, se constituyeron los seis paneles Delphi (cada uno con cuatro a cinco miembros del GA). En la segunda reunión, se revisaron las opiniones expresadas dentro de la primera ronda del Delphi y se firmaron los acuerdos de confidencialidad y declaraciones de posibles

Tabla 5: Resultados de estadística del Panel Delphi.

\begin{tabular}{|c|c|c|c|c|c|c|c|c|c|}
\hline Pregunta & Promedio & $\begin{array}{c}\text { Desviación } \\
\text { estándar }\end{array}$ & Mediana & Mínimo & Máximo & $\begin{array}{c}\text { Percentil } \\
25\end{array}$ & $\begin{array}{c}\text { Percentil } \\
75\end{array}$ & IC 95\% & $\begin{array}{l}\text { Porcentaje } \\
\text { de acuerdo }\end{array}$ \\
\hline 1 & 8.4 & 0.89 & 9 & 7 & 9 & 8 & 9 & $0.62(7.78-9.02)$ & 100 \\
\hline 3 & 8.2 & 1.10 & 9 & 7 & 9 & 7 & 9 & $0.76(7.44-8.96)$ & 100 \\
\hline 4 & 8.7 & 1.00 & 8 & 7 & 9 & 7 & 9 & $0.69(7.97-9.36)$ & 100 \\
\hline 5 & 8.0 & 1.00 & 8 & 7 & 9 & 7 & 9 & $0.69(7.31-8.69)$ & 100 \\
\hline 6 & 8.3 & 0.96 & 8.5 & 7 & 9 & 8 & 9 & $0.66(7.6-8.91)$ & 100 \\
\hline 7 & 8.5 & 0.58 & 8.5 & 8 & 9 & 8 & 9 & $0.40(8.1-8.90)$ & 100 \\
\hline 12 & 7.8 & 0.96 & 7.5 & 7 & 9 & 7 & 9 & $0.71(7.0-8.46)$ & 100 \\
\hline 13 & 8.0 & 0.82 & 8 & 7 & 9 & 8 & 9 & $0.57(7.4-8.57)$ & 100 \\
\hline 14 & 8.0 & 0.82 & 8 & 7 & 9 & 8 & 9 & $0.57(7.4-8.57)$ & 100 \\
\hline 15 & 9.0 & 0.00 & 9 & 9 & 9 & 9 & 9 & & 100 \\
\hline 16 & 8.7 & 0.82 & 9 & 7 & 9 & 9 & 9 & $0.57(8.10-9.23)$ & 100 \\
\hline 17 & 8.3 & 1.03 & 9 & 7 & 9 & 7.5 & 9 & $0.72(7.62-9.05)$ & 100 \\
\hline 18 & 9.0 & 0.00 & 9 & 9 & 9 & 9 & 9 & & 100 \\
\hline 19 & 8.3 & 1.03 & 9 & 7 & 9 & 7.5 & 9 & $0.72(7.62-9.05)$ & 100 \\
\hline 20 & 9.0 & 0.00 & 9 & 9 & 9 & 9 & 9 & & 100 \\
\hline 21 & 8.5 & 0.84 & 9 & 7 & 9 & 8.25 & 9 & & 100 \\
\hline 28 & 7.6 & 0.89 & 7 & 7 & 9 & 7 & 8 & $0.66(6.94-8.26)$ & 100 \\
\hline 29 & 8.0 & 1.00 & 8 & 7 & 9 & 7 & 9 & $0.69(7.31-8.69)$ & 100 \\
\hline 30 & 8.2 & 0.84 & 8 & 7 & 9 & 8 & 9 & $0.58(7.62-8.78)$ & 100 \\
\hline 31 & 8.4 & 0.89 & 9 & 7 & 9 & 8 & 9 & $0.62(7.78-9.02)$ & 100 \\
\hline 32 & 8.4 & 0.55 & 8 & 8 & 9 & 8 & 9 & $0.38(8.02-8.78)$ & 100 \\
\hline 33 & 8.4 & 0.89 & 9 & 7 & 9 & 8 & 9 & $0.62(7.78-9.02)$ & 100 \\
\hline 34 & 8.2 & 1.10 & 9 & 7 & 9 & 7 & 9 & $0.76(7.44-8.96)$ & 100 \\
\hline 35 & 8.5 & 0.55 & 8.5 & 8 & 9 & 8 & 9 & $0.38(8.12-8.88)$ & 100 \\
\hline 36 & 8.7 & 0.52 & 9 & 8 & 9 & 8.25 & 9 & $0.36(8.31-9.02)$ & 100 \\
\hline 37 & 8.5 & 0.55 & 8.5 & 8 & 9 & 8 & 9 & $0.38(8.12-8.88)$ & 100 \\
\hline 38 & 8.5 & 0.55 & 8.5 & 8 & 9 & 8 & 9 & $0.38(8.12-8.88)$ & 100 \\
\hline 39 & 8.5 & 0.84 & 9 & 7 & 9 & 8.25 & 9 & $0.58(7.92-9.08)$ & 100 \\
\hline 40 & 8.7 & 0.52 & 9 & 8 & 9 & 8.25 & 9 & $0.36(8.31-9.02)$ & 100 \\
\hline
\end{tabular}


conflictos de interés. La técnica nominal de los expertos fue utilizada durante las reuniones presenciales, lo que permitió una mayor interacción entre los expertos y, de esta manera, se acordaron los últimos cambios a las recomendaciones clínicas. En la tabla 5 se muestran los resultados estadísticos del panel Delphi.

En múltiples sesiones electrónicas subsecuentes, sesiones en vivo, videoconferencias, llamadas telefónicas y correos electrónicos, se comunicaron los avances, el vaciamiento y el procesamiento de datos. En una última reunión, el GN revisó el documento final en forma ajustada para México, y ésta se envió para su evaluación externa. La GPC fue desarrollada por la SMNyCT, en colaboración con A2DAHT (estos últimos recibieron honorarios profesionales). En resumen, se incluyeron aspectos de diagnóstico de EPOC, tratamiento farmacológico y no farmacológico para la cesación tabáquica, empleo de inmunizaciones, manejo de EPOC estable y exacerbación de la EPOC (manejo ambulatorio y hospitalario); además, se incluyeron medidas de soporte vital y al final de la vida. 


\section{4: Recomendaciones clínicas y evidencia científica}

En esta sección, se presentan las preguntas clínicas (PICO/PECO) y sus recomendaciones dirigidas con respecto a los tópicos mencionados previamente. En cada recomendación o recomendaciones para cada pregunta, se muestra el nivel de evidencia científica y el nivel de recomendación SIGN, seguido de una revisión de la literatura y un análisis de la misma.

\section{1: Diagnóstico de EPOC}

Pregunta clínica 1

¿La edad, los síntomas respiratorios o la exposición a factores de riesgo son útiles para el diagnóstico de sospecha de EPOC?

\section{Recomendación}

1 Se debe sospechar el diagnóstico de EPOC en personas de 40 años y más, con tabaquismo u otros factores de riesgo o síntomas crónicos, como disnea, tos y expectoración. , $15-17^{-17}$
Evidencia 2-

Recomendación D

Definición: La EPOC es una enfermedad común, prevenible y tratable, que se caracteriza por síntomas respiratorios persistentes y limitación del flujo aéreo, debido a anormalidades de la vía aérea o alveolar. Habitualmente es causada por una exposición significativa a partículas o gases nocivos. Los síntomas más comunes incluyen disnea, tos y expectoración, que con frecuencia los pacientes pueden atribuir poca importancia. ${ }^{2}$

El principal factor de riesgo para la EPOC es la exposición a humo de tabaco, aunque otras exposiciones como el humo producido por la combustión de biomasa o la contaminación atmosférica pueden contribuir. Además de estas exposiciones, existen factores individuales que pueden predisponer al desarrollo de la enfermedad; éstos incluyen alteraciones genéticas, desarrollo pulmonar anormal y envejecimiento acelerado. La EPOC puede estar marcada por períodos de empeoramiento agudo llamados agudizaciones o exacerbaciones; en la mayoría de los casos están asociadas con infecciones, enfermedades y condiciones crónicas concomitantes (comorbilidades), los cuales incrementan su morbilidad y mortalidad. ${ }^{2}$

La disnea es un síntoma cardinal de la EPOC y constituye la causa principal de discapacidad y ansiedad asociada con la enfermedad. El paciente típico con EPOC describe la disnea como un mayor esfuerzo para respirar, presencia de agitación, pesadez en el pecho o pecho apretado y falta de aire o ahogamiento. Los términos usados para describir la disnea pueden variar tanto individual como culturalmente..$^{2,22}$

La tos crónica es a menudo el primer síntoma que se presenta en la EPOC y ésta suele ser desatendida por parte de los pacientes por considerarla como una consecuencia lógica de fumar o por la exposición al medio ambiente. Al inicio, puede ser intermitente, pero subsecuentemente puede presentarse todos los días y a lo largo de períodos de tiempo. La tos en la EPOC puede ser productiva o no productiva. ${ }^{2}$ Los pacientes con EPOC producen cantidades pequeñas de expectoración. La producción regular de esputo por tres o más meses y al menos durante dos años consecutivos, en ausencia de otras causas que pueda explicarlo, constituye la definición clásica de bronquitis crónica. La presencia de esputo purulento refleja un incremento en los mediadores inflamatorios; su desarrollo puede identificar el inicio de una exacerbación bacteriana, aunque esta relación es relativamente débil. ${ }^{2}$

Los factores de riesgo que llevan al desarrollo de la EPOC pueden alteran el desarrollo pulmonar a lo largo de la vida de acuerdo con los siguientes patrones: 
1) impiden que el individuo alcance la función pulmonar máxima de acuerdo con su edad; 2) favorecen el declinar prematuro de la función pulmonar, y 3) favorecen el declinar acelerado de la función pulmonar. ${ }^{23}$ El tabaquismo es el principal factor de riesgo para el desarrollo de la EPOC. Tanto la duración como la dosis de tabaco fumado a lo largo de la vida son variables importantes a considerar. ${ }^{23} \mathrm{El}$ consumo de tabaco a través de otros dispositivos (como pipas de agua) se ha asociado con un mayor riesgo de EPOC comparado con no fumadores (OR ajustado, 10.61; IC $95 \%, 6.89-16.34$ ). ${ }^{24}$ De igual manera, el tabaquismo pasivo (humo de segunda mano) se ha relacionado con el desarrollo de la enfermedad. ${ }^{25}$

Numerosos estudios han mostrado que la exposición ambiental a partículas, polvos y antígenos orgánicos en el sitio de trabajo, especialmente con masa particulada menor a 2.5 micras, pueden ser factores de riesgo para el desarrollo de la enfermedad. ${ }^{26-37}$ De la misma manera, el humo de biomasa también se considera un factor de riesgo bien establecido (OR 2.44, IC 95\% 1.9-3.33). ${ }^{38}$

El antecedente de asma se ha asociado con patrones de crecimiento limitado y declinación temprana de la función pulmonar, los cuales podrían llevar a EPOC. ${ }^{39}$ El antecedente de tuberculosis pulmonar se encontró asociado con un incremento en el riesgo de obstrucción al flujo aéreo de manera independiente al tabaquismo, exposición a biomasa y diagnóstico previo de asma. ${ }^{40}$

Estudios observacionales indican que algunos factores genéticos moleculares se relacionan con el desarrollo de EPOC en poblaciones específicas, como polimorfismos genéticos, variantes en la función de enzimas antioxidantes, desregulación de metaloproteinasas y exceso de elastasas. Tiene particular importancia el déficit de alfa-1 antitripsina, cuya presencia deberá sospecharse en sujetos jóvenes con síntomas típicos de EPOC y datos radiográficos de enfisema. ${ }^{41-44}$

\section{Pregunta clínica 2}

¿Es necesaria para el diagnóstico de los pacientes con sospecha de EPOC la espirometría con broncodilatador?

\section{Recomendaciones}

1 La espirometría es imprescindible para diagnosticar la EPOC. Todo paciente con sospecha de EPOC debe completar una espirometría con prueba de broncodilatador para confirmar el diagnóstico. ${ }^{1-3,9,10,15-18}$

2

Se recomienda el uso de la espirometría con broncodilatador para el diagnóstico de casos de EPOC en la población $\geq 40$ años, que haya sido expuesta a factores de riesgo como tabaquismo ( $\geq 10$ paquetes/ año), humo de leña ( $\geq 200$ horas/año $0 \geq 10$ años), con síntomas respiratorios (búsqueda de casos) o sin síntomas respiratorios (tamizaje), ya sea tanto en la población abierta (global) como en la población que consulta por cualquier causa (oportunista).

\author{
Evidencia 2- \\ Recomendación C
}

Evidencia 2-

Recomendación C

Todo paciente con sospecha de EPOC, con factores de riesgo y síntomas respiratorios presentes, debe realizarse una espirometría (figura 4). La espirometría forzada con broncodilatador es la medición más objetiva y reproducible para 


\begin{tabular}{|c|c|c|}
\hline $\begin{array}{l}\text { Síntomas } \\
\text { - Disnea } \\
\text { - Tos crónica } \\
\text { - Expectoración }\end{array}$ & 1. Sospecha & $\begin{array}{l}\quad \text { Factores de riesgo } \\
\text { - Factores individuales } \\
\text { - Tabaquismo } \\
\text { - Contaminación intra/extramuros } \\
\text { - Ocupacional }\end{array}$ \\
\hline
\end{tabular}

Figura 4:

Algoritmo para el diagnóstico y la graduación de la obstrucción al flujo aéreo basado en la guía

GOLD, 2019. Aunque GOLD recomienda una relación $\mathrm{FEV}_{1} /$

$\mathrm{FVC}<0.70$ para diagnóstico, es recomendable usar en límite inferior de la normalidad (Tabla 6) en personas mayores de 60 años con la finalidad de disminuir la proporción de falsos positivos.

$\mathrm{FEV}_{1}=$ volumen espiratorio forzado en un segundo.
2. Diagnóstico confirmado por espirometría

$\mathrm{FEV}_{1} / \mathrm{FVC}$ posbroncodilatador $<$ LIN $<(0.70$ en menores de 60 años $)$

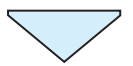

3. Graduación de la obstrucción al flujo aéreo

\begin{tabular}{|c|c|c|c|c|}
\hline GOLD & 1 & 2 & 3 & 4 \\
\hline FEV $_{1}, \%$ & $>80$ & $50-79$ & $30-49$ & $<30$ \\
\hline Grado & Leve & Moderado & Grave & Muy grave \\
\hline
\end{tabular}

evaluar la obstrucción al flujo aéreo, y constituye la prueba de función pulmonar imprescindible para establecer el diagnóstico de EPOC. ${ }^{45}$

Se recomienda realizar la espirometría bajo los estándares internacionales ATS/ ERS del año $2005 .{ }^{46-48}$ La maniobra espirométrica se realiza de manera forzada, midiendo el volumen del aire exhalado desde el punto de máxima inspiración (maniobra de capacidad vital forzada o FVC, por siglas en inglés). Otra variable a medir es el volumen de aire exhalado durante el primer segundo de la maniobra de FVC, que se conoce como volumen espiratorio forzado en el primer segundo o $\mathrm{FEV}_{1}$ (por sus siglas en inglés). ${ }^{48}$ Las variables espirométricas deben compararse con los valores de referencia poblacionales, los cuales se calculan con base en la estatura, sexo, edad y población racial. ${ }^{48}$ En el caso de México, los algoritmos de referencia que se recomiendan son los de Pérez-Padilla, PLATINO o, en su defecto, NHANES III, ya que éstos son las que mejor se ajustan a nuestra población. ${ }^{48}$

La presencia de obstrucción al flujo de aire se establece evaluando la relación $\mathrm{FEV}_{1} / \mathrm{FVC}$ después del broncodilatador comparándola contra el límite inferior de la normalidad (LIN). El criterio de obstrucción basado en una relación $\mathrm{FEV}_{1} / \mathrm{FVC}<0.70$ es de fácil aplicabilidad, pero puede no diagnosticar la presencia de obstrucción en sujetos jóvenes con factores de riesgo; asimismo, tiene un mayor riesgo de falsos positivos en personas $>60$ años sin factores de riesgo. ${ }^{48,49}$ En la tabla 6 se especifican los LIN para el cociente $F E V_{1} / F V C$ en la población mexicana por década de la vida desde los 40 años, cuya finalidad es la de reducir la proporción de falsos positivos.

No se recomienda utilizar la relación entre el $\mathrm{FEV}_{1}$ y la capacidad vital obtenida por una maniobra lenta o sin esfuerzo (capacidad vital lenta); la maniobra lenta puede ser más sensible para detectar limitación al flujo de aire, pero implica dos maniobras diferentes. ${ }^{48}$

La medición del flujo espiratorio máximo mediante flujómetro puede funcionar como tamizaje, pero no sustituye a la espirometría como prueba diagnóstica, debido a su baja especificidad ${ }^{45}$

Todo el personal de salud y de cualquier nivel de atención, que atienda a sujetos con factores de riesgo y síntomas respiratorios, debe tener acceso a la espirome- 
Tabla 6: Límite inferior normal del cociente $\mathrm{FEV}_{1} / \mathrm{FVC}^{4}{ }^{49}$

\begin{tabular}{ccc} 
& \multicolumn{2}{c}{$F E V_{1} / F V C(\%)$} \\
\cline { 2 - 3 } Década de la vida & Mujeres & Hombres \\
40 & 72 & 70 \\
50 & 70 & 68 \\
60 & 67 & 66 \\
70 & 65 & 64 \\
80 & 63 & 62
\end{tabular}

tría, y capacitarse en su ejecución e interpretación adecuada. ${ }^{2}$ Los servicios de espirometría deben evaluarse de manera periódica para asegurar un adecuado control de calidad, así como la actualización de los ejecutores de la prueba. 2,42,49

Pregunta clínica 3

¿Los estudios de laboratorio tienen utilidad para confirmar el diagnóstico de EPOC?

\section{Recomendación}

$1 \quad$ Los estudios de laboratorio no son útiles para confirmar el diagnóstico, pero sí para identificar comorbilidades o respuestas al tratamiento.

\section{Evidencia 3}

Recomendación D

En la evaluación inicial, se debe realizar una biometría hemática completa para identificar la presencia de anemia o policitemia.10,15 Una cuenta de eosinófilos en la biometría hemática, con niveles de corte superior a 100 o 300 células/ $\mu \mathrm{L}$, a pesar de estar dentro de los límites de la normalidad de la mayor parte de los laboratorios, puede identificar a los pacientes que pueden tener una buena respuesta al tratamiento con corticosteroide inhalado (CEI), adicionado al broncodilatador de larga acción, ${ }^{2}$ lo cual constituye como un biomarcador para estimar su eficacia para la prevención de exacerbaciones. ${ }^{2}$

La Organización Mundial de la Salud (OMS) recomienda que a todos los pacientes con diagnóstico de EPOC les sea practicado una determinación de alfa-1 antitripsina al menos una vez, especialmente en áreas con alta prevalencia de dicha enzima. En México, no se realiza de manera rutinaria dicha detección, debido a que no se considera un área de alta prevalencia..$^{50}$

Una baja concentración ( $<20 \%$ del valor normal) es altamente sugestiva de deficiencia homocigota. Los miembros de la familia deben ser tamizados también, y junto con el paciente, ser referidos a centros especializados para orientación y manejo. ${ }^{2}$

\section{Pregunta clínica 4}

¿La radiografía posteroanterior de tórax es indispensable para confirmar el diagnóstico del paciente con EPOC?

\section{Recomendación}

1 La radiografía posteroanterior (PA) de tórax no es útil para confirmar el diagnóstico de EPOC, pero sí lo es para identificar comorbilidades o hacer diagnósticos diferenciales. ${ }^{2,15}$
Evidencia 2Recomendación C 
Los cambios radiográficos asociados con EPOC incluyen aplanamiento diafragmático, horizontalización e incremento de los espacios intercostales, reducción rápida en las marcas vasculares e hiperclaridad pulmonar. Sin embargo, éstos no son diagnósticos y pueden estar presentes en otras enfermedades.

La utilidad de la radiografía de tórax en el paciente con EPOC se limita a identificar potenciales comorbilidades respiratorias como fibrosis pulmonar, bronquiectasias, patología pleural, neumonía, nódulos o tumoraciones, de igual manera en comorbilidades esqueléticas como cifoescoliosis, así como en cardíacas como cardiomegalia y en protocolo de estudio de tos crónica. ${ }^{2}$

\section{Pregunta clínica 5}

¿Qué otras pruebas de función respiratoria son útiles en el diagnóstico de los pacientes con sospecha de EPOC?

\section{Recomendación}

$1 \quad$ Otras pruebas de la función respiratoria (PFR) no son útiles para el diagnóstico,

Evidencia 2pero se pueden utilizar para la evaluación complementaria.

Por un lado, la oximetría de pulso es útil para evaluar la desaturación de oxígeno; por el otro, la gasometría arterial se utiliza para insuficiencia respiratoria e indicar si es necesario oxígeno suplementario. ${ }^{15,17}$ En todos los pacientes con signos clínicos sugestivos de falla respiratoria, insuficiencia cardiaca derecha o si la saturación arterial de oxígeno es $<90 \%$ debe realizarse gasometría arterial o determinación capilar de gases sanguíneos. ${ }^{2}$

La caminata de seis minutos se sugiere para evaluar la tolerancia al ejercicio, determinar el índice BODE (Body mass index, Obstruction, Dyspnea and Exercise) y medir el efecto de las intervenciones. ${ }^{17}$

La difusión pulmonar de monóxido de carbono (DLCO) es útil para el diagnóstico diferencial con asma ${ }^{2,17}$ y para evaluar a los pacientes con EPOC que presentan disnea, la cual parece fuera de proporción al grado de limitación del flujo por espirometría. ${ }^{2}$ El grado de atrapamiento aéreo e hiperinflación pulmonar se puede documentar por pletismografía corporal. ${ }^{2}$ En México, la disponibilidad de estas últimas dos pruebas de función pulmonar es aún limitada.

\section{2: EPOC: Medidas generales}

\section{Pregunta clínica 6}

¿Cuál es la eficacia y seguridad de las distintas estrategias terapéuticas farmacológicas y no farmacológicas (principalmente consejo antitabaco) para la cesación tabáquica del paciente con EPOC?

\section{Recomendaciones}

1 Estimular al paciente con EPOC a Evidencia 1+ dejar de fumar es la intervención prioritaRecomendación A ria más simple y la mejor costo-efectiva en el manejo; debe ofrecerse en cada visita. ${ }^{2,16,17,21}$ 
En cada consulta, se debe ofrecer un consejo breve y oportuno impartido por los médicos, enfermeras y otros profesionales de la salud; se debe apoyar con materiales de autoayuda, técnicas conductuales, programas incentivos y, posteriormente, referir a un programa de cesación tabáquica y apoyo social. , $^{17,21}$

3 Los medicamentos más efectivos para dejar de fumar con un perfil de seguridad adecuado en pacientes con dependencia nicotínica moderada y que tienen interés en abandonar el hábito tabáquico son la terapia de reemplazo de nicotina (TRN), bupropión y vareniclina (primera línea). 2,17,18,21

4 Todas las formas de TRN (parches y chicles) son útiles para ayudar a dejar de fumar y son más eficaces si se combinan. .,18,21 $^{2}$

5 En los pacientes con EPOC que son fumadores y que presentan baja motivación para dejar de fumar, se sugiere el uso de consejo médico/psicológico acompañado de terapia farmacológica. ${ }^{18}$

$6 \quad$ La terapia conductual en la que se incluye el soporte social combinada con los tratamientos farmacológicos disponibles debe utilizarse en ausencia de contraindicaciones y en fumadores dispuestos a dejar el consumo. ${ }^{18}$

7 Si el paciente se encuentra hospitalizado por exacerbación de la enfermedad, se recomienda iniciar la terapia de deshabituación tabáquica durante la hospitalización. ${ }^{18}$

8 No hay evidencia suficiente para recomendar la espirometría y la edad pulmonar como herramientas que promuevan la cesación tabáquica. ${ }^{51}$

9 Los programas de prevención para dejar de fumar deberán dirigirse a todas las edades mediante campañas comunitarias, en escuelas, radio y televisión, tanto a nivel local como a nivel nacional. ${ }^{15}$

10

La eficacia y seguridad del cigarrillo electrónico como apoyo en la cesación tabáquica es incierta, por lo cual no se recomienda su uso. ${ }^{2}$
Evidencia 1+ Recomendación A

Evidencia 1+ Recomendación A

Evidencia 1+ Recomendación A

Evidencia 1+ Recomendación A

Evidencia 1+ Recomendación A

Evidencia 1+ Recomendación A

Evidencia 1+ Recomendación A

Evidencia 1++ Recomendación A

Evidencia 1++ Recomendación A

El consejo breve es una actividad que dura de tres a cinco minutos y consiste en 5 pasos (cinco $\mathbf{A})$ : 
1. Averiguar: Identificar si el paciente fuma.

2. Aconsejar: Apoyarse de folletos e información sobre los daños del tabaco para comunicarle al paciente por qué debe dejar de fumar.

3. Apreciar: Considerar el grado de adicción y de motivación para dejar de fumar.

4. Ayudar: Diseñar un plan para dejar de fumar

5. Acompañar: Seguimiento para reforzar y prevenir las recaídas. ${ }^{52}$

Un estudio realizado por el Instituto Nacional de Enfermedades Respiratorias Ismael Cosío Villegas (INER) demostró que el 6.7\% de los fumadores que recibieron consejo breve dejaron de fumar seis meses después y el $16 \%$ inició un tratamiento para dejar de fumar. Al considerar su bajo costo e inversión de recursos de esta implementación, se sugiere que sea adoptada por los profesionales de la salud. ${ }^{53}$

La citisina no está disponible en México, mientras que la clonidina y nortriptilina son medicamentos de segunda línea. Los resultados de la espirometría -independientemente de su valor- deben incentivar para la cesación tabáquica. Se debe combinar bupropión con terapia de reemplazo de nicotina (TRN) en aquellos pacientes que no han tenido éxito para dejar el tabaco. ${ }^{17}$ En el mismo sentido, se puede combinar vareniclina con TRN o bupropión en este tipo de pacientes con recaídas ${ }^{18}$ que, en comparación con bupropión, se ha visto que es más efectiva para lograr una mayor abstinencia continua a un año. ${ }^{21}$ La TRN (goma de mascar, inhalador, spray nasal, parche transdérmico o tableta subcutánea de nicotina) incrementa de forma confiable la tasa de abstinencia a largo plazo de tabaquismo, y es significativamente más efectiva que el placebo. ${ }^{2}$

La vareniclina, el bupropión y la nortriptilina han demostrado incrementar las tasas de abandono a largo plazo del tabaquismo, pero siempre deben ser usadas como un componente dentro del programa de apoyo para abandono más que como intervención única. Dado que la dependencia al tabaco es una enfermedad crónica, los médicos deben reconocer que las fallas en el abandono y recaídas son frecuentes y reflejan la naturaleza crónica de la dependencia y la adicción, y por el contrario, no representan un fracaso del paciente o del médico. ${ }^{2}$

La orientación por parte de médicos y otros profesionales de la salud incrementan las tasas de abandono más que las estrategias iniciadas por el propio paciente. Incluso durante períodos breves (desde 3 minutos) de orientación al paciente sobre abandonar su hábito tabáquico se mejoran las tasas de cesación. Existe una relación entre la intensidad del consejo médico y el éxito en la cesación. Se han observado tasas de abandono del $10.9 \%$ a seis meses cuando los tutoriales del médico y las retroalimentaciones se ligan a las sesiones de consejo. La combinación de farmacoterapia y medidas de conducta incrementan las tasas de cesación de tabaco. ${ }^{2}$

Un ensayo clínico (EC) aleatorizado, doble ciego y controlado estudió la eficacia de un programa de tratamiento del tabaquismo en un grupo de fumadores que recibieron consejo intenso para el abandono del tabaco mientras estuvieron ingresados, en comparación con el cuidado estándar. Tras recibir el alta, los pacientes siguieron recibiendo consejo mediante un sistema automático de voz y además se les facilitó el tratamiento farmacológico elegido durante un período de tres meses (TRN, bupropión o vareniclina). Los resultados mostraron que la eficacia de este programa a los seis meses de seguimiento era significativamente más alta que la eficacia de los cuidados habituales: 27 en comparación con 16\% para el cuidado estándar (RR: 1.70; IC del 95\%, 1.15-2.51; $p=0.007$ ). ${ }^{18}$

Existe un incremento en el uso de los cigarrillos electrónicos como una forma de terapia de reemplazo de nicotina, aunque su eficacia a este respecto es controvertida. Su perfil general de seguridad no ha sido bien definido aún; algunas 
organizaciones han sugerido tener precaución y la necesidad de recolectar más información antes de promover su uso generalizado. ${ }^{2}$

\section{Pregunta clínica 7}

¿Cuál es la eficacia y seguridad de las inmunizaciones para evitar las exacerbaciones en pacientes con EPOC?

\section{Recomendaciones}

$1 \quad$ La vacunación anual contra la influenza está recomendada en todos los pacientes con EPOC, ya que disminuye el riesgo de exacerbaciones, hospitalización y muerte por enfermedad grave. ${ }^{2,21}$

2 Ambas vacunas contra neumococo: la vacuna polivalente de 23 polisacáridos (PPSV 23) y vacuna polivalente conjugada de 13 polisacáridos (PCV13) son recomendadas en todos los pacientes mayores a 65 años. La PCV13 ha demostrado reducir la bacteremia y la incidencia de enfermedad neumocócica invasiva. ${ }^{2,17}$

3 Además, la vacuna PPSV23 se recomienda en pacientes menores de 65 años con obstrucción grave $\left(\mathrm{FEV}_{1}<40 \%\right)$ o comorbilidad significativa, particularmente con enfermedad cardiovascular o pulmonar. ${ }^{2,17}$

$4 \quad$ No se deben usar lisados bacterianos en la prevención de exacerbaciones. ${ }^{17}$
Evidencia 1+ Recomendación A

Evidencia 2++ Recomendación B

Evidencia 1++ Recomendación A

Evidencia 1++ Recomendación A

La vacunación contra la influenza puede reducir la probabilidad de enfermedad grave, como infecciones del tracto respiratorio inferior que requieran hospitalización, y la muerte en los pacientes con EPOC. Sólo algunos estudios han evaluado exacerbaciones y han demostrado una reducción importante en el número total de exacerbaciones comparada con aquéllos que reciben placebo.

Se han encontrado diversos hallazgos en un estudio basado en poblaciones, los cuales sugieren que los pacientes con EPOC, principalmente los ancianos, tienen una disminución en el riesgo de enfermedad isquémica coronaria cuando se vacunan contra influenza a lo largo de varios años. La aparición de reacciones adversas es generalmente baja y transitoria. ${ }^{2}$

Tanto la PPSV 23 como la PCV13 son recomendadas por la guía GOLD de 2019 en todos los pacientes mayores de 65 años, así como en pacientes jóvenes con padecimientos concomitantes importantes. Una RS, que incluyó $12 \mathrm{EC}$, reportó que las vacunas de neumococo proporcionaron protección significativa para neumonía en pacientes con EPOC. De igual forma, se disminuyó la posibilidad de exacerbaciones. Esta revisión sistemática de la literatura (RS) no proveyó suficiente evidencia para contrastar los beneficios entre las distintas presentaciones de vacunas. La PPSV 23 demostró proveer una disminución en la incidencia de neumonía adquirida en la comunidad en pacientes con EPOC menores de 65 años. La PCV 13 mostró eficacia en la prevención de neumonía adquirida en la comunidad (45.6\%) y enfermedad neumocócica invasiva (75\%) en paciente con EPOC mayores a 65 años; la eficacia persistió por al menos 4 años. ${ }^{2}$ 
Neumol Cir Torax. 2019; 78 (supl. 1): s1-s76

\section{3: EPOC: Clasificación y diagnósticos diferenciales}

\section{Pregunta clínica 8 \\ ¿Cómo se debe clasificar la EPOC?}

\section{Recomendaciones}

1

EI GDG de GMEPOC siguiere la utiliza-
ción de la clasificación GOLD para gra-
duar la limitación al flujo de aire (Figura
5). Esta clasificación gradúa la gravedad
de la obstrucción en estadios 1, 2, 3 y 4 ;
para categorización clínica y con fines de
tratamiento se usan los grupos A, B, C, D,
con base en síntomas y exacerbaciones
$($ Figura 5)

Evidencia 1+ Recomendación A

Una vez establecido el diagnóstico de EPOC, de acuerdo con los síntomas y factores de riesgo y la confirmación de obstrucción al flujo de aire, se debe graduar la gravedad de la obstrucción al flujo aéreo determinado por el resultado en

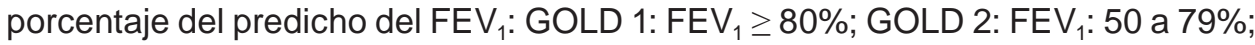
GOLD 3: $\mathrm{FEV}_{1}: 30$ a $49 \%$ y GOLD 4: $\mathrm{FEV}_{1}:<30 \%$ (Figura 4).

Para la clasificación GOLD en grupos A, B, C y D (figura 5), se requiere graduar los síntomas, de acuerdo con el grado de disnea del paciente y con la clasificación de mMRC (modified Medical Research Council) o la escala CAT (COPD Assessment Test), así como la presencia o no de exacerbaciones o agudizaciones de la EPOC (tabla 7). El grupo de GMEPOC propone, especialmente para médicos de primer y segundo nivel de contacto, sólo usar la escala mMRC y simplificar los grados de disnea a: sin disnea o con disnea leve (mMRC 0 y 1 , respectivamente), y disnea moderada (mMRC 2) y disnea grave (mMRC 3 y 4), que son los grados definidos para el ajuste de tratamiento farmacológico.

Para la evaluación de exacerbaciones se consideran dos tipos: con o sin exacerbaciones. Cuando se habla de exacerbaciones, éstas son definidas por, al menos,

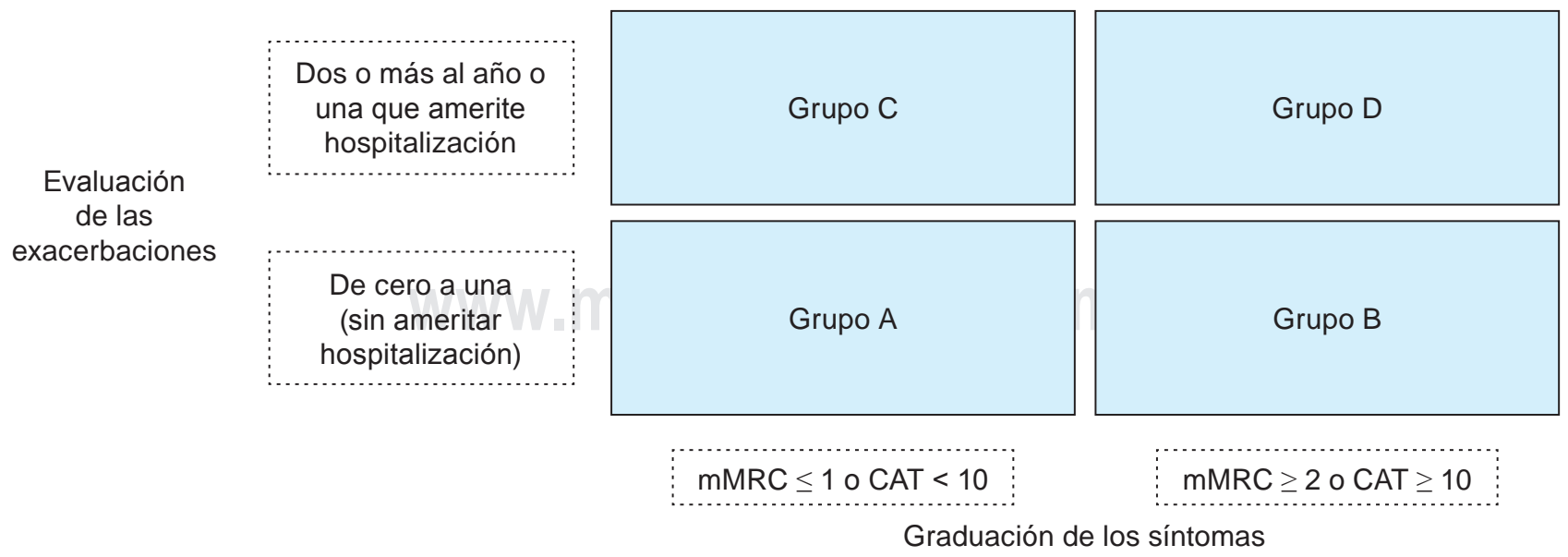

Figura 5: Clasificación clínica de la EPOC en grupos de acuerdo con GOLD, 2019. Los pacientes con diagnóstico establecido de EPOC se clasifican en cuatro grupos (A,B,C,D) con fines de tratamiento. En sentido vertical se clasifican de acuerdo con los síntomas con base en la escala de disnea mMRC (modified Research Council) o la escala de síntomas CAT (COPD Assessment Test). En sentido horizontal se clasifican con o sin exacerbaciones, panel superior e inferior, respectivamente. 
Neumol Cir Torax. 2019; 78 (supl. 1): s1-s76

Tabla 7: Parámetros clínicos a evaluar en el paciente con EPOC con fines de clasificación y tratamiento.

Evaluación de disnea de acuerdo con mMRC:

mMRC 0: Sólo me falta el aire con ejercicio intenso

mMRC 1: Me falta el aire caminando aprisa en plano 0 en una subida ligera

mMRC 2: Al caminar en plano soy más lento para mi edad o me detengo por falta de aire

mMRC 3: Me falta el aire al caminar menos de una cuadra (unos $100 \mathrm{~m}$ ) o después de pocos minutos

mMRC 4: Me falta demasiado el aire para salir de casa o para vestirme o desvestirme

Evaluación de la disnea GMEPOC (mMRC simplificada)

Sin disnea o disnea leve (mMRC 0 Y 1): Sólo falta de aire en ejercicio intenso (mMRC 0) o caminando aprisa en plano o en una subida ligera (mMRC 1)

Disnea moderada (mMRC 2): Al caminar en plano soy más lento para mi edad o me detengo por falta de aire

Disnea grave (mMRC 3 y 4): Me falta el aire al caminar menos de una cuadra, unos 100 m (mMRC3) o demasiada falta de aire para salir de casa o para vestirse/desvestirse (mMRC4)

Evaluación de exacerbaciones:

Sin exacerbaciones: Sin hospitalización por causa respiratoria y no más de una agudización respiratoria ambulatoria (último año)

Con exacerbaciones: Por lo menos, una hospitalización, una visita a urgencias o dos agudizaciones ambulatorias por causa respiratoria en el último año

Valoración de eosinófilos en sangre

Eosinófilos $\geq 300$ células/ $\mu \mathrm{L} 0 \geq 100$ células/ $\mu \mathrm{L}$ en algunos casos

mMRC = escala de disnea.

una hospitalización, una visita a urgencias o dos agudizaciones ambulatorias por causa respiratoria en el último año; sin exacerbaciones será sin antecedentes de hospitalización por causa respiratoria y no más de una agudización respiratoria ambulatoria en el último año.

Pregunta clínica 9

¿Qué enfermedades constituyen diagnósticos diferenciales o comorbilidades para la EPOC?

\section{Recomendación}

Se sugiere considerar las siguientes enfermedades como diagnósticos diferenciales o comorbilidades en pacientes con EPOC. Las enfermedades que constituyen diagnósticos diferenciales en pacientes con EPOC estable son:

1 Se sugiere considerar las siguientes enfermedades como diagnósticos diferenciales/

Evidencia 3 comorbilidades en pacientes con EPOC.

Las enfermedades que constituyen diagnósticos diferenciales en pacientes con EPOC estable son:

Condiciones intratorácicas que presentan o comparten síntomas, signos y/o datos espirométricos similares, como asma, bronquiectasias, insuficiencia cardiaca congestiva, carcinoma bronquial, neumopatías intersticiales, tuberculosis, bronquiolitis obliterante, panbronquiolitis difusa, fibrosis quística y displasia broncopulmonar. 
Condiciones extratorácicas que presentan o comparten síntomas, signos y/o datos espirométricos similares, como síndrome de tos de la vía aérea superior, (rinitis alérgica crónica, síndrome de descarga retronasal) reflujo gastroesofágico, tos por medicamentos (inhibidores de la enzima convertidora de angiotensina) y tos idiopática. ${ }^{2,16,17}$

2 Las enfermedades que constituyen diagnósticos diferenciales en pacientes con exacerbación de la EPOC son:

Condiciones intratorácicas que presentan o comparten síntomas, signos y/o datos espirométricos similares, como asma, bronquiectasias, insuficiencia cardiaca congestiva, carcinoma bronquial, neumopatías intersticiales, tuberculosis, bronquiolitis obliterante, panbronquiolitis difusa, fibrosis quística y displasia broncopulmonar. Enfermedades pulmonares: neumonía, neumotórax, edema pulmonar, embolia pulmonar, cáncer pulmonar, derrame pleural, obstrucción de la vía aérea superior y broncoaspiración recurrente.

Enfermedades no pulmonares: arritmias supraventriculares y ventriculares, ${ }^{54}$ cardiopatía isquémica, insuficiencia cardiaca izquierda, trastornos de ansiedad o pánico, uso de beta bloqueadores no selectivos o sedantes. ${ }^{2,16,17}$

El diagnóstico diferencial más importante de la EPOC es la distinción con el asma. En general, el asma inicia a temprana edad (antes de los 40 años) y los síntomas son más episódicos con predominio de sibilancias y síntomas alérgicos asociados, aunque también se debe considerar la coexistencia de las mismas. ${ }^{2}$

Otros padecimientos a considerar en el diagnóstico diferencial son causas de hemoptisis, síndrome de hipoventilación, trastornos de ansiedad y reacciones adversas a medicamentos.

\section{4: EPOC estable: Tratamiento farmacológico}

\section{Pregunta clínica 10}

¿Cuál es la eficacia y seguridad de los anticolinérgicos de acción prolongada (LAMA, por sus siglas en inglés) y de los broncodilatadores $\beta_{2}$ agonistas de acción prolongada (LABA, por sus siglas en inglés) como monoterapia, o en combinación para el manejo de los pacientes con EPOC? 


\section{Recomendaciones}

1 Los broncodilatadores inhalados de acción prolongada son de primera elección para el tratamiento de la EPOC sintomática. ${ }^{2}$

2 Los LAMA y LABA mejoran significativamente la función pulmonar, la disnea y la calidad de vida, además de reducir la tasa de exacerbaciones. Los LAMA tienen un mayor efecto en reducir la tasa de exacerbaciones y hospitalizaciones comparado con LABA. ${ }^{2}$

3 Se sugiere iniciar con tiotropio debido a que mejora la efectividad de la rehabilitación pulmonar incrementando la tolerancia al ejercicio. ${ }^{2}$ Además, reduce la frecuencia de exacerbaciones comparado con los LABA y con un perfil de seguridad similar. ${ }^{17}$

$4 \quad$ El uso de la doble terapia broncodilatadora (LABA + LAMA) comparado con su monoterapia (LABA o LAMA) está recomendado en pacientes que persisten sintomáticos o con una calidad de vida muy afectada. ${ }^{17}$

\author{
Evidencia 1++ \\ Recomendación A
}

Evidencia 1++

Recomendación A

Evidencia 1+

Recomendación B

Evidencia 1++

Recomendación A

Los LAMA bloquean el receptor muscarínico M3, expresado en el músculo liso de la pared bronquial. No existe RS que haya evaluado la eficacia y seguridad del tiotropio en pacientes con EPOC estable. Sin embargo, EC demostraron un incremento significativo en el $\mathrm{FEV}_{1}$ y en la FVC $(p<0.01)$. Se observó también mejoría de síntomas, sibilancias y disnea, principalmente a favor del grupo con LAMA en comparación con placebo $(p<0.05)$. La calidad de vida mostró mejoría en un EC en comparación con el grupo placebo, empleando para ello el Cuestionario Respiratorio Saint George (SGRQ) $(p<0.05)$. El uso de medicamentos de rescate disminuyó en el grupo con LAMA ( $p<0.001)$. Las exacerbaciones se presentaron en una menor proporción de pacientes con LAMA (36\%) en comparación con el grupo placebo $(42 \%)$, con una reducción global del $14 \%(p<0.05)$. No hubo diferencias significativas en la proporción de pacientes que presentaron al menos una exacerbación. ${ }^{16}$

Los LAMA también han demostrado, además de mejorar los síntomas y estado de salud, que mejoran la efectividad de la rehabilitación pulmonar, reduciendo las hospitalizaciones y exacerbaciones. En un estudio a largo plazo, el tiotropio adicionado a la terapia estándar no tuvo efecto en la pérdida de la función pulmonar. Su perfil de seguridad es muy bueno, son pobremente absorbidos y la frecuencia de eventos adversos es muy baja, aun usándolos en un rango amplio de dosificación. Se han reportado resequedad oral y sabor metálico. En EC, no se ha informado que haya un aumento en el riesgo cardiovascular ni en la mortalidad. ${ }^{2}$

Los LABA actúan directamente en los receptores adrenérgicos del músculo liso bronquial, incrementando con ello la concentración intracelular de AMP cíclico y su acción dura al menos 12 horas. Una RS evaluó la eficacia y seguridad de los LABA en comparación con placebo, sin embargo, los resultados en diversos desenlaces no son consistentes. En lo referente a mejoría de síntomas, algunos de los estudios reportan mejoría de síntomas diurnos y nocturnos a favor de los LABA $(p=0.01)$. 
En otros estudios no se ha demostrado beneficio en la mejoría de los síntomas. En lo que respecta a la disnea, cinco EC fallaron en demostrar beneficio clínico, aunque dos estudios posteriores sí encontraron diferencias significativas a favor de LABA en la mejoría de la disnea $(p<0.05)$.

Un estudio reportó disminución en el uso de SAMA de rescate en el grupo tratado con LAMA en comparación con el grupo placebo $(p<0.045)$. Globalmente, los EC fueron inconsistentes en demostrar la mejoría en la calidad de vida. En lo que respecta a las exacerbaciones, los resultados fueron inconsistentes en demostrar beneficio a favor de LABA. ${ }^{16}$

Una RS Cochrane reciente tuvo como objetivo evaluar la eficacia y seguridad de los LABA en pacientes con EPOC. Ésta incluyó 26 EC con 14,939 pacientes con síntomas moderados a graves al momento de su inclusión, $F E V_{1}$ entre 33 y $55 \%$, y una calificación en el comportamiento de la calidad de vida (SGRQ, por sus siglas en inglés) entre 44 y 55 . La evidencia mostró que los LABA mejoran la calidad de vida (diferencia de medias [DM] de SGRQ -2.31, con un intervalo de confianza del 95\% [IC95\%; -3.09 a 1.54]) con una disminución de las exacerbaciones que requirieron hospitalización (OR 0.73, IC95\% 0.56-0.95). El número de personas que requirieron esquemas de corticosteroides orales o antibióticos por exacerbaciones fue menor en el grupo de LABA (52 pacientes menos en comparación con el grupo placebo por cada mil pacientes tratados). La mortalidad fue baja en ambos grupos y no hubo diferencias significativas entre ambos (OR 0.90, IC95\% 0.75-1.08) ni en incidencia de eventos adversos (OR 0.97, IC95\% $0.83-1.14)$. Con base en los $26 \mathrm{EC}$ incluidos, los autores concluyeron que los LABA son efectivos y seguros en el tratamiento a mediano y largo plazo en pacientes con EPOC moderado a grave..$^{2,55}$

La eficacia y seguridad de la combinación de LABA/LAMA tiene sentido, al combinar dos broncodilatadores con diferente mecanismo de acción y administrados por vía inhalada. Algunos estudios han mostrado cierta inconsistencia en la mejoría de algunos desenlaces clínicos. Los beneficios reportados incluyen mejoría en la calidad de vida, disnea, función pulmonar (aumento del $\mathrm{FEV}_{1}$ ) y uso de medicamentos de rescate, pero no se ha visto superioridad de la combinación en comparación con los medicamentos como monoterapia, en lo que respecta a la incidencia de exacerbaciones. Una RS de EPOC moderada-grave mostró mejoría en la función pulmonar y la disnea a favor de la combinación. Estos hallazgos han sido replicados con medicamentos más recientes, como la combinación de indacaterol más glicopirronio. En términos generales, se recomienda la combinación LABA/ LAMA en pacientes con EPOC de moderado-grave que persisten sintomáticos a pesar de la monoterapia..$^{2,17}$

\section{Pregunta clínica 11}

¿Cuál es la indicación de los LABA más corticosteroides inhalados (CEI) para el manejo de los pacientes con EPOC?

\section{Recomendaciones}

1 Se recomienda iniciar el tratamiento con LABA más CEI en pacientes con EPOC es-

Evidencia 1++ Recomendación A table sintomáticos ( $m M R C \geq 2$ o CAT $\geq 10$ ), con exacerbaciones frecuentes (al menos una hospitalización, o dos o más exacerbaciones moderadas en el último año) y que cursen con eosinófilos en sangre periférica $\geq 300$ células/ $\mu \mathrm{L}$ o con historia de asma. ${ }^{2}$ 
2 Se recomienda escalar el tratamiento a
LABA más CEI en el paciente con exacerba-
ciones que inició con monoterapia bron-
codilatadora (LAMA o LABA) y que curse
con eosinófilos en sangre periférica $>300$
células/ $\mu \mathrm{L}$ o eosinófilos en sangre periférica
$>100$ células/ $\mu \mathrm{L}$ y una hospitalización o dos
exacerbaciones moderadas.

3 La combinación LABA más CEl es más efectiva que la monoterapia para mejorar la función pulmonar y la calidad de vida, así como para reducir las exacerbaciones en pacientes con exacerbaciones. ${ }^{2}$ El tratamiento regular con CEl incrementa el riesgo de neumonía, particularmente en aquéllos con enfermedad grave. ${ }^{17}$

$4 \quad$ Se prefiere el uso de LAMA sobre la terapia combinada (LABA/CEI).

$5 \quad$ No se recomienda la monoterapia con CEI.
Evidencia 1++ Recomendación A

Evidencia 1++ Recomendación A

Evidencia 2++ Recomendación B

Evidencia 1++ Recomendación A

Una RS Cochrane evaluó la combinación de LABA y CEI en pacientes con EPOC en comparación con CEl como monoterapia. Ésta incluyó 15 estudios con 7,814 pacientes con EPOC grave y con baja reversibilidad. Dicha RS mostró disminución en la incidencia de exacerbaciones a favor de la terapia combinada (RR 0.87; IC95\% 0.80-0.94). El beneficio en cuanto a las PFR y la calidad de vida fueron menores.

Otra RS Cochrane evaluó la combinación de LABA y CEI en pacientes con EPOC en comparación con LABA como monoterapia. Ésta incluyó 14 estudios con 11,794 pacientes con EPOC grave e informó una disminución en la incidencia de exacerbaciones (RR 0.76; IC95\% 0.68-0.84) y una disminución del riesgo de exacerbaciones con la combinación (42 versus $47 \%$ ). No hubo diferencias en las hospitalizaciones (RR 0.79; IC95\% 0.55-1.13) ni en la mortalidad (OR 0.92, IC95\% 0.76-1.11). La neumonía ocurrió con mayor frecuencia en los pacientes que utilizaron la combinación (OR 1.55; IC95\% 1.20-2.01). Otros desenlaces también mostraron beneficio de la combinación contra la monoterapia con LABA (calidad de vida, uso de medicamentos de rescate y disnea), aunque no se alcanzó la significancia estadística. Los autores concluyeron que la calidad es moderada y que se requiere más investigación de alta calidad. .7,56,57

Algunos estudios han informado que la cuenta de eosinófilos en sangre puede ser usada como predictor de la respuesta al CEI en la prevención de exacerbaciones. El punto de corte sugerido es eosinófilos en sangre periférica $>300$ células/ $\mu \mathrm{L}$ o eosinófilos en sangre periférica $>100$ células/ $\mu \mathrm{L}$ y una hospitalización o dos exacerbaciones moderadas. ${ }^{2}$ La evidencia entre LAMA y combinación con CEI es similar en eficacia. Respecto a seguridad, existe mayor riesgo al combinar LABA y CEI. La evidencia favorece tanto a tiotropio y combinación de LABA y CEI al mejorar la disnea, la calidad de vida, un menor número de exacerbaciones y hospitalización por ellas. La utilización de LAMA en comparación con la terapia combinada LAMA y CEI resulta en aumento del riesgo de desarrollar neumonía. ${ }^{2,17}$

Pregunta clínica 12

¿Cuál es la indicación de los LABA, LAMA y CEI combinados (triple terapia) para el manejo de los pacientes con EPOC? 


\section{Recomendaciones}

1 Se debe considerar escalar a triple terapia en pacientes con EPOC estable que persisten con síntomas (disnea $\mathrm{mMRC} \geq 2$ o CAT $\geq 10$ ), a pesar de terapia dual (LABA/LAMA) y que además cursen con eosinófilos en sangre periférica $\geq 300$ células/ $\mu \mathrm{L}$ o tengan historia sugerente de asma. ${ }^{2}$

2 También se debe considerar escalar a triple terapia en pacientes con EPOC estable y exacerbaciones frecuentes (al menos una hospitalización o dos o más exacerbaciones moderadas en el último año) y que cursen con eosinófilos en sangre periférica $\geq 100$ células $/ \mu \mathrm{L}^{2}{ }^{2}$

3 La triple terapia mejora la función pulmonar, los síntomas, calidad de vida y reduce las exacerbaciones comparado con CEI y LABA, LABA y LAMA, o monoterapia con LAMA. $^{2}$

\author{
Evidencia 1++ \\ Recomendación A
}

Evidencia 1++

Recomendación A

Evidencia 1++

Recomendación A

El escalamiento hacia la triple terapia con LABA más LAMA y CEI puede ocurrir de diversas maneras. ${ }^{58}$ Éste puede mejorar la función pulmonar, los desenlaces reportados por los pacientes y prevenir las exacerbaciones. ${ }^{59-62} \mathrm{El}$ añadir un LAMA a una combinación de LABA y CEI mejora la función pulmonar y los desenlaces reportados por los pacientes y, en particular, el riesgo de exacerbación. ${ }^{60,63-66}$

Una RS Cochrane, cuyo objetivo fue evaluar la triple terapia (CEI/LABA/ LAMA) en comparación con la doble combinación, incluyó tres EC con 1,021 pacientes, reportando beneficio discreto en la calidad de vida (SGRQ DM -2.49 , IC95\% -4.04 a -0.94). No obstante, no hubo diferencia significativa en lo que respecta a las hospitalizaciones, mortalidad o episodios de neumonía y exacerbaciones. ${ }^{67}$

Un EC doble ciego con grupos paralelos reportó que el tratamiento con triple terapia en un solo inhalador tuvo mayores beneficios clínicos en comparación con tiotropio en los pacientes con EPOC sintomático, $\mathrm{FEV}_{1}<50 \%$ e historia de exacerbaciones; ${ }^{68}$ otros ensayos clínicos aleatorizados doble ciego han informado beneficios de la triple terapia mediante un inhalador único comparado con la terapia con combinación de LABA y LAMA. ${ }^{69,70}$ Hay evidencia en cuanto al conteo de neutrófilos que muestran pobre beneficio en aquéllos con menos de 100 células; en conteos mayores a 300 células se presenta una mejor respuesta. ${ }^{68,70-72}$

Se sugiere escalar a triple terapia LABA, CEl y LAMA en aquellos pacientes que cursan con enfermedad moderada a muy grave, si persisten con exacerbaciones 0 que no lleven un control adecuado de la enfermedad aún después de recibir doble terapia broncodilatadora LABA y LAMA o LABA y CEI. ${ }^{17}$ 


\section{Recomendaciones}

1 Los broncodilatadores de acción corta $\left(\beta_{2}{ }^{-}\right.$ agonistas y/o anticolinérgicos) (SABA) se deben utilizar a demanda, además de añadirse al tratamiento de base, sea cual sea el nivel de gravedad de la enfermedad, para el alivio inmediato de los síntomas de los pacientes con EPOC. ${ }^{18}$

2 Los SABA o SAMA se emplean únicamente como medicamentos de rescate, ya que mejoran el $\mathrm{FEV}_{1}$ y los síntomas. ${ }^{2}$

3 La combinación es superior a la monoterapia
Evidencia 1-

Recomendación B

Evidencia 1++ Recomendación A

Evidencia 1+ Recomendación A

La acción principal de los $\beta_{2}$-agonistas (SABA) es la relajación del músculo liso de la vía aérea al estimular los receptores $\beta_{2}$-agonistas. El efecto de los SABA tiene una duración de 4 a 6 horas. El uso regular y por razón necesaria de los SABA mejora la $\mathrm{FEV}_{1}$ y los síntomas obstructivos. Al usarse, por razón necesaria, y en una sola dosis en la EPOC, parece que el uso rutinario del levalbuterol no tiene ventaja sobre broncodilatadores convencionales. ${ }^{2}$

Los fármacos anticolinérgicos inhiben el efecto de la acetilcolina en los receptores muscarínicos M1 y M3 expresados en músculo liso de la vía aérea. Los anticolinérgicos de acción corta (ipratropio y oxitropio) también bloquean al receptor neuronal inhibitorio $\mathrm{M} 2$, el cual puede causar broncoconstricción vagal inducida. ${ }^{2}$

Una RS evaluó, en términos de función pulmonar, el estado de salud y los requerimientos de esteroides orales, la efectividad y la seguridad del uso de SABA en pacientes con EPOC. Ésta incluyó 13 EC calificados con alta calidad metodológica, mostrando una mejoría significativa del $\mathrm{FEV}_{1}$ (DMP 0.14L, IC95\% 0.04-0.25) y de la FVC (DMP 0.30L IC95\% 0.02 - 0.58). También se observó una mejoría en los valores de flujometría y severidad de la disnea. Los pacientes que abandonaron el estudio fueron el doble en el grupo placebo en comparación con SABA. ${ }^{73}$

Los broncodilatadores de acción corta ( $\beta_{2}$-agonistas y anticolinérgicos) se deben utilizar a demanda, añadidos al tratamiento de base, sea cual sea el nivel de gravedad de la enfermedad, para el alivio inmediato de los pacientes con EPOC. ${ }^{16}$ Los SABA son el tratamiento de primera elección para todas las etapas de la EPOC. ${ }^{15,16}$ En pacientes con EPOC moderado a grave con exacerbaciones (más de dos veces por año), el tratamiento con SABA se debe agregar a los de acción prolongada. En pacientes que permanecen sintomáticos, aún con el uso de SABA, se debe intensificar el tratamiento agregando un anticolinérgico de acción corta o un broncodilatador de acción prolongada. En pacientes con enfermedad moderada a grave que permanecen sintomáticos aún con el uso de SABA, es preferible agregar broncodilatador de acción prolongada para disminuir la frecuencia de exacerbaciones, mejorar la tolerancia al ejercicio reducir la disnea y mejorar la tolerancia al ejercicio. ${ }^{74}$

Debido a que su actividad continúa siendo regular durante la noche en los enfermos con EPOC estable, se recomiendan los $\beta_{2}$-agonistas de larga duración. ${ }^{16}$ El tiotropio se emplea en una sola dosis diaria, con ello se mantienen adecuados niveles del medicamento, favoreciendo la reducción de las exacerbaciones graves de la EPOC. Tres EC demostraron mejoría significativa del FEV $\mathrm{F}_{1}$, cuando se usó SAMA en comparación con placebo $(p<0.001)$. Los resultados en síntomas y calidad de vida no han sido consistentes. ${ }^{16}$ 
Pregunta clínica 14

¿Cuál es la eficacia y seguridad de los broncodilatadores de corta y larga acción nebulizados para el manejo de los pacientes con EPOC?

\section{Recomendaciones}

A pesar de que los inhaladores de dosis medida presurizados (IDMp) y los inhaladores de polvo seco (IPS) son los dispositivos de inhalación más utilizados, podrían ser inadecuados en algunos escenarios clínicos (pacientes muy ancianos, con deterioro cognitivo, hospitalizados), por lo que en poblaciones específicas de pacientes (flujo inspiratorio muy bajo) el tratamiento, tanto de rescate como de mantenimiento, con nebulizadores, puede otorgar los mismos beneficios que los IDM o los IPS., ${ }^{2,75}$
Evidencia 1+ Recomendación A

Los inhaladores de polvo seco y los inhaladores con dosis medida presurizadas (IPS y IDMp o DPI y pMDIs, respectivamente, por sus siglas en inglés) son los dispositivos de administración de medicamentos más comúnmente utilizados, pero pueden no ser adecuados en algunos pacientes, como en ancianos, pacientes con discapacidad cognitiva y enfermos hospitalizados.

A medida que más medicamentos están disponibles en forma de soluciones, los pacientes con EPOC y sus cuidadores están cada vez más satisfechos con el suministro de medicamentos nebulizados, lo que proporciona beneficios similares a los medicamentos suministrados vía inhalador manual para aliviar los síntomas y mejorar su calidad de vida. ${ }^{65,75}$ Aunque los IPS y los IDMp son los dispositivos más comúnmente utilizados, GOLD ${ }^{2}$ recomienda a los nebulizadores para poblaciones específicas de pacientes (pacientes con flujo inspiratorio muy bajo), en los cuales la terapia nebulizada pueda proveer más beneficios que los IPS y los IDMp. La iniciativa GOLD recomienda evaluar los beneficios de la terapia nebulizada de acuerdo con los síntomas y continuar el tratamiento siempre que no se puedan lograr beneficios similares con alternativas portátiles más sencillas y costo-efectivas, esto de acuerdo con varios EC. Además, tanto los pacientes como sus cuidadores, están cada vez más satisfechos con el suministro de medicamentos nebulizados y han reportado beneficios en el alivio de los síntomas, la facilidad en su uso y la mejora en la calidad de vida al utilizar este sistema. ${ }^{75}$

A pesar de que los IPS y los IDMp son efectivos en la mayoría de los pacientes con EPOC, los pacientes ancianos y aquéllos con discapacidad cognitiva pueden beneficiarse por el uso de un nebulizador, ya que pueden tener dificultades para sincronizar la inhalación con el mecanismo de activación del inhalador o pueden no ser capaces de generar un flujo de inspiración suficiente contra la resistencia de un DPI, que se activa con la inspiración para generar un aerosol efectivo.

Los inhaladores de vapor lento (IVL o SMls, por sus siglas en inglés) son inhaladores compactos y portátiles, con múltiples dosis, que utilizan preparados líquidos similares a aquéllos que son empleados en los nebulizadores, pero, al igual que los IPS y los IDMp, requieren manipulación para generar el aerosol y técnicas de inspiración especiales para la administración efectiva del medicamento en aerosol hacia los pulmones.

La opción entre una terapia dependerá finalmente de un amplio rango de factores que incluyen al médico que prescribe, la disponibilidad de los medicamentos/ dispositivos específicos, costo del medicamento y las preferencias y satisfacción 
Neumol Cir Torax. 2019; 78 (supl. 1): s1-s76

de los pacientes. Cada uno de los dispositivos disponibles para administrar medicamentos a los pacientes con EPOC tiene ventajas y desventajas. ${ }^{75}$

En los pacientes con EPOC, los nebulizadores son alternativas a los IPS y los IDMp para proporcionar terapia inhalada, siempre que el medicamento esté disponible y sea químicamente estable en forma líquida. ${ }^{75} \mathrm{~A}$ pesar de algunos inconvenientes asociados con los nebulizadores, (por ejemplo, períodos de tratamiento de duración variable y limpieza diaria) la evidencia actual sugiere que la eficacia de los tratamientos administrados a los pacientes con EPOC moderada a grave por vía de nebulizadores es similar a la observada con los IPS y los IDMp. ${ }^{75}$

\section{Pregunta clínica 15}

¿Cuál es la eficacia y seguridad de los SABA orales para el manejo de los pacientes con EPOC?

\section{Recomendaciones}

1 La terapia inhalatoria es la vía de elección, porque el tiempo de acción es más rápido, se necesita una menor dosis y hay menos efectos colaterales. ${ }^{15}$

$2 \quad$ Los broncodilatadores inhalados se prefieren sobre los broncodilatadores orales. ${ }^{2} \mathrm{Se}$ sugiere evitar el uso de SABA orales (jarabe

Evidencia 1+ Recomendación A o tableta) en todos los grupos de edad, debido a que su inicio de acción es más lento (de 30 a 60 minutos), ${ }^{76,77}$ su estrecho índice terapéutico, su absorción gastrointestinal errática que resulta en una eficacia variable e inconsistente, así como su elevada incidencia de efectos secundarios: taquicardia, temblor, calambres, hipokalemia y leve caída en la saturación arterial de oxígeno. ${ }^{73,78,79}$
Evidencia 1+ Recomendación B

Pregunta clínica 16

¿Cuál es la eficacia y seguridad de los CEI para el manejo de los pacientes con EPOC?

\section{Recomendaciones}

1 No se recomienda la monoterapia con $\mathrm{CE}^{1,2}$ El tratamiento a largo plazo con CEI debe

Evidencia 1++ considerarse en asociación con LABA, o bien con LABA y LAMA en los escenarios descritos en las preguntas 11 y 12 de la presente guía.

El tratamiento regular con CEI como monoterapia no modifica o es mínimo el beneficio sobre la declinación de la función pulmonar a largo plazo ni la mortalidad, pero mejora la calidad de vida .2,15,21,80-82 Los CEI deben considerarse en pacientes con EPOC moderada a grave y que presenten exacerbaciones frecuentes. Los $\mathrm{CEl}$, como monoterapia, disminuyen la tasa de exacerbaciones comparados con placebo. ${ }^{21} \mathrm{El}$ uso de los CEI debe ser siempre en combinación con LABA, porque 
aumentan su efectividad al mejorar la función pulmonar, calidad de vida y la tasa de exacerbaciones. ${ }^{2,17,16}$ No debe ser propuesto como monoterapia a largo plazo en EPOC, ya que es menos eficaz que LABA y la combinación LABA y CEI. ${ }^{16,17}$

Existe evidencia de que los $\mathrm{CEl}$ están asociados con una mayor prevalencia de candidiasis oral, disfonía, neumonía no fatal, osteoporosis, moretones, riesgo incrementado de cataratas, diabetes y tuberculosis. ${ }^{2,16,17,21,65,66,68,70,83}$ El retiro de los CEl del tratamiento está relacionado inconsistentemente con el incremento en las exacerbaciones y con la pérdida de función pulmonar. ${ }^{2,21}$ De momento, hay poca evidencia y sigue siendo controversial que los CEI tengan algún efecto sobre las citocinas, proteína $\mathrm{C}$ reactiva y células inflamatorias (neutrófilos, pero no los eosinófilos) relativamente insensibles a los efectos de los esteroides. ${ }^{16,17}$

No hay suficiente información para establecer la dosis mínima requerida para lograr los beneficios probados. ${ }^{16}$ La reversibilidad a los corticosteroides orales no predice la respuesta a los $\mathrm{CEI}$, por lo que no debe ser usado como una estrategia para identificar a pacientes que se les deba administrar CEl. ${ }^{16}$

\section{Pregunta clínica 17}

¿Cuál es la eficacia y seguridad de las metilxantinas para el manejo de los pacientes con EPOC?

\section{Recomendaciones}

$1 \quad$ No se recomienda el uso de metilxantinas (teofilina) en el tratamiento de la EPOC estable, a menos que no exista disponibilidad de ningún broncodilatador de acción prolongada como tratamiento de mantenimiento o el paciente sea incapaz de utilizar fármacos inhalados. ${ }^{2,16}$

2 La teofilina tiene un efecto broncodilatador mínimo y los efectos en la sintomatología también son reducidos. No debe utilizarse como tratamiento de primera línea. ${ }^{18}$

3 Si se utiliza en el tratamiento de la EPOC estable, requiere vigilancia estricta de los niveles séricos (5 a $15 \mu \mathrm{g} / \mathrm{dl}) .{ }^{15}$ Los pacientes ancianos requieren de monitorización estrecha, debido a la frecuencia de alteraciones en la farmacocinética del fármaco, comorbilidades y polifarmacia. ${ }^{2,16}$

\author{
Evidencia 2++ \\ Recomendación B
}

Evidencia 1++ Recomendación A

Evidencia 2++ Recomendación C

El uso de la teofilina a dosis bajas también contribuye a una motilidad ciliar y está indicado en el tratamiento del paciente con EPOC GOLD D.,2 En una RS con un metaanálisis, dos investigadores de manera independiente, analizaron cuatro bases de datos, donde, finalmente, incluyeron 7 cohortes observacionales. En dicha RS se encontró que el uso de manera crónica de teofilina incrementa ligeramente el riesgo de mortalidad en todas causas en pacientes con EPOC. ${ }^{84}$

Las metilxantinas han sido utilizadas a lo largo del tiempo como broncodilatadores orales o intravenosos, considerando que actúan como inhibidores no selectivos de la enzima fosfodiesterasa. También se les ha encontrado un rango de acciones no broncodilatadoras, principalmente sobre la función en los músculos respiratorios, sobre todo en el diafragma. Es evidente que posee un efecto broncodilatador 
modesto en comparación con los $\beta_{2}$-agonistas y los anticolinérgicos. Asimismo, un EC de tres grupos demostró que la combinación con salmeterol y teofilina produce una mejoría significativa en la disnea y en la función pulmonar comparada con la administración por separado de salmeterol o teofilina. ${ }^{85}$

Existe evidencia limitada y contradictoria con respecto al efecto de la teofilina de baja dosis en tasas de exacerbación. Su índice terapéutico requiere de monitorear los niveles séricos óptimos (de 5 a $10 \mu \mathrm{g} / \mathrm{dL}$ ), por lo que se requiere una vigilancia muy estricta. La teofilina tiene un efecto broncodilatador terapéutico pequeño y la mayor parte del beneficio se produce sólo cuando se administran a altas dosis, casi tóxicas, presentando los pacientes una amplia gama de efectos indeseables, principalmente arritmias auriculares y ventriculares (que pueden resultar fatales) y crisis convulsivas (independientemente si el paciente tiene historia previa de epilepsia). Otros efectos secundarios incluyen cefalea, insomnio, náuseas, dispepsias, además de tener interacciones significativas con medicamentos de uso común, como digital y cumarina, entre otros. Estos eventos adversos pueden ocurrir aún dentro del rango terapéutico de los niveles séricos de teofilina. ${ }^{86-88}$ El grupo de trabajo aconseja fuertemente evitar su uso en la gran mayoría de los pacientes que serán atendidos en primer nivel de atención.

\section{Pregunta clínica 18}

¿Cuál es la eficacia y seguridad de los corticosteroides sistémicos para el manejo de los pacientes con EPOC estable?

\section{Recomendaciones}

1 Los glucocorticoides orales a largo plazo no se recomiendan en el tratamiento de la EPOC estable. ${ }^{15,21}$

2 Los pacientes con EPOC que, posterior a una exacerbación, no puedan desescalarse

\author{
Evidencia 1+ \\ Recomendación A
} de los esteroides orales, deben recibir la dosis mínima tolerable, así como profilaxis y monitorización de osteoporosis. .,16 $^{2}$

3 El uso a largo plazo de corticosteroides orales tiene muchos efectos adversos sin evidencia de beneficios. ${ }^{2}$
Evidencia 1Recomendación B

Evidencia 1++ Recomendación A

El uso de corticoesteroides sistémicos a largo plazo produce muchos efectos adversos, incluyendo miopatía, la cual puede empeorar la debilidad muscular que acompaña al paciente con EPOC grave y que lo puede llevar a insuficiencia respiratoria. Otros efectos indeseables principalmente son: diabetes mellitus, hipertensión arterial, supresión adrenal, predisposición a infecciones graves como neumonía o tuberculosis, osteoporosis y mayor riesgo de fracturas..$^{89.90}$

Pregunta clínica 19

¿Cuál es la eficacia y seguridad de los mucolíticos para el manejo de los pacientes con EPOC?

\section{Recomendaciones}

1 Los mucolíticos, como antioxidantes, se recomiendan en pacientes seleccionados. ${ }^{2}$
Evidencia 1++ Recomendación A 
2

Se sugiere evaluar su administración en pacientes con tos crónica productora de esputo viscoso, adherente, de difícil expectoración y que muestre evidencia de mejoría sintomática con su empleo. ${ }^{15}$

3 En los pacientes con exacerbaciones o con bronquitis crónica, la carbocisteína puede agregarse al tratamiento de mantenimiento de la EPOC estable. ${ }^{18}$

4

En pacientes con obstrucción grave y exacerbaciones a pesar de terapia inhalada óptima, se sugiere el uso de mucolíticos orales para prevenir exacerbaciones futuras.

5

Los mucolíticos no deben usarse de forma rutinaria para prevenir exacerbaciones. ${ }^{16}$

\author{
Evidencia 2++ \\ Recomendación A
}

Evidencia 1+

Recomendación B

Evidencia 3

Recomendación D

Evidencia 2

Recomendación D

El moco de las vías respiratorias es parte de la función inmunitaria nativa del pulmón que atrapa partículas y microorganismos, lo que permite su eliminación mediante el transporte ciliar y la tos. La hipersecreción de moco y la tos productiva crónica son las características de la bronquitis crónica en la EPOC.

La sobreproducción, la hipersecreción de las células caliciformes y la disminución de la eliminación del moco son los principales mecanismos responsables del exceso de moco en la bronquitis crónica. La acumulación de moco en pacientes con EPOC afecta la función pulmonar, la calidad de vida relacionada con la salud, las exacerbaciones de la EPOC, las hospitalizaciones y la mortalidad. EI tratamiento con mucolíticos (ambroxol, glicerol yodado, carbocisteína, erdosteína y la $\mathrm{N}$-acetilcisteína) puede emplearse en pacientes con EPOC, en la variedad de bronquitis crónica. Su mecanismo de acción es por diversos efectos biológicos, como la reducción de la producción de mucina, la mejora en la hiperplasia de las células caliciformes, el transporte mucociliar, la reducción de la inflamación de las vías respiratorias y los efectos antioxidantes y antivirales. Estos medicamentos mejoran los síntomas, la reología de esputo, la calidad de vida y reducen la frecuencia de exacerbaciones.

Nunca deben de ser utilizados como monoterapia. Asimismo, se ha demostrado que producen mayor beneficio en los pacientes que están recibiendo corticosteroides inhalados. ${ }^{91-94}$

\section{Pregunta clínica 20}

¿Cuál es la eficacia y seguridad de los inhibidores de la fosfodiesterasa 4 (IPDE4) para el manejo de los pacientes con EPOC?

\section{Recomendaciones}

1 En los pacientes con EPOC, bronquitis crónica $\left(\mathrm{FEV}_{1} \leq 50 \%\right)$ e historia de exacerba-

Evidencia 1+ ciones, los IPDE4 (roflumilast) son fármacos de segunda línea, cuyo efecto mejora la función pulmonar y reduce las exacerbaciones moderadas y graves. ${ }^{2,18}$ 
Evidencia 1+ minuye las exacerbaciones en los pacientes con la combinación LABA+CEI a dosis fija.,217,20,21
Recomendación A

La principal acción de los inhibidores de fosfodiesterasa 4 (IPDE4) es reducir la inflamación bronquial, inhibiendo la degradación del AMP cíclico. Es importante señalar que no es un broncodilatador, pero contribuye a disminuir las exacerbaciones moderadas y graves de la EPOC, teniendo su mayor efecto cuando se administran en conjunto con los corticosteroides sistémicos o con la combinación LABA/CEI a dosis fija. También contribuye a mejorar la función pulmonar y reduce las exacerbaciones moderadas y graves.

Los mucolíticos están indicados principalmente en los pacientes en los que predominan los signos y síntomas de bronquitis crónica, tos productiva o con broncorrea, quienes tienen un $\mathrm{FEV}_{1} \leq 50 \%$, sobre todo en los pacientes con historia de exacerbaciones frecuentes. Tiene más efectos secundarios que la medicación inhalada, pero son reversibles, disminuyen con el tiempo y, por lo regular, no es necesario suspenderlo. Los efectos más frecuentes son: diarrea, nauseas, ansiedad, depresión, pérdida de peso, hiporexia, dolor abdominal, cefalea y trastornos del sueño. Los pacientes más sensibles son los delgados o los que sufren de depresión. ${ }^{95-97}$ En general, tiene más efectos secundarios que la medicación inhalada, ocurren durante su ingesta, son reversibles y disminuyen con el tiempo, no obstante, han sido motivo de retiro en los estudios. ${ }^{2,17,20,21}$

Si los pacientes tratados con doble o triple terapia continúan con exacerbaciones frecuentes, pueden considerarse las siguientes opciones:

- Añadir roflumilast. Esto debe considerarse en pacientes con un $\mathrm{FEV}_{1}<50 \%$ del predicho y con bronquitis crónica, particularmente si ellos han experimentado al menos una hospitalización por exacerbación en el año previo.

- Añadir un macrólido. La mejor evidencia disponible es para el uso de azitromicina, especialmente en los fumadores no activos. Sin embargo, se debe de considerar el riesgo de adquirir gérmenes resistentes.

- Suspender el CEI. Se puede considerar retirar los CEI por efectos adversos (como el desarrollo de neumonía) o la falta de eficacia. Sin embargo, un conteo de eosinófilos de sangre periférica $\geq 300$ células/ $\mu \mathrm{L}$ define a los pacientes con mayor probabilidad de exacerbaciones tras el retiro de CEI y quienes deberían estar en vigilancia estrecha por riesgo de recaída. ${ }^{2}$

El grupo de trabajo de GMEPOC consideró que los IPDE4 son una herramienta útil en pacientes bien seleccionados, los cuales deberán de contar con evaluación por el especialista.

\section{Pregunta clínica 21}

¿Cuál es la eficacia y seguridad de los antibióticos para el manejo de los pacientes con EPOC estable?

\section{Recomendaciones}

$1 \quad$ La evidencia muestra que, en pacientes con EPOC estable, obstrucción de moderada a grave y riesgo elevado de exacerbaciones (a pesar del tratamiento óptimo con broncodilatadores y CEI), el uso de antibióticos profilácticos podría disminuir la frecuencia de exacerbaciones. ${ }^{2}$
Evidencia 1Recomendación B 
2 La coexistencia de EPOC con bronquiectasias e infección bronquial crónica (colonización) sugiere el tratamiento con antibiótico.

3 El uso a largo plazo de macrólidos (azitromicina y eritromicina) reduce las exacerbaciones en un año. ${ }^{2}$

$4 \quad$ El tratamiento con azitromicina se asocia con una mayor incidencia de resistencia bacteriana. $^{2}$

5 El tratamiento con azitromicina se asocia con una mayor incidencia de daños a la audición. $^{2}$

6 La terapia con fluoroquinolonas no se sugiere emplear como tratamiento profiláctico de exacerbaciones.

$7 \quad$ No hay información para prolongar estos esquemas más allá de un año.

\author{
Evidencia 3 \\ Recomendación C
}

Evidencia 1+ Recomendación B

Evidencia 1+ Recomendación A

Evidencia 1-

Recomendación B

Evidencia 2+

Recomendación C

Evidencia 1+ Recomendación B

El tratamiento profiláctico con antibiótico se ha empleado en la prevención de las exacerbaciones. Una RS evaluó la efectividad y seguridad de los antibióticos. Los autores incluyeron seis estudios; el riesgo de sesgo de los mismos fue alto, por lo cual se concluyó que no había evidencia suficiente para recomendarlos. La mayoría de los estudios fallaron en demostrar un beneficio consistente en la disminución de las exacerbaciones. ${ }^{2,16}$

La dosis usada de azitromicina fue $250 \mathrm{mg}$ diarios o $500 \mathrm{mg}$ tres veces por semana, y de eritromicina fue de $500 \mathrm{mg}$ dos veces al día, ambos por un año. Además de los problemas de audición, se menciona la prolongación del intervalo QT. ${ }^{2}$

\section{5: EPOC estable. Estrategias de tratamiento inicial y de ajuste}

\section{Pregunta clínica 22}

¿Cuáles son las estrategias de tratamiento inicial y escalamiento/desescalamiento en el tratamiento farmacológico?

\section{Recomendaciones}

1 GMEPOC propone el esquema ilustrado en la Figura 6 (basado en GOLD 2019), ${ }^{2}$ para

Evidencia 1++ tratamiento inicial y de ajuste. El tratamiento Recomendación A inicial se basa en la eficacia y seguridad de los medicamentos LABA, LAMA y CEI, solos y combinados; incluye los pasos 1 y 2, correspondientes a monoterapia (LABA o LAMA) o doble terapia (LABA+LAMA o $\mathrm{LABA}+\mathrm{CEI})$. 
Evidencia 4 to farmacológico en GMEPOC (Figura 6) Recomendación D corresponden a cambios, desde monoterapia con LABA o LAMA (paso 1) a doble terapia con LABA+LAMA o LABA+CEI (paso 2) y hasta triple terapia con $\angle A B A+L A M A+C E I$ (paso 3). Además, puede incluir ajuste con antiinflamatorios orales con roflumilast o macrólido (paso 4). Estos ajustes se basan en las recomendaciones GOLD 2019, de acuerdo a datos de eficacia y seguridad, pero no han sido evaluados sistemáticamente. ${ }^{2}$

3 La estrategia de desescalamiento está dirigida sólo al retiro de CEI y debe realizarse bajo vigilancia médica estrecha. Este proceso también se basa en datos de eficacia y seguridad y no ha sido evaluado sistemáticamente.

Con fines de educación profesional y manejo de EPOC en primer y segundo nivel de atención, el grupo GMEPOC propone el esquema de tratamiento inicial y de ajuste farmacológico que se ilustra en la Figura 6. Las medidas generales y de prevención, especialmente el manejo del tabaquismo activo, deben aplicarse en todos los pacientes, independientemente del nivel de gravedad. ${ }^{2}$ En el paciente con diagnóstico de EPOC estable y posterior a la evaluación de la disnea y la frecuencia de las exacerbaciones (Tabla 7), se recomienda los siguientes tratamientos iniciales:

\section{Terapia inicial}

\section{Paso 1: Monoterapia (LAMA o LABA)}

1. Valorar un broncodilatador. En pacientes con EPOC estable sin disnea o disnea leve (mMRC 0 o mMRC 1) y sin exacerbaciones frecuentes se debe valorar un broncodilatador (GOLD A).

2. LABA o LAMA. En pacientes con disnea moderada (mMRC 2) y sin exacerbaciones frecuentes se debe prescribir un broncodilatador de acción prolongada LAMA o LABA (GOLD B)

3. LAMA. En pacientes con exacerbaciones, que cursen sin disnea o disnea leve ( $m M R C$ y 1 ; GOLD C) o con disnea moderada (mMRC 2, GOLD D) se debe prescribir un broncodilatador de larga duración tipo LAMA por su efecto en reducción de las exacerbaciones.

\section{Paso 2: Doble terapia ( $L A B A+\angle A M A$ o $L A B A+C E I)$}

1. LABA + LAMA. En pacientes con disnea grave (mMRC 3 y 4) y con exacerbaciones se debe iniciar un tratamiento con doble broncodilatador (LAMA + L ABA), preferentemente en un solo dispositivo.

2. $\mathrm{LABA}+\mathrm{CEI}$. En pacientes con disnea moderada o grave (mMRC 2, 3 y 4) y con uno o más de los siguientes criterios: 1) con exacerbaciones; 2) una cifra de eosinófilos de $\geq 300$ células $/ \mathrm{mL}$ o 3) historia de asma (GOLD D); se 


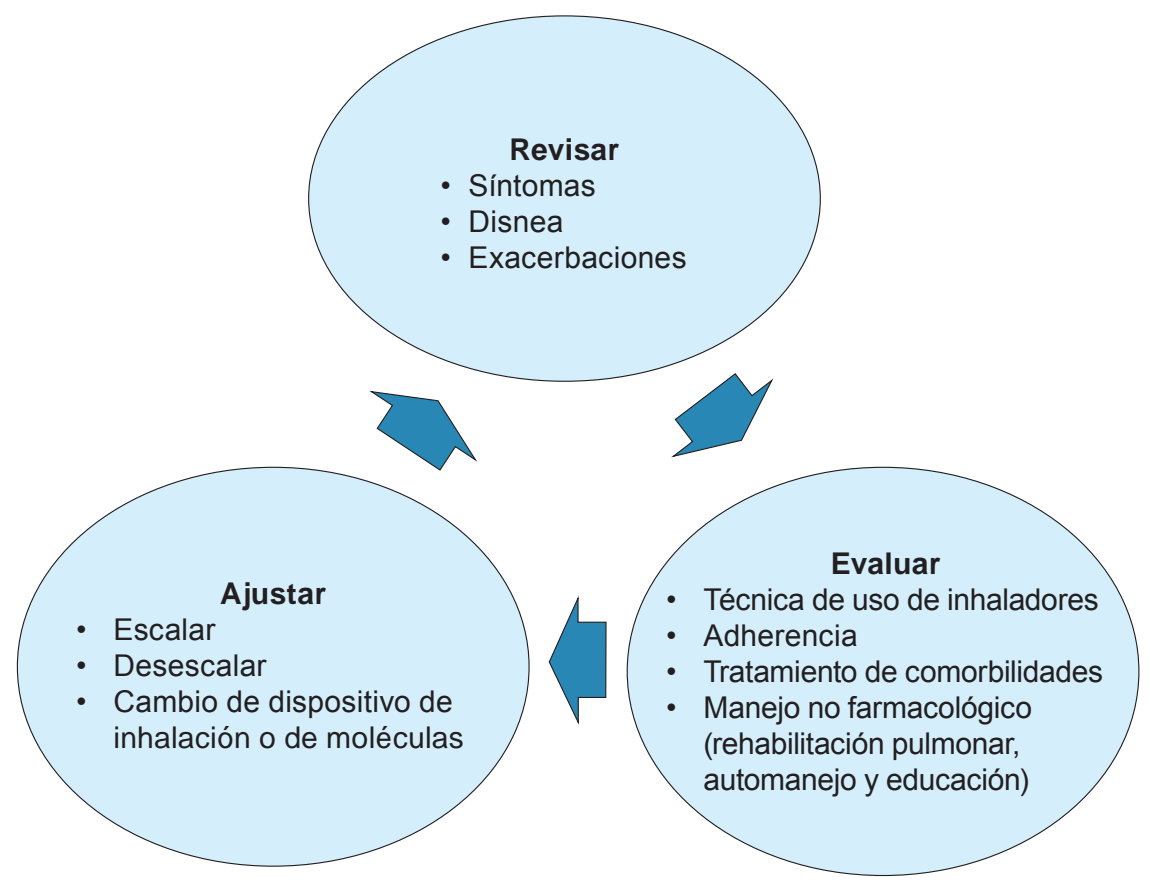

Tratamiento inicial y de ajuste de la EPOC (GMEPOC 2020)

Ajuste terapéutico

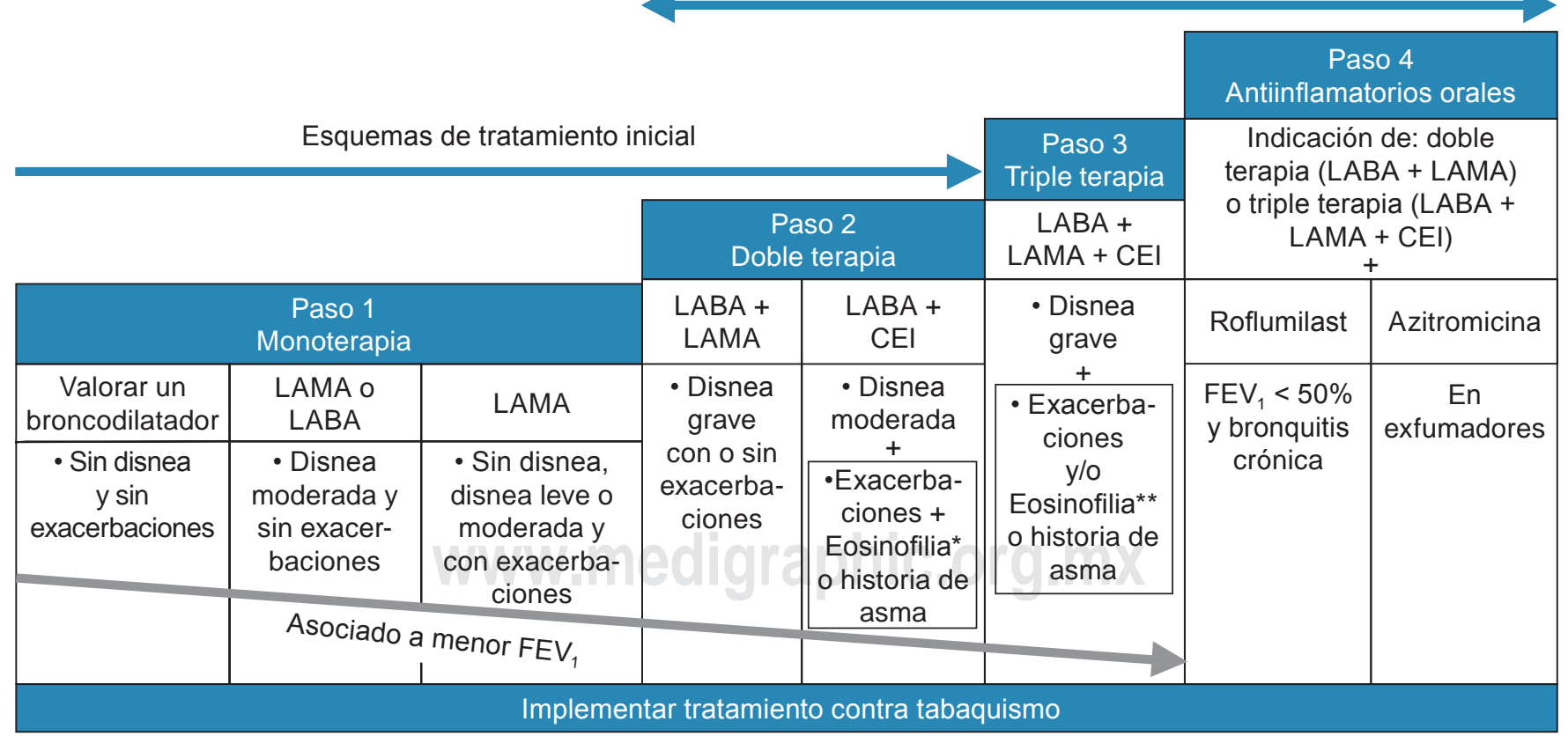

Figura 6: Esquema de ajuste terapéutico para pacientes con EPOC en tratamiento inicial o de ajuste, basado en GOLD, 2019. En todas las etapas se debe implementar tratamiento contra tabaquismo (tabaquismo activo). El tratamiento se debe establecer con base en la evaluación de la disnea, las exacerbaciones y la cifra de eosinófilos en sangre (ver Tabla 7). Para mayor información, referise al texto de la pregunta clínica 22.

* Cifra de eosinófilos en sangre periférica de $\geq 300$ células/ $\mu \mathrm{L}$.

** Cifra de eosinófilos en sangre periférica de $\geq 100$ células/ $\mu \mathrm{L}$ y al menos 1 hospitalización o dos exacerbaciones moderadas en el último año. 
debe prescribir un broncodilatador de larga duración tipo LABA combinado con corticosteroide inhalado (dosis baja), preferentemente en un solo dispositivo.

\section{Ajuste de tratamiento}

\section{Estrategias de escalamiento}

Todo paciente con tratamiento previo, o al menos seis meses después del tratamiento inicial, debe ser reevaluado en cuanto a disnea y exacerbaciones. Si la disnea no mejora o incrementa o existen exacerbaciones durante ese periodo, se debe ajustar el tratamiento farmacológico. La respuesta al ajuste de escalamiento debe ser revisada en cada consulta.

Ajuste de paso 1 a paso 2. Monoterapia (LABA o LAMA) a doble terapia (LABA + LAMA o LABA + CEI)

- Cambio de monoterapia con LABA o LAMA a doble terapia (LABA + LAMA)

- Pacientes sin exacerbaciones que aumentan de disnea leve a moderada ( $\mathrm{mMRC} 0$ y 1 a mMRC 2) o cambio a disnea grave (mMRC 3 y 4)

- Pacientes sin exacerbaciones que cambia a exacerbaciones.

- Cambio de monoterapia con LABA o LAMA a doble terapia LABA + CEI

- Pacientes que se encuentren con monoterapia LABA o LAMA, que muestren una cifra de eosinófilos en sangre de $\geq 300$ células/ $\mu \mathrm{L}$ o una cifra de eosinófilos de $\geq 100$ células/ $\mu \mathrm{L}$ que muestren dos o más exacerbaciones moderadas $o$ al menos una hospitalización.

Paso 3. Ajuste a triple terapia (LABA + LAMA + CEI)

- Escalamiento de paso 1 con monoterapia (LAMA o LABA) o paso 2 con doble terapia (LABA + LAMA) a paso 3 con triple terapia (LABA + LAMA + CEI): pacientes mono o doble terapia que cambia a exacerbaciones y disnea grave, se demuestra una cifra de eosinófilos de $\geq 100$ células/ $\mu \mathrm{L}$ con dos o más exacerbaciones moderadas o al menos una hospitalización.

- Cambio de doble terapia (LABA + CEI) a triple terapia $(\mathrm{LABA}+\mathrm{LAMA}+\mathrm{CEI})$ : pacientes en paso 2 con criterios de doble terapia $L A B A+C E I$ que continúan con exacerbaciones o que persisten o incrementan en disnea (disnea moderada a grave).

\section{Ajustes de desescalamiento}

- Ajuste de triple terapia (LAMA + LABA + CEI) o doble terapia $(\mathrm{LABA}+\mathrm{CEI}) \mathrm{a}$ doble terapia (LABA + LAMA).

- Pacientes que carezcan de indicación de CEI (criterio de eosinófilos en sangre y de exacerbaciones).

- Pacientes que no muestren respuesta favorable a esteroides.

\section{Paso 4. Adición de antiinflamatorios orales}

Se debe considerar en pacientes con indicación de doble terapia con LABA + LAMA (paso 2) o triple terapia con LAMA + LABA + CEI (paso 3).

- Roflumilast: Pacientes con doble terapia (LABA + LAMA) con fenotipo bronquítico crónico, $\mathrm{FEV}_{1}<50 \%$ y $\leq 100$ eosinófilos se recomienda envío a especialista para evaluar inicio de roflumilast.

- Macrólido: En pacientes con EPOC estable, como profilaxis en pacientes con obstrucción moderada a grave y riesgo elevado de exacerbaciones (a pesar del tratamiento óptimo con broncodilatadores y CEI). Asimismo, la coexistencia 
de EPOC con bronquiectasias e infección bronquial crónica (colonización) sugiere el tratamiento con antibiótico. Reduce las exacerbaciones en un año que es el tiempo recomendado de tratamiento, ${ }^{2}$ pero la azitromicina se puede asociar con mayor incidencia de resistencia bacteriana y daños a la audición. $^{2}$

\section{Consideraciones adicionales}

- Si el paciente se encuentra sin disnea ni exacerbaciones, deberá continuar con la misma monoterapia (LABA o LAMA) o doble broncodilatadora (LABA + LAMA).

- En el paciente con disnea moderada o grave (mMRC 2, 3 o 4) que no mejora a pesar de la doble terapia broncodilatadora de acción prologada (LABA + LAMA), se recomienda probar cambio de moléculas, revisar el uso adecuado del dispositivo de inhalación, cambio de dispositivos o investigar otras causas de disnea. ${ }^{2,98}$

- En general, todas las combinaciones LABA + LAMA son competentes en términos de eficacia y seguridad. Se ha descrito una discreta, pero significativa superioridad en la eficacia de la combinación de vilaterol/umeclidinium contra olodateriol/tiotropio. ${ }^{99}$

- En los pacientes que estén recibiendo CEI y desarrollen neumonía, se debe revisar si el beneficio de continuarlo es mayor que el riesgo. Si se decide continuar con el CEI, se debe usar la dosis mas baja recomendada, y se debe asegurar que estos pacientes reciban vacunación contra neumococo e influenza.

\section{6: Tratamiento complementario de la EPOC estable}

Pregunta clínica 23

¿Cuál es la eficacia y seguridad del oxígeno suplementario para el manejo de los pacientes con EPOC estable?

\section{Recomendaciones}

1 Se recomienda la administración de oxígeno suplementario debido a que, a largo plazo, incrementa la supervivencia en pacientes con EPOC e hipoxemia crónica y grave en reposo. $^{2}$

2 Las indicaciones para su uso son las siguientes:

- $\mathrm{PaO}_{2}<55 \mathrm{mmHg}$ o $\mathrm{SpO}_{2}<88 \%$

- $\mathrm{PaO}_{2}$ entre 55 a $60 \mathrm{mmHg}$ o $\mathrm{SpO} 2>$ $88 \%$ en presencia de alguna o más de las siguientes comorbilidades: hipertensión pulmonar, cor pulmonale, arritmias, poliglobulia con hematocrito > $55 \%$, hipoxemia nocturna (desaturación $<90 \%$ durante $30 \%$ o más del tiempo de sueño) y datos de insuficiencia cardíaca derecha. ${ }^{2}$
Evidencia 1++ Recomendación A

Evidencia 1++ Recomendación A 
El uso de oxigenoterapia a largo plazo en pacientes con EPOC estable y $\mathrm{PaO}_{2}$ $>60 \mathrm{mmHg}$ y $\mathrm{SpO}_{2}>90 \%$ en reposo que presentan desaturación inducida por ejercicio no prolonga la supervivencia, el tiempo a la primera hospitalización ni la distancia caminada en la C6M no proveen un beneficio sostenido en la función pulmonar ni en la salud en general, ${ }^{2}$ por lo que su recomendación queda a criterio del médico tratante.

4 Para obtener los beneficios de la oxigenoterapia a largo plazo, debe indicarse al menos 15 horas diarias (incluyendo el período de sueño) e idealmente 20 horas diarias. ${ }^{2}$

5 Los pacientes con oxigenoterapia a largo plazo que salgan de su domicilio deben ser prescritos con dispositivos ambulatorios (cilindros o concentradores portátiles), adicionales al concentrador de oxígeno. ${ }^{16}$

6

La normoxemia en reposo y a nivel del mar no excluye el desarrollo de hipoxemia grave durante un viaje aéreo. ${ }^{2}$

$7 \quad$ El personal de salud debe evaluar si el uso de oxigenoterapia en EPOC puede ocasionar depresión respiratoria, ${ }^{16}$ por lo que se recomienda la titulación de oxígeno suplementario por personal experto, en cuanto sea posible.
Evidencia 3

Recomendación D

Evidencia 1+ Recomendación A

Evidencia 2

Recomendación D

Evidencia 3

Recomendación D

Evidencia 4

Recomendación D

La terapia con oxígeno suplementario a largo plazo está indicada para pacientes estables con:

- $\mathrm{PaO}_{2}$ con niveles iguales o por debajo de $55 \mathrm{mmHg}(7.3 \mathrm{kPa})$ o $\mathrm{SaO}_{2} \leq 88 \%$ con o sin hipercapnia confirmada en dos ocasiones en un período de tres semanas.

- $\mathrm{PaO}_{2}$ entre 55-60 mmHg (7.3- 8.0 kPa), o $\mathrm{SaO}_{2}$ de 88\%, si existe evidencia de hipertensión pulmonar, edema periférico que sugiera insuficiencia cardíaca congestiva o policitemia (hematocrito $>55 \%$ ).

Una vez instaurada la terapia con oxígeno a largo plazo, el paciente debe ser reevaluado tras 60 a 90 días con gasometría arterial u oximetría de pulso, mientras respira el mismo nivel de oxígeno o aire en su domicilio para determinar si el oxígeno es terapéutico y todavía deba indicarse, respectivamente. En la Figura 7 se ilustra el algoritmo para la prescripción de oxígeno, recomendado, GOLD 2019. ${ }^{2}$

La disnea puede mejorar con el uso de oxígeno suplementario en los pacientes con EPOC; quienes estén levemente hipoxémicos o no hipoxémicos no son candidatos, de otra manera, para oxigenoterapia domiciliaria cuando se usa durante ejercicio o en la rehabilitación formal. Sin embargo, los estudios no han demostrado mejoría en disnea en las actividades de la vida diaria ni beneficio a la calidad de 
Hipoxemia arterial definida como:

$\mathrm{PaO}_{2}<55 \mathrm{mmHg}(8 \mathrm{kPa}) \circ \mathrm{SaO}_{2}<88 \%$ o $\mathrm{PaO}_{2}>55 \mathrm{mmHg}$

$(>7.3 \mathrm{kPa}$ pero $<8 \mathrm{kPa}$ ) con insuficiencia cardíaca derecha o eritrocitosis

Prescribir oxígeno suplementario y titular para mantener la $\mathrm{SaO}_{2} \geq 90 \%$

\begin{abstract}
Figura 7:
Algoritmo para la prescripción de oxígeno suplementario en paciente con EPOC estable.
\end{abstract}

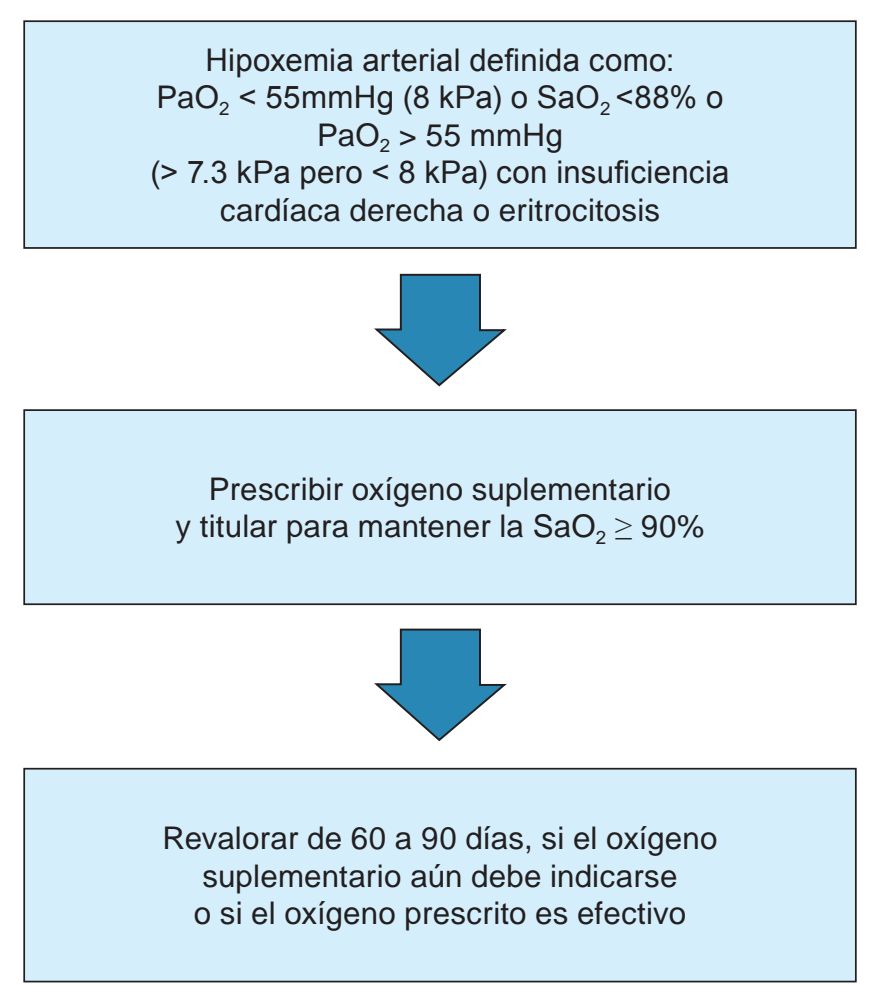

vida. $^{2,21}$ Los pacientes con hipoxemia nocturna requerirán de oxigenoterapia nocturna y debe ser considerada en aquellos con normoxemia durante el día, pero que cursan con somnolencia diurna, poliglobulia o cor pulmonale. Se debe indicar con evidencia de desaturaciones repetidas $<88 \% .{ }^{21}$ Debe prescribirse con precaución porque el control respiratorio depende en parte del grado de hipoxemia, así que la oxigenoterapia puede resultar en supresión del centro respiratorio. ${ }^{16}$

La oxigenoterapia debe ser administrada por largos períodos durante el día y la noche, así como de forma ambulatoria para facilitar el ejercicio y aliviar los síntomas, de manera como se consigue con los dispositivos de entrega rápida. ${ }^{16}$ Además, puede suministrarse por cilindros, concentradores eléctricos fijos y portátiles o tanques de oxígeno líquido. ${ }^{16}$ Las puntas nasales de alto flujo reducen la hipercapnia y mejoran la calidad de vida en sujetos con EPOC estable hipercápnico. ${ }^{2}$ Después de la prescripción de oxigenoterapia los pacientes deben ser reevaluados después de 60 a 90 días con gasometría arterial o saturación de oxígeno y respiración de oxígeno o aire ambiente para confirmar su indicación. ${ }^{2,16,17}$

Los pacientes con EPOC que planean realizar un viaje aéreo deben ser evaluados con su médico, principalmente si su función pulmonar $\left(\mathrm{FEV}_{1}\right)$ es $<50 \%$ y la saturación de oxígeno es $<88 \% \circ \mathrm{PaO}_{2}<70 \mathrm{mmHg}$, pero los pacientes que ya usan oxigenoterapia pueden realizar viajes aéreos; después de su correspondiente evaluación se debe incrementar el flujo de oxígeno de 1-2 L.2,16,21 Aunque los viajes aéreos son seguros para la mayoría de estos pacientes, idealmente deben de mantener una $\mathrm{PaO}_{2}>50 \mathrm{mmHg}$ durante el vuelo. En caso de hipoxemia moderada o grave a nivel del mar, esto puede lograrse con un flujo de tres litros por minuto con puntas nasales o $\mathrm{FiO}_{2}$ al $31 \%$ con mascara facial. ${ }^{2,21}$ Los pacientes con saturación de oxígeno en reposo $>94 \%$ o > $84 \%$ en la caminata de seis minutos pueden viajar sin mayor valoración, aunque es importante enfatizar que la oxigenación en reposo a nivel de mar no excluye el desarrollo de hipoxemia durante el vuelo. Se debe considerar las comorbilidades (insuficiencia cardíaca y anemia) que podrían dañar 
Neumol Cir Torax. 2019; 78 (supl. 1): s1-s76

la entrega tisular de oxigeno. Los desplazamientos (caminar) prolongados en los aeropuertos puede agravar la disnea y la hipoxemia, por lo que deben atenderse como personas con movilidad limitada. ${ }^{2,21}$

La oxigenoterapia es el componente clave del tratamiento hospitalario de las exacerbaciones. El oxígeno suplementario debe incrementarse hasta obtener una saturación de oxígeno de $88-92 \%$ y en evidencia C. Se asocia con disminución en la mortalidad y menor incidencia de acidosis hipercápnica, sin efecto en los requerimientos de ventilación mecánica ni estancia hospitalaria. La máscara facial (Venturi) como dispositivo para alto flujo ofrece una entrega de oxígeno más exacta y controlada que la cánula nasal. 2,17,16,21 Para la titulación de oxígeno vía cánula nasal, se debe iniciar con un flujo de dos litros por minuto o máscara tipo Venturi $\left(\mathrm{FiO}_{2}\right.$ 0.24-0.28) para mantener una $\mathrm{SpO}_{2}>88 \% \circ \mathrm{PaO}_{2}>60 \mathrm{mmHg}$ sin provocar acidosis respiratoria $(\mathrm{pH}<7.30$ ), evaluada con gasometría a los 30 minutos de iniciada la terapia; habitualmente se logra este objetivo con 0.5 a dos litros por minuto con puntas nasales. ${ }^{17,21} \mathrm{Si}$ el paciente inicia oxigenoterapia por primera vez durante una exacerbación, el requerimiento de oxígeno debe ser reevaluado de 2 a 8 semanas posteriores al evento. ${ }^{21}$

Otras consideraciones de tratamiento incluyen usar aire comprimido y no oxígeno durante las nebulizaciones para evitar la elevación de la $\mathrm{PaCO}_{2}$ y la acidosis respiratoria en pacientes con hipercapnia previa; ${ }^{17}$ las puntas nasales de alto flujo en pacientes con insuficiencia respiratoria aguda puede ser una alternativa a la oxigenoterapia estándar y a la ventilación mecánica no invasiva, porque reduce la necesidad de ventilación mecánica y la mortalidad, además de que mejora la oxigenación, la ventilación y la hipercapnia. ${ }^{2,17}$ Sólo debe administrarse en presencia de hipoxemia leve o moderada, y como ya se definió cuando hay cor pulmonale; cuando no hay indicación, como en este caso, no se ha demostrado mayor sobrevida. 2,100,101

\section{Pregunta clínica 24}

¿Cuál es la eficacia y seguridad de la rehabilitación pulmonar para el manejo de los pacientes con EPOC?

\section{Recomendaciones}

$1 \quad$ La inactividad física es un predictor fuerte de mortalidad. ${ }^{2}$ En general, la rehabilitación pulmonar (RP) reduce la disnea y mejora la fatiga, la ansiedad, la depresión, la calidad de vida y la tolerancia al ejercicio, además, reduce las hospitalizaciones en pacientes con EPOC estable. Se involucra al paciente en el control de su enfermedad y ha demostrado ser costo-efectiva. ${ }^{2,21}$

2 Se recomienda la RP en todos los pacientes con síntomas relevantes (mMRC mayor o igual a 2), limitación en sus actividades 0 que se consideran a sí mismos con discapacidad por EPOC a pesar de recibir un tratamiento farmacológico adecuado. ${ }^{15,16,18}$

3 Por sus beneficios, el grupo de trabajo de GMEPOC recomienda ofrecerla a todos los pacientes con EPOC estable.
Evidencia 1++ Recomendación A

Evidencia 1++ Recomendación A

Evidencia 4 Recomendación D 
$4 \quad$ Los programas de RP deben incluir intervenciones multidisciplinarias adaptadas a las necesidades de los pacientes. El proceso de $\mathrm{RP}$ debe incorporar un programa de entrenamiento físico, educación sobre la enfermedad e intervenciones nutricionales, psicológicas y conductuales, ya que mejoran el apego. ${ }^{2,15,16}$

5 Un programa de acondicionamiento debe durar mínimo seis semanas para mejores resultados. ${ }^{15}$

$6 \quad$ Los pacientes deben ser concientizados acerca del compromiso con dicho programa para alcanzar los beneficios. ${ }^{16}$

7 El programa de rehabilitación respiratoria debe incluir entrenamiento muscular, tanto de extremidades inferiores como superiores. ${ }^{18}$

8 Los pacientes con expectoración abundante deben aprender el uso de máscaras de presión espiratoria positiva. ${ }^{16}$

9 Los pacientes con expectoración abundante también deben aprender técnicas respiratorias de ciclo activo. ${ }^{16}$

10 La RP reduce las hospitalizaciones en los pacientes que han presentado exacerbaciones recientes (se debe iniciar posterior al egreso hospitalario o en el período comprendido en las cuatro semanas desde la última hospitalización). ${ }^{2,18}$

11 En los pacientes hospitalizados por una exacerbación de EPOC se sugiere no iniciar la RP durante la hospitalización. ${ }^{19}$

12 Se debe aconsejar a los pacientes en programa de RP, que tras su finalización sigan realizando ejercicios de rehabilitación de forma indefinida en su domicilio. ${ }^{18}$

13 Los programas domiciliarios de mantenimiento son una alternativa válida a la RP hospitalaria desde las fases iniciales de la enfermedad..$^{15}$

14 La RP no es apta para pacientes incapaces de caminar, que tengan angina inestable 0 antecedente reciente de infarto al miocardio. ${ }^{16}$
Evidencia 1+ Recomendación A

Evidencia 1-

Recomendación B

Evidencia 1-

Recomendación B

Evidencia 1++ Recomendación A

Evidencia 1-

Recomendación B

Evidencia 3

Recomendación C

Evidencia 1-

Recomendación B

Evidencia 3

Recomendación D

Evidencia 1++

Recomendación A

Evidencia 1+ Recomendación B

Evidencia 3

Recomendación C

La RP mejora de forma estadística y clínicamente significativa la calidad de vida, de acuerdo con el instrumento Health Related Quality of Life (CRQ), la capacidad funcional de ejercicio (mejoría en caminata de seis minutos o 49 metros, IC 95\% 26 a 72) y la capacidad máxima de ejercicio (mejoría en caminata de seis minutos 
de 5.4 watts IC 95\%, 0.5 a 10.2).$^{16}$ Además, mejora el sentir de los pacientes en el control de su enfermedad ${ }^{21}$ y se adquieren beneficios óptimos a partir de programas de rehabilitación que duran de 6 a 8 semanas. ${ }^{2}$ La rehabilitación cardiovascular disminuye significativamente la angina inestable y las cirugías de revascularización, los factores de riesgo cardiovasculares y los reinfartos; sin embargo, existe variabilidad entre los estudios. Además, existe un impacto positivo sobre la calidad de vida relacionada a la salud. El grupo de GMEPOC recomienda que los pacientes con complicaciones cardiovasculares deben ser evaluados por Cardiología. ${ }^{102,103} \mathrm{En}$ general, la fatiga puede mejorar mediante programas educativos de autocuidados y rehabilitación pulmonar. ${ }^{2}$

\section{7: Exacerbación de la EPOC: Manejo ambulatorio}

\section{Pregunta clínica 25}

¿Cuál es la eficacia y seguridad de los corticosteroides sistémicos para el manejo ambulatorio de los pacientes con exacerbación de la EPOC?

\section{Recomendaciones}

1 Los corticosteroides sistémicos reducen la gravedad de la exacerbación ${ }^{40}$ y pueden mejorar la función pulmonar $\left(\mathrm{FEV}_{1}\right)$, la oxigenación y el tiempo de recuperación. . $^{2,40}$

2 En ausencia de contraindicaciones significativas, se deben considerar corticosteroides orales en pacientes ambulatorios que presenten exacerbación e incremento significativo de la disnea que interfiera con sus actividades diarias. ${ }^{15,16}$

3 Se recomienda prescribir vía oral (exclusivamente) una dosis equivalente a $40 \mathrm{mg} /$ diarios de prednisona. ${ }^{17}$

$4 \quad$ Una alternativa es $30 \mathrm{mg} /$ diarios de prednisolona. ${ }^{16}$

5 La duración del tratamiento se recomienda como máximo de 5-7 días. ${ }^{2}$

$6 \quad$ No se recomienda prolongar el tratamiento más de 14 días ya que no se han obtenido mayores beneficios. ${ }^{15,16}$

7 Se sugiere considerar profilaxis para osteoporosis en los pacientes que requieran ciclos cortos de esteroide de manera frecuente. ${ }^{16}$

8 Los pacientes deben ser informados sobre el porqué, cuándo y cómo debe suspenderse el tratamiento con esteroides sistémicos, así como los efectos adversos de la terapia prolongada. ${ }^{16}$

\author{
Evidencia 1++ \\ Recomendación A
}

Evidencia 1-

Recomendación B

Evidencia 1++ Recomendación A

Evidencia 4 Recomendación D

Evidencia 1++ Recomendación A

Evidencia 1++ Recomendación A

Evidencia 4 Recomendación D

Evidencia 4 Recomendación D

Está bien demostrado que el uso de CE sistémicos como mantenimiento en los pacientes con EPOC estable no juega un papel terapéutico en relación con 
la estabilización, el deterioro anatomopatológico, fisiológico ni clínico, pues no alteran la evolución natural de la enfermedad. Un curso corto de corticosteroides sistémicos por no más de siete días es una excelente opción terapéutica para tratar las exacerbaciones de la EPOC, ya que mejoran la insuficiencia respiratoria, la función pulmonar medida por el $\mathrm{FEV}_{1}$ y la hipoxemia; además, disminuye el riesgo de recaídas, la falla al tratamiento y la estancia hospitalaria. La reversibilidad a los CE sistémicos no predice la respuesta benéfica de los $\mathrm{CEI}$, por lo que una prueba terapéutica de esteroides orales no debe ser usada como una estrategia para identificar a que pacientes se les debe prescribir los esteroides inhalados. ${ }^{104-106}$ La duración del tratamiento con corticoides sistémicos no se recomienda por más de siete días en pacientes con EPOC grave en exacerbación. No se ha estudiado cursos de menor tiempo en pacientes con EPOC leve a moderado. ${ }^{103}$

\section{Pregunta clínica 26}

¿Cuál es la eficacia y seguridad de los antibióticos para el manejo ambulatorio de los pacientes con exacerbación de la EPOC?

\section{Recomendaciones}

1 Deben usarse antibióticos en los pacientes con una exacerbación que presentan incremento de la disnea, del volumen y aparición de purulencia del esputo. ${ }^{15}$

2 El esputo purulento es el factor más importante para iniciar antibióticos. ${ }^{15,16,18}$

3 Los pacientes con exacerbaciones sin esputo purulento no requieren antibiótico a menos de que haya evidencia de ocupación alveolar en la radiografía de tórax o signos clínicos de neumonía. ${ }^{15,16}$

4 Se recomienda considerar el uso de antibiótico en pacientes con exacerbación de leve-moderada-grave y nivel de PCR elevado acompañado o no de expectoración purulenta. ${ }^{17}$

5 El tratamiento empírico puede iniciarse con un aminopenicilina, macrólido, cefalosporina (segunda o tercera generación) o fluoroquinolona. ${ }^{2,16}$

6 La selección del antibiótico debe guiarse por los patrones de sensibilidad local. ${ }^{16,19}$

7 La duración recomendada de tratamiento es de siete días. ${ }^{15}$

8 La duración mínima del tratamiento es de cinco días. ${ }^{15}$
Evidencia 1-

Recomendación B

Evidencia 1++ Recomendación A

Evidencia 1-

Recomendación B

Evidencia 1-

Recomendación B

Evidencia 1-

Recomendación B

Evidencia 1Recomendación B

Evidencia 1Recomendación B

Evidencia 3 Recomendación C

Las exacerbaciones son provocadas principalmente por infecciones virales y bacterianas, la contaminación ambiental y la temperatura ambiente. Se asocian con una mayor producción de purulencia y presencia de bacterias en el esputo. 
Neumol Cir Torax. 2019; 78 (supl. 1): s1-s76

También existe evidencia de un aumento en los neutrófilos y los eosinófilos en las vías respiratorias de manera significativa, lo que confiere el color de la purulencia al esputo. Siempre se ha especulado sobre el papel de las bacterias en las exacerbaciones de la EPOC, ya que pueden ser cultivadas del esputo en $51-70 \%$ de los pacientes durante las exacerbaciones, pero algunos organismos también pueden crecer hasta en 25 a $48 \%$ de las vías respiratorias en pacientes estables. Se sabe que las exacerbaciones se caracterizan por aumento de la disnea, el volumen y la purulencia del esputo.

El beneficio de los antibióticos utilizados para las exacerbaciones graves que requieren cuidados intensivos está bien establecido, no así durante las exacerbaciones moderadas y el tratamiento en el ámbito ambulatorio, pues éste sigue siendo controvertido. Algunos antibióticos como los macrólidos, además tienen efectos inmunomoduladores, antiinflamatorios y antibacterianos. En estudios pasados se observó que el uso continuo de antibióticos no contribuía a disminuir las exacerbaciones de la EPOC, ni siquiera utilizándolos como profilácticos durante los meses de invierno. Estudios más recientes han demostrado que su uso regular puede reducir la tasa de exacerbación. Se ha demostrado que la azitromicina (250 $\mathrm{mg} /$ día o $500 \mathrm{mg}$ tres veces por semana) o la eritromicina (500 mg dos veces por día) durante un año en pacientes propensos, redujo el riesgo de exacerbaciones en comparación con el tratamiento estándar de la EPOC. El uso crónico de azitromicina se ha asociado a un aumento en la incidencia de resistencia bacteriana, prolongación del intervalo QT y deterioro en las pruebas auditivas.

Un análisis post hoc sugiere un beneficio menor en los fumadores activos. A pesar de todo, no hay datos que muestren la eficacia o la seguridad del tratamiento crónico con azitromicina para prevenir las exacerbaciones de la EPOC más allá de un año de tratamiento. ${ }^{107-109}$

La terapia con antibióticos redujo el riesgo de fracaso del tratamiento y aumentó el tiempo entre exacerbaciones de EPOC. ${ }^{19}$ Una RS evaluó la eficacia y seguridad de los antibióticos en comparación a placebo para el manejo de las exacerbaciones, mostró que el uso de los antibióticos disminuye la mortalidad a corto plazo en $77 \%$, la falla al tratamiento en $53 \%$ y la expectoración purulenta en $44 \%$. La evidencia soporta el manejo de pacientes con enfermedad moderada a grave. Algunos biomarcadores han demostrado ser específicos para infección bacteriana, como la procalcitonina, pero su uso es poco disponible. Una RS sugiere que el uso de la procalcitonina en la toma de decisiones para el uso de antibióticos disminuyó la prescripción de los mismos sin afectar los desenlaces. En general, se sugiere el uso de los antibióticos cuando se presentan tres condiciones: incremento en disnea, aumento en el esputo y presencia de esputo purulento. ${ }^{2}$

\section{Pregunta clínica 27}

¿Cuál es la eficacia y seguridad de las metilxantinas para el manejo ambulatorio de los pacientes con exacerbación de la EPOC?

\section{Recomendaciones}

$1 \quad$ No se recomienda el uso de metilxantinas (teofilina) en el tratamiento de la EPOC a menos que no exista disponibilidad de ningún broncodilatador de acción prolongada como tratamiento de mantenimiento o que el paciente sea incapaz de utilizar fármacos inhalados., ${ }^{2,16}$

2 Las metilxantinas no deben utilizarse como tratamiento de primera línea. ${ }^{18}$

Evidencia 1Recomendación B

Evidencia 1+ Recomendación B 


\section{Revisión de la literatura y análisis}

El costo es bajo y se encuentra en cuadros básicos, el estrecho margen de beneficio/ toxicidad obliga a elegir perfil de paciente y en especial, considerar su capacidad arritmógena y depletora de potasio en el paciente cardiópata, primera comorbilidad de los pacientes. La teofilina sólo debe ser usada en pacientes que han agotado todas las posibilidades de tratamiento, ya que su perfil de eficacia es muy pobre. ${ }^{110} \mathrm{El}$ rango sérico más confiable para considerar ventana terapéutica y alejarse efectos adversos es de 8 a $12 \mu \mathrm{g} / \mathrm{dL}$. Esta se debe utilizar en caso de que la terapia inhalatoria no dé resultados. ${ }^{2}$

Pregunta clínica 28

¿Se debe suspender o retrasar el inicio con LABA o LAMA en los pacientes con exacerbación de EPOC

\section{Recomendación}

1 Aunque no hay muchos estudios clínicos que evalúen el uso de broncodilatadores de larga

Evidencia 4 Recomendación D acción inhalados $\left(\beta_{2}\right.$-agonistas, anticolinérgicos o combinaciones), con o sin CEI durante las exacerbaciones, se recomienda iniciar o continuar estos tratamientos en cuanto el paciente se encuentre más estable. ${ }^{2}$

A pesar de la falta de evidencia, si se realiza monitoreo constante de los posibles efectos adversos y se realiza educación directa y supervisada de la técnica de inhalación junto con la selección adecuada de los dispositivos, se podría atribuir a que promueven el alivio de la sintomatología pre y posexacerbación. En las exacerbaciones hay que regresar a los inhaladores de corta duración por un tiempo para después volver a los de control (LABA/LAMA). Son importantes como tratamiento base, se deben vigilar las condiciones generales del paciente para evitar subestimar síntomas de gravedad.

Pregunta clínica 29

¿Cuál es la eficacia y seguridad de los SABA y SAMA inhalados para el manejo ambulatorio de los pacientes con exacerbación de la EPOC?

\section{Recomendaciones}

1 Los SABA con o sin SAMA están recomendados como broncodilatadores iniciales para tratar una exacerbación. ${ }^{2}$

2 El manejo en domicilio de las exacerbaciones incluye incremento de dosis y frecuencia de los SABA con o sin SAMA. ${ }^{2}$

3 En caso de que la respuesta clínica fuera insuficiente para SABA debe asociarse al SAMA. ${ }^{2}$

\author{
Evidencia 2++ \\ Recomendación C \\ Evidencia 1+ \\ Recomendación A \\ Evidencia 2++ \\ Recomendación C
}

Los SABA siguen siendo la primera línea de intervención, de igual manera aumentar la dosis o frecuencia a partir de la tercera aplicación podría resultar útil, incluso por la falla en la técnica de administración y condiciones del paciente (limi- 
tación al flujo) o disponibilidad de los dispositivos (eficacia del pMDI versus MNF jet con boquilla). Los SABA y SAMA podrían ayudar a que el empeoramiento de la exacerbación no se deba a un efecto adverso del medicamento, sin embargo, se debe valorar la repercusión cardíaca por el uso de los $\beta_{2}$-agonistas y espaciar la dosis los más pronto posible. En general, ofrecen un control de broncodilatación efectiva y permiten vigilar datos y signos de gravedad, que pongan en riesgo la vida del paciente. ${ }^{2}$ La dosis consiste en una inhalación cada hora hasta tres dosis, posteriormente cada 2 a 4 horas.

\section{Pregunta clínica 30}

¿Cuál es el dispositivo de elección para los fármacos inhalados en el manejo ambulatorio de los pacientes con exacerbación de la EPOC?

\section{Recomendaciones}

$1 \quad$ Pueden usarse tanto nebulizadores como inhaladores manuales (IDMp o IPS) en las exacerbaciones. ${ }^{15,16}$

2 La elección entre terapia nebulizada e inhalada dependerá de la dosis de medicamento que se requiera, la condición clínica de los pacientes para usar los dispositivos (IDMp o IPS) y los recursos disponibles para supervisar la administración de la terapia. ${ }^{16}$

\author{
Evidencia 1++ \\ Recomendación A
}

Evidencia 3 Recomendación C

No existe evidencia que la terapia nebulizada sea mejor que el uso correcto de inhaladores de dosis medida, con o sin aerocámara. Dependerá de las condiciones y disponibilidad de los dispositivos para el paciente y de la correcta técnica de inhalación. En todo caso, de acuerdo con la guía de práctica clínica de la AARC, la técnica correcta de nebulización con el dispositivo de pequeño volumen y boquilla muestra una mejoría ligeramente significativa en el depósito de partículas que con mascarilla, pues los factores que modifican la entrega del medicamento en este dispositivo son variados. ${ }^{111}$ El uso de la terapia nebulizada se debe valorar sólo en pacientes que no puedan usar los inhaladores o no tengan suficiente fuerza para realizar la inhalación, ya que con la terapia inhalada bien usada no hay diferencia, además es mucho más práctico y económico. Se ha demostrado que el tamaño de la partícula tiene un papel importante en la eficacia broncodilatadora. El desarrollo de nuevas tecnologías permite que el fármaco alcance mayor profundidad en la vía aérea, por lo que da resultados clínicos satisfactorios. Las nebulizaciones ayudan con la humidificación de la vía aérea que pudiera ser útil en pacientes con exceso de secreciones. Lo más importante es seleccionar el dispositivo acorde con las características y necesidades del paciente. Ambas estrategias son igualmente útiles.

\section{8: Exacerbación de la EPOC: Manejo hospitalario}

\section{Pregunta clínica 31}

¿Cuál es la eficacia y seguridad de las metilxantinas para el manejo hospitalario de los pacientes con exacerbación de la EPOC?

\section{Recomendaciones}

$1 \quad$ Las metilxantinas no se recomiendan debido a sus efectos secundarios. ${ }^{2}$
Evidencia 1Recomendación B 
Deberán agotarse las primeras líneas de tratamiento inhalado antes de la administración de metilxantinas. Éstas no son de primera opción; en el caso de usarse, se deben considerar sus efectos secundarios, tanto centrales como cardiovasculares. Además no han demostrado superioridad a los SABA o SAMA y muestran riesgo de toxicidad con incremento de efectos adversos. ${ }^{2}$

Pregunta clínica 32

¿Cuál es la eficacia y seguridad de los SABA y SAMA inhalados para el manejo hospitalario de los pacientes con exacerbación de la EPOC?

\section{Recomendaciones}

$1 \quad$ Los SABA con o sin SAMA están recomendados como broncodilatadores iniciales para tratar una exacerbación. ${ }^{2,18}$

2 En caso de que la respuesta clínica fuera insuficiente debe asociarse al $\beta_{2}$-agonista de acción corta un anticolinérgico de acción corta. ${ }^{18}$
Evidencia 2+

Recomendación C

Evidencia 2+ Recomendación C

Se debería continuar con la primera línea de tratamiento SABA con o sin SAMA, pues permite el monitoreo de los síntomas y signos de gravedad que puedan poner en riesgo la vida del paciente y además se pueden monitorear sus efectos y ajustarse las dosis en un corto período de tiempo.

Pregunta clínica 33

¿Cuál es el dispositivo de elección para los fármacos inhalados en el manejo hospitalario de los pacientes con exacerbación de la EPOC?

\section{Recomendaciones}

$1 \quad$ Pueden usarse tanto nebulizadores como inhaladores manuales (IDMp o IPS) en las exacerbaciones ${ }^{15,16}$

2 La elección entre terapia nebulizada e inhalada dependerá de la dosis de medicamento que se requiera, la condición clínica de los pacientes para usar los dispositivos (IDMp o IPS) y los recursos disponibles para supervisar la administración de la terapia. ${ }^{16}$

3 Si el paciente se encuentra con hipercapnia y acidosis, las nebulizaciones deben administrarse con aire comprimido, sin oxígeno (para evitar empeorar la hipercapnia). Si se requiere de oxigenoterapia adicional deberá administrarse de manera simultánea por puntas nasales. ${ }^{16}$

4 Se debe promover el cambio a inhaladores manuales en cuanto el paciente se estabilice, ya que pueden favorecer un egreso hospitalario más temprano. ${ }^{16}$
Evidencia 1++ Recomendación A

Evidencia 4 Recomendación D

Evidencia 4 Recomendación D

Evidencia 4 Recomendación D 
Se deberá, como recomendación, evaluar las condiciones del paciente en cuanto a técnica de inhalación y posibles efectos de la oxigenoterapia, y si está siendo administrada con o sin humedad; para el manejo hospitalario es necesario evaluar si el paciente puede realizar la técnica correcta con boquilla o mascarilla. Existen posibilidades de adaptar el equipo del paciente para recibir ambas terapias simultáneas (mascarilla accesoria a MNB tipo Jet), sin embargo, no se cuenta con evidencia y se tiene que realizar un seguimiento cercano a la técnica y eventos del paciente. Los gases deberán cumplir con las Normas Oficiales Mexicanas para su envasado y distribución. Los generadores de aerosoles de administración hospitalaria, como el tipo Jet, deberán operarse bajo los lineamientos de flujo adecuados de acuerdo con las recomendaciones de la Asociación Americana de Cuidados Respiratorios (AARC), así como los dispositivos de oxigenoterapia pertinentes, pues permiten flexibilidad y seguridad en el manejo de los pacientes. ${ }^{11}$

\section{Pregunta clínica 34}

¿Cuál es la eficacia y seguridad de los antibióticos para el manejo hospitalario de los pacientes con exacerbación de la EPOC?

\section{Recomendaciones}

$1 \quad$ Los antibióticos pueden disminuir el tiempo de recuperación y reducir el riesgo de recaída temprana, falla a tratamiento y estancia hospitalaria. La duración de la terapia debe ser de cinco a siete días. ${ }^{2}$

2 En la exacerbación moderada o grave, los antibióticos están indicados cuando se cumplan al menos dos de los tres criterios de Anthonisen: incremento de la disnea, del volumen y aparición de purulencia del esputo, ${ }^{1,518}$ así como datos clínicos de infección (fiebre y leucocitosis). ${ }^{21}$

3 La historia de esputo purulento es el factor más importante para iniciar antibiótico. ${ }^{15,16,18}$

4 Se deben iniciar antibióticos en las exacerbaciones de EPOC que requieran ingreso hospitalario, en particular, aquellos pacientes que ingresan a la UCl. ${ }^{17}$

5 En la exacerbación muy grave, que requiere asistencia ventilatoria, la cobertura antibiótica es obligatoria. ${ }^{15,18}$

6 El tratamiento empírico puede iniciarse con un aminopenicilina, macrólido, cefalosporina (segunda o tercera generación), fluoroquinolona y antibióticos contra Pseudomonas en caso de factores de riesgo. ${ }^{2,16}$

7 La selección del antibiótico debe guiarse por los patrones de sensibilidad local. ${ }^{16,19}$
Evidencia 1-

Recomendación B

Evidencia 1-

Recomendación B

Evidencia 1+ Recomendación B

Evidencia 1++ Recomendación A

Evidencia 2-

Recomendación C

Evidencia 1-

Recomendación B

Evidencia 1Recomendación B 
Evidencia 4 miento antibiótico es adecuado en cuanto se Recomendación D tenga el resultado de la sensibilidad de los cultivos solicitados. ${ }^{16}$

La decisión de antibióticos sistémicos debe establecerse de acuerdo a las recomendaciones enumeradas previamente (Pregunta 26). Los antibióticos están indicados cuando hay datos clínicos que sugieren presencia de infección bacteriana. Una revisión sistemática reportó que los antibióticos disminuyen de forma significativa el riesgo de fracaso del tratamiento, la estancia hospitalaria y la mortalidad. Cuando los pacientes se encuentran hospitalizados con exacerbación grave, los antibióticos han mostrado disminuir los fracasos al tratamiento, pero no la estancia hospitalaria ni la mortalidad..$^{17}$

Los estudios y las guías de práctica clínica recomiendan el uso de antibióticos cuando el paciente ingresa a UCI. La expectoración purulenta y la PCR elevada son indicadores de la necesidad de usar antibiótico durante las estancias hospitalarias. ${ }^{17}$

La administración de los antibióticos que no están fabricados en formas específicas para nebulizar, deberá ocurrir siempre y cuando se seleccione el generador de aerosol correcto; en este caso, de acuerdo con la AARC, los micronebulizadores de malla vibrante son los adecuados para ello. Asimismo, sin un correcto asesoramiento de la técnica inhalatoria y posibles factores que afecten a la entrega del medicamento, como condiciones del equipo o dilución y preparación incorrecta, podrían provocar el fracaso en la terapia. ${ }^{111}$ Para el paciente en VMI, se deberá evaluar siempre la disponibilidad de este nebulizador y se ha demostrado que la posición del generador de aerosol en el circuito de ventilación afecta en la entrega del medicamento. La ruta de administración del antibiótico, oral o intravenosa, dependerá de la capacidad de la tolerancia del paciente a la vía oral y de las características farmacológicos del antibiótico, aunque se prefiere la vía oral. ${ }^{2}$

\section{Pregunta clínica 35}

¿Cuál es la eficacia y seguridad del oxígeno suplementario para el manejo hospitalario de los pacientes con exacerbación de la EPOC?

\section{Recomendaciones}

$1 \quad$ La oximetría de pulso debe medirse en los pacientes con exacerbación de EPOC si no hay acceso a la medición de gases arteriales. En presencia de datos clínicos de exacerbación grave es de gran valor. ${ }^{16}$

2 Todo el personal de salud involucrado en el cuidado de los pacientes con exacerbaciones de EPOC debe tener acceso a un oxímetro de pulso, entrenarse en su uso y estar consciente de que esta herramienta no da información sobre el $\mathrm{pH}$ y la $\mathrm{PaCO}_{2} \cdot{ }^{16}$

3 Cuando el paciente con exacerbación de EPOC llega al hospital debe tomarse gasometría arterial con registro de la fracción inspirada de oxígeno. ${ }^{16}$

\section{Evidencia 4 \\ Recomendación D}

Evidencia 4

Recomendación D

Evidencia 4

Recomendación D 
4

En caso de ser necesario debe suministrarse oxígeno de manera controlada $\left(\mathrm{FiO}_{2} 28 \%\right.$ o 0.5 a $2.0 \mathrm{~L} / \mathrm{m}$ ) para mantener una $\mathrm{SpO}_{2}$ en un rango individualizado (> 88\%).

5 Si el paciente se encuentra en acidosis o hipercapnia, las nebulizaciones deben administrarse con aire comprimido, sin oxígeno (para evitar empeorar la hipercapnia). Si se requiere de oxigenoterapia adicional deberá administrarse de manera simultánea por puntas nasales.

6 La gasometría arterial debe repetirse de manera regular de acuerdo con la respuesta al tratamiento. Su medición intermitente es obligatoria en la recuperación de los pacientes con falla respiratoria, hipercapnia y acidosis hasta que alcancen la estabilidad.

$7 \quad$ La oximetría de pulso puede servir en la monitorización de los pacientes con falla respiratoria sin hipercapnia ni acidosis respiratoria.

8 Todos los pacientes que presentaron algún episodio de falla respiratoria durante la exacerbación deben tener parámetros satisfactorios en la oximetría de pulso y la gasometría arterial antes del egreso.

9 Los pacientes deben recibir información apropiada que les permita entender el uso correcto de los medicamentos, incluyendo el oxígeno suplementario antes del egreso.
Evidencia 2++

Recomendación C

Evidencia 4

Recomendación D

Evidencia 4

Recomendación D

Evidencia 4

Recomendación D

Evidencia 4

Recomendación D

Evidencia 4

Recomendación D

La administración de oxígeno es un componente clave en la atención de los pacientes con EPOC con exacerbaciones que se manejan de forma hospitalaria. La meta de saturación de oxígeno se prefiere entre el 88-92\%. Se recomienda el monitoreo frecuente de los gases arteriales con el objetivo de evaluar la retención de $\mathrm{CO}_{2}$ y el equilibrio ácido-base. ${ }^{2}$ Hay distintas formas y dispositivos para la administración de oxígeno. La terapia de oxígeno con puntas nasales con flujo alto (PNFA) es una alternativa de oxígeno suplementario no presurizada y no invasiva y puede disminuir la necesidad de intubación orotraqueal. Las RS han mostrado que, en paciente con insuficiencia respiratoria secundaria a exacerbación por EPOC, la PNFA disminuye la necesidad de intubación orotraqueal, pero no hubo un efecto significativo en la mortalidad. ${ }^{2}$

El apoyo ventilatorio (AV) y la admisión a la unidad de terapia intensiva (UTI) se considera en pacientes con exacerbación grave para el manejo de la falla respiratoria aguda. La ventilación mecánica no invasiva (VMNI) se prefiere para la administración de oxígeno suplementario de forma inicial. EC han informado tasas de éxito del $80-85 \%$ con este sistema. Los beneficios clínicos se reflejan en la mejoría de la acidosis respiratoria, la disminución de la taquicardia y de la retención de bióxido de carbono $\left(\mathrm{CO}_{2}\right)$, también disminuyen 
las complicaciones asociadas con la ventilación mecánica, como neumonía y estancias hospitalarias prolongadas. Una vez que los pacientes toleran cuatro horas de respiración no asistida, la VMNI puede suspenderse sin necesidad de «destete ". ${ }^{1}$ Una RS que incluyó 14 EC demostró eficacia en la disminución de la mortalidad (7.1\% versus $13.9 \%$; RR 0.54 , IC95\% $0.38-0.76)$, necesidad de intubación ( $12 \%$ versus $30.6 \%$; RR 0.43 , IC95\% 0.35-0.53), estancia hospitalaria (DM 2.88 días menos, IC95\% 1.17-4.59 días menos), estancia en UTI (DM 4.99 días menos, IC95\% 0-9.99 días menos) y complicaciones (15.7\% versus $42 \%$; RR 0.39, IC95\% 0.26-0.59). ${ }^{21}$

La ventilación mecánica invasiva (VMI) se reserva para los pacientes en los que las técnicas iniciales han fallado. La mortalidad de estos pacientes es variable y se ha reportado un rango de 17-49\% y una alta proporción de pacientes que han requerido este apoyo. También se observan altas tasas de mortalidad en los primeros 12 meses después el internamiento, principalmente en pacientes con pobre capacidad pulmonar. ${ }^{2}$ Contar con dispositivos de fácil acceso en los servicios correspondientes puede ser el camino inicial para alcanzar el objetivo.

En la EPOC la oxigenoterapia se considera parte del tratamiento, pero si no se monitorea con gasometría arterial, el riesgo de acidosis respiratoria es alto. Por eso se prefiere administrar en las dosis más bajas posibles, para alcanzar una $\mathrm{SpO}_{2}$ no $>94 \%$. Si no se cuenta con gasometría arterial, el riesgo de presentar acidosis respiratoria es muy alto y la indicación de VMNI o incluso VMI puede presentarse rápidamente.

\section{Pregunta clínica 36}

¿Cuál es la eficacia y seguridad de los corticosteroides sistémicos para el manejo hospitalario de los pacientes con exacerbación de la EPOC?

\section{Recomendaciones}

1 Los corticosteroides sistémicos reducen la gravedad de la exacerbación ${ }^{21}$ y pueden mejorar la función pulmonar $\left(\mathrm{FEV}_{1}\right)$, la oxigenación, el tiempo de recuperación y acortar la estancia intrahospitalaria. ${ }^{2}$

2 Durante el manejo hospitalario y. en ausencia de contraindicaciones significativas, deben administrarse corticosteroides (orales o parenterales) en conjunto con otras terapias, particularmente, en las exacerbaciones de graves a muy graves ${ }^{2}$

3 Se recomienda usar de rutina la vía oral (a dosis equivalente de $40 \mathrm{mg} /$ día de prednisona o $30 \mathrm{mg} /$ día de prednisolona y limitar el uso parenteral, siempre y cuando la vía gastrointestinal y su función estén intactas. ${ }^{16,17}$

$4 \quad$ La duración del tratamiento se recomienda como máximo de 5-7 días. No se reco-

Evidencia 1++ Recomendación A

Evidencia 1++ Recomendación A

Evidencia 1++ Recomendación A

Evidencia 1++ Recomendación A mienda prolongar el tratamiento más de 14 días, ya que no se han obtenido mayores beneficios. ${ }^{15,16}$ 


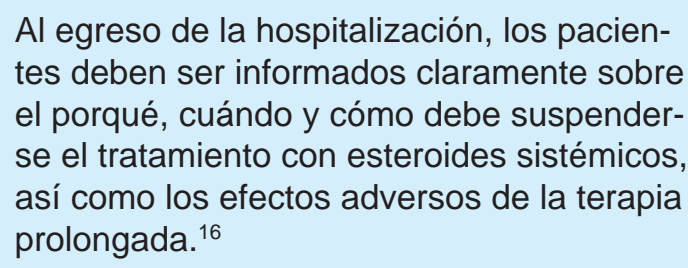

La GPC de ATS/ERS 2017 llevó a cabo una RS al identificar dos EC que evaluaron la eficacia y seguridad de los corticosteroides sistémicos por vía oral, en comparación con la administración intravenosa en el manejo de exacerbaciones de la EPOC. ${ }^{19}$ Los resultados del metaanálisis mostraron que no hubo diferencias estadísticamente significativas en lo referente a falla de tratamiento (53.5\% intravenoso versus $49.6 \%$ vía oral; RR 1.09 , IC95\% $0.87-1.37$ ), mortalidad (5.5\% intravenoso versus $1.7 \%$ para vía oral; RR 2.78 , IC95\%0.67-11.51), readmisión hospitalaria (14.2\% intravenoso versus $12.4 \%$ vía oral; RR 1.13, IC95\% 0.60-2.13), días de hospitalización (DM 0.71 más días con terapia intravenosa versus vía oral, IC95\% 1.35-2.78). Los eventos adversos se incrementan con la terapia parenteral en comparación con la vía oral (70\% versus 20\%; RR 3.50, IC95\% 1.39-8.8). Derivado de estos resultados, la terapia intravenosa se recomienda en pacientes que no pueden tolerar la vía oral. ${ }^{19}$ Respecto a los corticosteroides sistémicos en la EPOC no existe realmente una contraindicación absoluta para su aplicación, y el beneficio se ha demostrado con niveles de evidencia altos.

\section{Pregunta clínica 37}

¿Cuál es la eficacia y seguridad de la ventilación mecánica no invasiva (VMNI) para el manejo hospitalario de los pacientes con exacerbación de la EPOC?

\section{Recomendaciones}

$1 \quad$ La VMNI es el tratamiento de elección en el paciente con exacerbación de EPOC y falla respiratoria aguda, en ausencia de contraindicaciones absolutas. Esta modalidad mejora el intercambio de gases, reduce el esfuerzo respiratorio y la necesidad de intubación; disminuye los días de estancia intrahospitalaria y mejora la supervivencia. ${ }^{2}$

2 La VMNI está indicada cuando, a pesar del tratamiento médico óptimo, persiste o empeora la insuficiencia respiratoria hipercápnica durante la exacerbación $(\mathrm{pH}<7.35) .{ }^{21}$

3 Puede considerarse también el uso de VMNI en pacientes en protocolo de destete de ventilación mecánica invasiva y con difícil retiro de la misma. ${ }^{15}$

$4 \quad$ La VMNI debe aplicarse por personal entrenado, con experiencia en su uso y conocedor de las limitaciones de esta modalidad ventilatoria. ${ }^{15,16}$
Evidencia 1++ Recomendación A

Evidencia 1++ Recomendación A

Evidencia 1++ Recomendación A

Evidencia 4 Recomendación 4 
Al iniciarse debe tenerse un plan esta-

Evidencia 4 blecido y claro en caso de deterioro del Recomendación 4 paciente que incluya el tratamiento a seguir. ${ }^{15,16}$

La VMNI debería ser la única opción en la insuficiencia respiratoria tipo 20 hipercápnica. Tiene todo el soporte científico como una indicación absoluta para el paciente con exacerbación de la EPOC e insuficiencia respiratoria hipercápnica. Sin embargo, existen centros hospitalarios que no cuentan con este recurso y son con VMNI. Se propone que el costo de interfases y circuitos para acoplarlos a ventiladores de críticos es mucho más económico y eficaz en el manejo de estos pacientes. Una RS que incluyó 14 EC demostró eficacia en la disminución de la mortalidad (7.1\% versus $13.9 \%$; RR 0.54 , IC95\% $0.38-0.76)$, necesidad de intubación (12\% versus 30.6\%; RR 0.43, IC95\% 0.35-0.53), estancia hospitalaria (DM 2.88 días menos, IC95\% 1.17-4.59 días menos) estancia en UTI 4.99 días menos, IC95\% 0.0-9.99 días menos) y complicaciones (15.7\% versus $42 \%$; RR $0.39, \mathrm{IC} 95 \%$ 0.26-0.59). ${ }^{19} \mathrm{La}$ orden de intubación absoluta en estos pacientes es la pérdida del estado de conciencia, Glasgow menor a 8 y choque séptico. La VMNI es la terapia por excelencia para el tratamiento de la insuficiencia respiratoria tipo 2 en EPOC exacerbado.

El mejor resultado de la VMNI se obtiene combinando presión positiva continua (CPAP) y ventilación con soporte por presión (VSP)..$^{15}$ Debe contarse con el equipo e interfases adecuadas para asegurar el éxito de la aplicación de la VMNI. ${ }^{15}$ Los parámetros iniciales deben ser los menos molestos para el paciente; así, es posible iniciar con presión positiva espiratoria (EPAP) de $4 \mathrm{~cm}$ de $\mathrm{H}_{2} \mathrm{O}$ y presión positiva inspiratoria (IPAP) $5 \mathrm{~cm}$ arriba $\left(9 \mathrm{~cm}\right.$ de $\mathrm{H}_{2} \mathrm{O}$ total). Se debe hacer el ajuste de los parámetros del ventilador en los primeros 15 minutos de colocado el VMNI. ${ }^{15}$ El objetivo de la VMNI es disminuir la sobrecarga de trabajo respiratorio; de esta manera, se debe titular el EPAP hasta que cada esfuerzo inspiratorio del paciente desencadene flujo por parte de la máquina..$^{15} \mathrm{La}$ IPAP se debe ajustar para que alcance un volumen corriente o tidal $(\mathrm{Vt})$ de $7-8 \mathrm{~mL} / \mathrm{kg}$ de peso ideal..$^{15}$ Debido a que es un modo espontáneo se debe hacer todos los esfuerzos desencadenados por el paciente; no tiene utilidad programar ciclos inspiratorios por parte del ventilador. ${ }^{15}$

Pregunta clínica 38

¿Cuál es la eficacia y seguridad de la ventilación mecánica invasiva (VMI) para el manejo hospitalario de los pacientes con exacerbación de la EPOC?

\section{Recomendaciones}

1 En caso de considerarse necesario, los pacientes con EPOC agudizado deberán

Evidencia 4 Recomendación D recibir tratamiento en la unidad de cuidados intensivos con ventilación mecánica invasiva (VMI). ${ }^{16}$

2 La VMI está indicada en los pacientes con acidosis respiratoria $(\mathrm{pH}<7.25)$, deterioro del nivel de conciencia e inestabilidad hemodinámica. ${ }^{2}$ 
Dentro de los criterios de elegibilidad para intubación y VMI, se deben considerar el estado funcional, el índice de masa corporal (IMC), los requerimientos habituales de oxígeno suplementario, las comorbilidades, la historia de ingresos previos a UTI, la edad y la función pulmonar $\left(\mathrm{FEV}_{1}\right){ }^{16}$

4

$\mathrm{Ni}$ la edad ni el FEV $\mathrm{F}_{1}$ influyen de manera aislada en la decisión de intubar a los pacientes con EPOC agudizado. ${ }^{2,15,16}$

\author{
Evidencia 1++ \\ Recomendación A
}

Evidencia 1++

Recomendación A

El uso de VMI sigue siendo en algunos centros la única opción para estos pacientes. Se propone que, si un paciente ingresa a UTI por insuficiencia respiratoria hipercápnica, ya sea por no contar o por fracaso de la VMNI, el proceso de liberación de la VMI sea rápido como se ha propuesto en la mayoría de UTI en el mundo. El tiempo promedio de VMI es de cinco días. Los protocolos de «destete» rápido aplican a estos pacientes, al retirar la sedación en forma temprana y al ponerlos en modo espontáneo lo más rápido posible. En el manejo de estos pacientes, si se prolongan los días de sedación y ventilación controlada, el diafragma progresará rápidamente a disfunción (disfunción diafragmática inducida por el ventilador), debido al daño estructural diafragmático preexistente.

\section{9: EPOC: Manejo complementario y apoyo al final de la vida}

\section{Pregunta clínica 39}

¿Cuál es la eficacia y seguridad de la rehabilitación pulmonar en la EPOC agudizada?

\section{Recomendaciones}

$1 \quad$ En pacientes hospitalizados con exacerbación de la EPOC, sugerimos no iniciar rehabilitación pulmonar (RP) durante la hospitalización. ${ }^{19}$

2 La fisioterapia con máscaras de presión positiva espiratoria debe considerarse en pacientes seleccionados como apoyo en el aclaramiento de secreciones. ${ }^{16}$

3 Se recomienda iniciar la RP inmediatamente después de finalizar el tratamiento de la exacerbación o en el período comprendido en las tres semanas siguientes del egreso hospitalario. ${ }^{18,19}$

\author{
Evidencia 2+ \\ Recomendación C \\ Evidencia 1- \\ Recomendación B
}

Evidencia 1++

Recomendación A

El proceso de RP requiere de fortalecer los músculos respiratorios (cintura escapular), misma que está comprometida por la misma exacerbación. Una vez que el paciente clínicamente tiene un menor trabajo respiratorio puede iniciarse la RP, pero se requiere de un equipo altamente entrenado. El paciente que ya egresado del hospital debe someterse a un plan de dieta, RP y el manejo de secreciones se realizará ya sea con fármacos o dispositivos que faciliten la expulsión de secreciones. $^{2,99}$ 


\section{Pregunta clínica 40}

¿Cuál es la eficacia y seguridad de los cuidados paliativos y de apoyo al final de la vida en los pacientes con EPOC?

\section{Recomendaciones}

1 Los síntomas de ansiedad y depresión son comunes en pacientes con EPOC. ${ }^{21}$

2 La presencia de ansiedad o depresión debe considerarse en los pacientes con EPOC que presentan estas características: 1) hipoxemia, 2) disnea grave, y 3) hospitalizados por exacerbación. ${ }^{16}$

3 La ansiedad y la depresión en pacientes con EPOC deben ser tratadas de manera habitual, si bien hay que tener en cuenta la edad de los pacientes, efectos adversos de los fármacos e interacciones farmacológicas, sobre todo en los pacientes polimedicados. ${ }^{18}$

$4 \quad$ En pacientes con EPOC con síntomas de ansiedad o depresión y con escasa predisposición a seguir un tratamiento farmacológico, se sugiere ofrecer tratamiento psicológico basado en principios de la terapia cognitivo-conductual. ${ }^{18}$

5 Los pacientes con EPOC deben ser evaluados frecuentemente acerca de su capacidad de realizar actividades diarias y el grado de disnea que éstas le producen. ${ }^{16}$

6 Deben considerarse analgésicos opioides en pacientes con EPOC en etapa terminal y disnea que no responde a otro tipo de terapia médica. ${ }^{2,16}$

7 Se pueden considerar benzodiacepinas, antidepresivos tricíclicos, tranquilizantes, oxígeno en ciclos cortos. ${ }^{2,16}$

8 Otras opciones son estimulación eléctrica neuromuscular e incluso la administración directa de aire desde un ventilador son terapias que pueden mejorar la disnea en pacientes con EPOC en etapa terminal, sin respuesta al tratamiento médico de la enfermedad.

9 La terapia de oxígeno en ciclos cortos debe considerarse únicamente en episodios de disnea grave que no resuelvan con otros tratamientos. ${ }^{16}$
Evidencia 1+

Evidencia 4

Recomendación D

Evidencia 4

Recomendación D

Evidencia 3

Recomendación C

Evidencia 4

Recomendación D

Evidencia 2+

Recomendación C

Evidencia 4

Recomendación D

Evidencia 2+

Recomendación C

Evidencia 2+

Recomendación C 
10

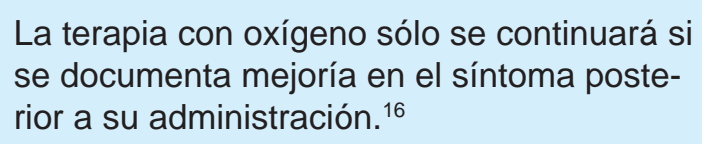

La terapia con oxígeno sólo se continuará si se documenta mejoría en el síntoma posterior a su administración. ${ }^{16}$

11 La fatiga puede mejorar mediante programas educativos de autocuidados y rehabilitación pulmonar. ${ }^{2}$

12 En pacientes con mala nutrición, la suplementación nutricional puede mejorar la fuerza de los músculos respiratorios y la salud en general. ${ }^{2}$

13 Los pacientes con EPOC en estadío terminal, así como sus familiares y cuidadores deben tener acceso a equipos multidisciplinarios de cuidados paliativos, incluyendo admisión a sitios de cuidados especiales. ${ }^{2}$
Evidencia 4

Recomendación D

Evidencia 1-

Recomendación B

Evidencia 1-

Recomendación B

Evidencia 4

Recomendación D

Posiblemente profundizar los contrastes de benzodiacepinas bajo el efecto farmacológico de inhibidores del impulso respiratorio con las consecuencias conocidas. El paciente con EPOC tiene alta incidencia de depresión, por lo que los antidepresivos están totalmente indicados. En los casos terminales, se debe apoyar con fármacos. La estimulación eléctrica y el aire a la cara no tienen ningún papel en el alivio de la disnea. Tiene buen soporte los opiáceos para aliviar disnea en estos pacientes. 


\section{5: Consideraciones adicionales}

Investigación futura

Existen temas dentro de la guía que no tienen respuestas o que la evidencia no ha alcanzado la cobertura adecuada para dar poder a ciertas recomendaciones, por lo que a nivel mundial existen grupos de trabajo que se encargan de crear protocolos dirigidos a responder éstas.

\section{Actualización}

Se planea un período de actualización de la Guía de Práctica Clínica para incorporar nueva evidencia científica a las recomendaciones de 3 a 4 años.

\section{Declaración de conflicto de intereses}

Los expertos clínicos del GN y del GA de GMEPOC declaran no tener ningún conflicto de interés.

JLMB, MAFM, JVR, MRV recibieron honorarios como parte del grupo metodológico independiente.

\section{Información importante}

Esta GPC y los documentos que sean publicados, basados en ella, representan herramientas originadas por el consenso de expertos clínicos acerca de las terapias y toma de decisiones vigentes para el manejo de EPOC. Este documento ha sido publicado para que especialistas consideren las recomendaciones clínicas y las incorporen a su toma de decisiones de su práctica clínica cotidiana. Sin embargo, estas recomendaciones no se encuentran por arriba del criterio clínico independiente de cada médico y de las condiciones individuales de cada paciente. 


\section{6: Referencias}

1. Institute for Health Metrics and Evaluation (IHME). Findings from the Global Burden of Disease Study 2017. Seattle, WA: IHME; 2018. Disponible en: http://ghdx.healthdata. org/gbd-2017

2. GOLD. Global Initiative for chronic obstructive lung disease global strategy for the diagnosis, management and prevention of chronic obstructive pulmonary disease (2019 REPORT). Disponible en: www.goldcopd.org

3. Menezes AM, Perez-Padilla R, Jardim JR, et al. Chronic obstructive pulmonary disease in five Latin American cities (the PLATINO study): A prevalence study. Lancet 2005;366:1875-1881.

4. Perez-Padilla R, Menezes AM. Chronic obstructive pulmonary disease in Latin America. Ann Glob Health 2019;85(1). doi:10.5334/aogh.2418.

5. Lamprecht B, Soriano JB, Studnicka M, et al. Determinants of underdiagnosis of COPD in national and international surveys. Chest 2015;148(4):971-85.

6. Talamo C, de Oca MM, Halbert R, et al. Diagnostic labeling of COPD in five Latin American cities. Chest 2007;131(1):60-67.

7. Reynales-Shigematsu LM. Costos de atención médica de las enfermedades atribuibles al consumo de tabaco en América: revisión de la literatura. Salud Publica Mex 2006;48 suppl I:S190-S200.

8. Fernández-Plata R, Martínez-Briseño D, García-Sancho F, et al. Métodos para la estimación de costos en salud de la EPOC: resultados basales. Neumol Cir Tórax 2016;75(1):4-11.

9. Mannino DM. Counting costs in COPD. Chest 2015;147(1):3-5.

10. Fervers B, Burgers JS, Voellinger R, et al. Guideline adaptation:an approach to enhance efficiency in guideline development and improve utilization. BMJ Qual Saf 2011;20(3):228-236

11. Brouwers MC, Kho ME, Browman GP, et al. AGREE II: advancing guideline development, reporting and evaluation in health care. CMAJ 2010;182(18):E839-E842.

12. O'Sullivan D, Wilk S, Michalowski W, Farion K. Using PICO to align medical evidence with MDs decision making models. Stud Health Technol Inform.2013;192:1057. Available from: http://www.ncbi.nlm.nih.gov/pubmed/23920831

13. SIGN. SIGN 50 a guideline developer's handbook. Scottish Intercollegiate Guidelines Network. Healthcare improvement Scotland. 2011.

14. Fink A, Kosecoff J, Chassin M, Brook RH. Consensus methods: characteristics and guidelines for use. Am J Public Health 1984;74(9):979-983.

15. Secretaría de Salud [Internet]. Diagnóstico y tratamiento de la enfermedad pulmonar obstructiva crónica. 2009. Disponible en: http://www.cenetec.salud.gob.mx

16. National Institute for Health and Care Excellence. Chronic obstructive pulmonary disease in over 16s: diagnosis and management. 2010.

17. Montes de Oca M, López-Varela MV, Acuña A, et al. Guía de práctica clínica de la enfermedad pulmonar obstructiva crónica (EPOC) ALAT-2014: Preguntas y respuestas. Arch Bronconeumol; 51(8):403-416. Disponible en: http://dx.doi.org/10.1016/j. arbres.2014.11.017

18. Miravitlles M, Soler-Cataluña JJ, Calle M, et al. Guía española de la enfermedad pulmonar obstructiva crónica (GesEPOC) 2017. Tratamiento farmacológico en fase estable. Arch Bronconeumol 2017;53(6):324-335.

19. Wedzicha JA, Miravitlles M, Hurst JR, et al. Management of COPD exacerbations: a European Respiratory Society/American Thoracic Society guideline. Eur Respir J 2017;49:1600791. https://doi.org/10.1183/13993003.00791-2016

20. Wedzicha JA, Calverley PMA, Albert RK, et al. Prevention of COPD exacerbations: a European Respiratory Society/American Thoracic Society guideline. Eur Respir J 2017;50(3): pii: 1602265. doi: 10.1183/13993003.02265-2016

21. Yang IY, Brown JL, George J, et al. COPD-X Australian and New Zealand guidelines for the diagnosis and management of chronic obstructive pulmonary disease: 2017 update. Med J Aust 2017;207(10):436-442.

22. Vazquez-Garcia JC, Balcázar-Cruz CA, Cervantes-Mendez LG, Mejía-Alfaro R, CossíoAlcantara J, Ramírez-Venegas A. El leguaje de la disnea. Una visión desde el español de México. Arch Bronchoneumol 2006;42(5):211-217. 
23. Peto J. That the effects of smoking should be measured in pack-years: misconceptions 4. Br J Cancer 2012;107(3):406-7.

24. She J, Yang P, Wang Y, et al. Chinese water-pipe smoking and the risk of COPD. Chest 2014;146(4):924-931.

25. Yin $\mathrm{P}$, Jiang CQ, Cheng KK, et al. Passive smoking exposure and risk of COPD among adults in China: the Guangzhou Biobank Cohort Study. Lancet 2007;370(9589):751-757.

26. Wang $\mathrm{C}, \mathrm{Xu}$ J, Yang L, et al. Prevalence and risk factors of chronic obstructive pulmonary disease in China (the China Pulmonary Health [CPH] study): National cross-sectional study. Lancet 2018;391(10131):1706-1717.

27. Korn RJ, Dockery DW, Speizer FE, Ware JH, Ferris BGJ. Occupational exposures and chronic respiratory symptoms. A population-based study. Am Rev Respir Dis 1987;136(2):298-304.

28. Borlee F, Yzermans CJ, Aalders B, et al. Air pollution from livestock farms is associated with airway obstruction in neighboring residents. Am J Respir Crit Care Med 2017;196(9):1152-1161.

29. Guillien A, Puyraveau M, Soumagne T, et al. Prevalence and risk factors for COPD in farmers: a cross-sectional controlled study. Eur Respir J 2016;47(1):95-103.

30. Oxman AD, Muir DC, Shannon HS, Stock SR, Hnizdo E, Lange HJ. Occupational dust exposure and chronic obstructive pulmonary disease. A systematic overview of the evidence. Am Rev Respir Dis 1993;148(1):38-48.

31. Sunyer J, Zock JP, Kromhout $\mathrm{H}$, et al. Lung function decline, chronic bronchitis, and occupational exposures in young adults. Am J Respir Crit Care Med 2005;172(9):1139-1145.

32. Terho EO. Work-related respiratory disorders among Finnish farmers. Am J Ind Med 1990;18(3):269-272.

33. Dalphin JC, Debieuvre D, Pernet D, et al. Prevalence and risk factors for chronic bronchitis and farmer's lung in French dairy farmers. Br J Ind Med 1993;50(10):941-944.

34. Terho EO, Husman K, Vohlonen I. Prevalence and incidence of chronic bronchitis and farmer's lung with respect to age, sex, atopy, and smoking. Eur J Respir Dis Suppl 1987;152:19-28.

35. Pope CA 3rd, Ezzati M, Dockery DW. Fine-particulate air pollution and life expectancy in the United States. N Engl J Med 2009;360(4):376-386.

36. Zhou Y, Wang C, Yao W, et al. COPD in Chinese nonsmokers. Eur Respir J 2009;33(3):509-518.

37. Andersen ZJ, Hvidberg M, Jensen SS, et al. Chronic obstructive pulmonary disease and long-term exposure to traffic-related air pollution: a cohort study. Am J Respir Crit Care Med 2011;183(4):455-461.

38. Hu G, Zhou Y, Tian J, et al. Risk of COPD from exposure to biomass smoke: a metaanalysis. Chest 2010;138(1):20-31.

39. McGeachie MJ, Yates KP, Zhou X, et al. Patterns of growth and decline in lung function in persistent childhood asthma. N Engl J Med 2016;374(19):1842-152.

40. Lam KH, Jiang CQ, Jordan RE, et al. Prior TB, smoking, and airflow obstruction: a crosssectional analysis of the Guangzhou Biobank Cohort Study. Chest 2010;137(3):593-600.

41. Barnes PJ. Genetics and pulmonary medicine. 9. Molecular genetics of chronic obstructive pulmonary disease. Thorax 1999;54(3):245-252.

42. Silverman EK. Genetics of chronic obstructive pulmonary disease. Novartis Found Symp 2001;234:45-64.

43. Silverman EK, Chapman HA, Drazen JM, et al. Genetic epidemiology of severe, earlyonset chronic obstructive pulmonary disease. Risk to relatives for airflow obstruction and chronic bronchitis. Am J Respir Crit Care Med 1998;157(6 Pt 1):1770-1778.

44. Marciniak SJ, Lomas DA. What can naturally occurring mutations tell us about the pathogenesis of COPD? Thorax 2009;64(4):359-364.

45. Jackson $\mathrm{H}$, Hubbard R. Detecting chronic obstructive pulmonary disease using peak flow rate: cross sectional survey. BMJ 2003;327(7416):653-654.

46. Benítez-Pérez RE, Torre-Bouscoulet L, Villca-Alá N, Del-Río-Hidalgo RF, Pérez-Padilla R, Vázquez-García JC, et al. Espirometría: recomendaciones y procedimiento. 2016;75(2):173-190.

47. Pellegrino R, Viegi G, Brusasco V, Crapo RO, Burgos F, Casaburi R, et al. Interpretative strategies for lung function tests. Eur Respir J. 2005;26(5):948-968.

48. Vazquez-García JC, Pérez-Padilla R. Manual de Espirometría. Ciudad de México, México. Graphimedic. 2019. 
49. Swanney MP, Ruppel G, Enright PL, Pedersen OF, Crapo RO, Miller MR, et al. Using the lower limit of normal for the FEV1/FVC ratio reduces the misclassification of airway obstruction. Thorax. 2008;63(12):1046-1051.

50. Pérez-Rubio G, Jiménez-Valverde LO, Ramírez-Venegas A, et al. Prevalencia de variantes de alto riesgo de alfa-1 antitripsina en población mestiza mexicana y su relación con los valores de la función pulmonar. Arch Bronconeumol 2015;51(2):80-85.

51. Westerdahl E, Arne M, Larsson M, Engman KO. Spirometry to motivate smoking cessation - a systematic review. Eur Respir J 2018;52(suppl 62):PA1734. Available from:http://erj.ersjournals.com/content/52/suppl_62/PA1734.abstract

52. Consenso Mexicano. Guías para el diagnóstico y tratamiento de la EPOC. 2012;71(1).

53. García-Gómez L, Sansores RH, Díaz VN, et al. Impacto del consejo breve para dejar de fumar. Salud Publica Mex 2015;57(5):366-367.

54. Rusinowicz T, Zielonka TM, Zycinska K. Cardiac arrhythmias in patients with exacerbation of COPD. Adv Exp Med Biol 2017;1022:53-62.

55. Km K, Mavergames C, Jae W, Kew KM, Mavergames C, Walters JE. Long-acting beta 2 -agonists for chronic obstructive pulmonary disease (Review) Long-acting beta 2 -agonists for chronic obstructive pulmonary disease. Cochrane Database Syst Rev 2013;(10): CD010177. DOI: 10.1002/14651858.CD010177.pub2

56. Nannini LJ, Lasserson TJ, Poole P. Combined corticosteroid and long-acting beta(2)agonist in one inhaler versus long-acting beta(2)-agonists for chronic obstructive pulmonary disease. Cochrane Database Syst Rev 2012;(9):CD006829.

57. Nannini LJ, Poole P, Milan SJ, Kesterton A. Combined corticosteroid and long-acting beta(2)-agonist in one inhaler versus inhaled corticosteroids alone for chronic obstructive pulmonary disease. Cochrane database Syst Rev 2013;(8):CD006826.

58. Brusselle G, Price D, Gruffydd-Jones K, et al. The inevitable drift to triple therapy in COPD: an analysis of prescribing pathways in the UK. Int J Chron Obstruct Pulmon Dis 2015;10:2207-2217.

59. Welte T, Miravitlles M, Hernandez $\mathrm{P}$, et al. Efficacy and tolerability of budesonide/ formoterol added to tiotropium in patients with chronic obstructive pulmonary disease. Am J Respir Crit Care Med 2009;180(8):741-750.

60. Singh D, Brooks J, Hagan G, Cahn A, O'Connor BJ. Superiority of "triple" therapy with salmeterol/fluticasone propionate and tiotropium bromide versus individual components in moderate to severe COPD. Thorax 2008;63(7):592-598.

61. Jung KS, Park HY, Park SY, et al. Comparison of tiotropium plus fluticasone propionate/ salmeterol with tiotropium in COPD: a randomized controlled study. Respir Med 2012;106(3):382-389.

62. Hanania NA, Crater GD, Morris AN, Emmett AH, O'Dell DM, Niewoehner DE. Benefits of adding fluticasone propionate/salmeterol to tiotropium in moderate to severe COPD. Respir Med 2012;106(1):91-101.

63. Frith PA, Thompson PJ, Ratnavadivel R, et al. Glycopyrronium once-daily significantly improves lung function and health status when combined with salmeterol/fluticasone in patients with COPD: the GLISTEN study, a randomized controlled trial. Thorax 2015;70(6):519-527.

64. Siler TM, Kerwin E, Singletary K, Brooks J, Church A. Efficacy and safety of umeclidinium added to fluticasone propionate/salmeterol in patients with COPD: results of two randomized, double-blind studies. COPD 2016;13(1):1-10.

65. Singh D, Papi A, Corradi M, et al. Single inhaler triple therapy versus inhaled corticosteroid plus long-acting beta2-agonist therapy for chronic obstructive pulmonary disease (TRILOGY): a double-blind, parallel group, randomised controlled trial. Lancet 2016;388(10048):963-973.

66. Lipson DA, Barnacle H, Birk R, et al. Fulfil trial: once-daily triple therapy for patients with chronic obstructive pulmonary disease. Am J Respir Crit Care Med 2017;196(4):438-446.

67. Karner C, Cates CJ. Combination inhaled steroid and long-acting beta (2)-agonist in addition to tiotropium versus tiotropium or combination alone for chronic obstructive pulmonary disease. Cochrane database Syst Rev 2011;(3):CD008532.

68. Vestbo J, Papi A, Corradi M, et al. Single inhaler extrafine triple therapy versus longacting muscarinic antagonist therapy for chronic obstructive pulmonary disease (TRINITY): a double-blind, parallel group, randomised controlled trial. Lancet 2017;389(10082):1919-1929. 
69. Lipson DA, Barnhart F, Brealey N, et al. Once-daily single-inhaler triple versus dual therapy in patients with COPD. N Engl J Med 2018;378(18):1671-1680.

70. Papi A, Vestbo J, Fabbri L, et al. Extrafine inhaled triple therapy versus dual bronchodilator therapy in chronic obstructive pulmonary disease (TRIBUTE): a doubleblind, parallel group, randomised controlled trial. Lancet 2018;391(10125):1076-1084.

71. Bafadhel M, Peterson S, De Blas MA, et al. Predictors of exacerbation risk and response to budesonide in patients with chronic obstructive pulmonary disease: a post-hoc analysis of three randomised trials. Lancet Respir Med 2018;6(2):117-126.

72. Pascoe S, Locantore N, Dransfield MT, Barnes NC, Pavord ID. Blood eosinophil counts, exacerbations, and response to the addition of inhaled fluticasone furoate to vilanterol in patients with chronic obstructive pulmonary disease: a secondary analysis of data from two parallel randomised controlled trials. Lancet Respir Med 2015;3(6):435-442.

73. Sestini P, Renzoni E, Robinson S, Poole P, Ram FS. Short-acting beta 2 agonists for stable chronic obstructive pulmonary disease. Cochrane Database Syst Rev 2002;(4):CD001495.

74. O'Donnell DE, Aaron S, Bourbeau J, et al. Canadian Thoracic Society recommendations for management of chronic obstructive pulmonary disease - 2007 update. Can Respir J 2007;14 Suppl B:5B-32B.

75. Tashkin DP. A review of nebulized drug delivery in COPD. Int J Chron Obstruct Pulmon Dis 2016;11:2585-2596.

76. National Asthma Council Australia. Australian Asthma Handbook, Version 2.0. Melbourne: National Asthma Council Australia; 2016. [último acceso 07 Noviembre 2019] Disponible en: http://www.asthmahandbook.org.au

77. Paediatric Society of New Zealand. Best practice evidence-based guideline: Management of asthma in children aged 1-15 years. 2005.

78. Academy of Medicine of Malaysia, Malaysian Thoracic Society, Lung Foundation of Malaysia. Clinical practice guidelines for the management of childhood asthma. Kuala Lumpur: Academy of Medicine of Malaysia, Malaysian Thoracic Society, Lung Foundation of Malaysia. 2014

79. Ram FSF, Sestini P. Regular inhaled short acting beta2 agonists for the management of stable chronic obstructive pulmonary disease: Cochrane systematic review and meta-analysis. Thorax 2003;58(7):580-584.

80. Burge PS, Calverley PM, Jones PW, Spencer S, Anderson JA, Maslen TK. Randomised, double blind, placebo controlled study of fluticasone propionate in patients with moderate to severe chronic obstructive pulmonary disease: the ISOLDE trial. BMJ 2000;320(7245):1297-1303.

81. Watz H, Tetzlaff K, Wouters EFM, et al. Blood eosinophil count and exacerbations in severe chronic obstructive pulmonary disease after withdrawal of inhaled corticosteroids: a post-hoc analysis of the WISDOM trial. Lancet Respir Med 2016;4(5):390-398.

82. Magnussen H, Disse B, Rodriguez-Roisin R, et al. Withdrawal of inhaled glucocorticoids and exacerbations of COPD. N Engl J Med 2014;371(14):1285-1294.

83. Buhl R, Criee CP, Kardos $\mathrm{P}$, et al. Dual bronchodilation versus triple therapy in the "real-life" COPD DACCORD study. Int J Chron Obstruct Pulmon Dis 2018;13:2557-2568.

84. Horita N, Miyazawa N, Kojima R, et al. Chronic use of theophylline and mortality in chronic obstructive pulmonary disease: a meta-analysis. Arch Bronconeumol 2016;52(5):233-238.

85. ZuWallack RL, Mahler DA, Reilly D, Church N, Emmett A, Rickard K, Knobil K. Salmeterol plus theophylline combination therapy in the treatment of COPD. Chest. 2001 Jun;119(6):1661-70.

86. Devereux G, Cotton S, Fielding S, McMeekin N, Barnes PJ, Briggs A, et al. Effect of Theophylline as Adjunct to Inhaled Corticosteroids on Exacerbations in Patients With COPD: A Randomized Clinical Trial. JAMA. 2018 Oct;320(15):1548-1559.

87. Ram FS, Jones PW, Castro AA, et al. Oral theophylline for chronic obstructive pulmonary disease. Cochrane database Syst Rev. 2002;(4):CD003902.

88. Cosio BG, Shafiek H, Iglesias A, et al. Oral low-dose theophylline on top of inhaled fluticasone-salmeterol does not reduce exacerbations in patients with severe COPD: a pilot clinical trial. Chest 2016;150(1):123-130. 
89. Walters JAE, Tan DJ, White CJ, Gibson PG, Wood-Baker R, Walters EH. Systemic corticosteroids for acute exacerbations of chronic obstructive pulmonary disease. Cochrane database Syst Rev 2014;(9):CD001288.

90. Walters JAE, Walters EH, Wood-Baker R. Oral corticosteroids for stable chronic obstructive pulmonary disease. Cochrane database Syst Rev 2005;(3):CD005374.

91. Cazzola M, Rogliani P, Calzetta L, Hanania NA, Matera MG. Impact of mucolytic agents on COPD exacerbations: a pair-wise and network meta-analysis. COPD 2017;14(5):552-563.

92. Ramos FL, Krahnke JS, Kim V. Clinical issues of mucus accumulation in COPD. Int $J$ Chron Obstruct Pulmon Dis 2014;9:139-150.

93. Aaron SD. Mucolytics for COPD: negotiating a slippery slope towards proof of efficacy. Eur Respir J 2017;50(4). pii:1701465.

94. Turner RD, Bothamley GH. N-acetylcysteine for COPD: the evidence remains inconclusive. Lancet Respir Med 2014;2(4):e3.

95. Brown WM. Treating COPD with PDE 4 inhibitors. Int J Chron Obstruct Pulmon Dis 2007;2(4):517-533.

96. Martinez FJ, Calverley PM, Goehring UM, Brose M, Fabbri LM, Rabe KF. Effect of roflumilast on exacerbations in patients with severe chronic obstructive pulmonary disease uncontrolled by combination therapy (REACT): a multicentre randomised controlled trial. Lancet 2015;385(9971):857-866.

97. Rabe KF, Calverley PMA, Martinez FJ, Fabbri LM. Effect of roflumilast in patients with severe COPD and a history of hospitalisation. Eur Respir J 2017;50(1).

98. Dougall S, Bolt J, Semchuk W, Winkel T. Inhaler assessment in COPD patients: A primer for pharmacists. Can Pharm J (Ott). 2016;149(5):268-273.

99. Feldman GJ, Sousa AR, Lipson DA, Tombs L, Barnes N, Riley JH, et al. Comparative Efficacy of Once-Daily Umeclidinium/Vilanterol and Tiotropium/Olodaterol Therapy in Symptomatic Chronic Obstructive Pulmonary Disease: A Randomized Study. Adv Ther. 2017;34(11):2518-2533.

100. Rehabilitation AACVPR. Guidelines for pulmonary rehabilitation programs. Human Kinetics; 2011.

101. CENETEC. Oxigenoterapia crónica ambulatoria en edad adulta y pediátrica en los tres niveles de atención. México; 2015.

102. Gassner LA, Dunn S, Piller N. Aerobic exercise and the post myocardial infarction patient: a review of the literature. Heart Lung 2003;32(4):258-265.

103. Clark AM, Hartling L, Vandermeer B, McAlister FA. Meta-analysis: secondary prevention programs for patients with coronary artery disease. Ann Intern Med 2005;143(9):659-672.

104.Walters JA, Tan DJ, White CJ, Wood-Baker R. Different durations of corticosteroid therapy for exacerbations of chronic obstructive pulmonary disease. Cochrane Database Syst Rev 2018;3:CD006897.

105. Cheng T, Gong Y, Guo Y, et al. Systemic corticosteroid for COPD exacerbations, whether the higher dose is better? A meta-analysis of randomized controlled trials. Clin Respir J 2013;7(4):305-318.

106.Abroug F, Ouanes I, Abroug S, et al. Systemic corticosteroids in acute exacerbation of COPD: a meta-analysis of controlled studies with emphasis on ICU patients. Ann Intensive Care 2014;4:32.

107. Albert RK, Connett J, Bailey WC, et al. Azithromycin for prevention of exacerbations of COPD. N Engl J Med 2011;365(8):689-698.

108. Sethi S, Jones PW, Theron MS, et al. Pulsed moxifloxacin for the prevention of exacerbations of chronic obstructive pulmonary disease: a randomized controlled trial. Respir Res 2010;11:10.

109. Vollenweider DJ, Frei A, Steurer-Stey CA, Garcia-Aymerich J, Puhan MA. Antibiotics for exacerbations of chronic obstructive pulmonary disease. Cochrane Database Syst Rev 2018;10:CD010257.

110. Medicine TLR. The death of low-dose oral theophylline for COPD? Lancet Respir Med. 2018 Jul;6(7):479. doi: 10.1016/S2213-2600(18)30240-6.

111. Strickland SL, Rubin BK, Haas CF, Volsko TA, Drescher GS, O'Malley CA. AARC clinical practice guideline: effectiveness of pharmacologic airway clearance therapies in hospitalized patients. Respir Care 2015;60(7):1071-1077. Available from: http:// rc.rcjournal.com/cgi/doi/10.4187/respcare.04165 


\section{7: Anexos}

\section{ANEXO A. DOCUMENTO DE ALCANCES DE LA GUÍA}

1. Título de la Guía de Práctica Clínica

1.1. Título abreviado

2. Antecedentes

3. Justificación para el desarrollo de la Guía de Práctica Clínica

4. Población que será incluida en la Guía de Práctica Clínica

4.1. Población a ser considerada

4.2. Población excluida

4.3. Tópicos que no serán considerados en la Guía de Práctica Clínica

5. Escenarios clínicos en donde se aplicarán las recomendaciones de la Guía de Práctica Clínica

6. Procesos clínicos que serán considerados en la Guía de Práctica Clínica

6.1. Intervenciones y tratamientos que serán considerados

6.2. Desenlaces clínicos a ser evaluados

7. Aportaciones clínicas que consideramos de relevancia en la guía

8. Información Adicional

9. Grupo de desarrollo nuclear de la GPC

10. Grupo ampliado de desarrollo

11. Tiempos de entrega

\section{Título de la Guía de Práctica Clínica: GUÍA MEXICANA DE EPOC 2020}

\subsection{Título abreviado: GMEPOC, 2020}

\section{Antecedentes}

La Sociedad Mexicana de Neumología en colaboración con el Centro Nacional de Excelencia Tecnológica, apoyados metodológicamente por la agencia «lbero American Agency for Development and Assessment of Health Technologies» Ilevarán a cabo el desarrollo de una Guía de Práctica Clínica que cumpla con los más altos estándares internacionales sobre el diagnóstico y tratamiento de la EPOC para apoyar a los médicos de atención primaria y especialistas en su toma de decisiones clínicas y brindar recomendaciones puntuales sobre los distintos tópicos a este respecto.

- Esta Guía de Práctica Clínica (GPC) cumple con estándares bien validados y publicados por distintas instituciones a nivel internacional como el Instituto de Medicina de Estados Unidos (IOM, por sus siglas en inglés), el Instituto de Excelencia Clínica del Reino Unido (NICE, por sus siglas en inglés), la Red Colegiada para el Desarrollo de Guías de Escocia (SIGN, por sus siglas en inglés) y la Red Internacional de Guías (G-I-N, por sus siglas en inglés).

- Se llevará también una estrategia de promoción, diseminación e implementación de las recomendaciones contenidas en esta GPC para apoyar a los distintos tomadores de decisiones, tanto elaboradores de políticas en salud, administrativos, médicos especialistas, así como otros profesionales de la salud, pacientes y sus cuidadores para lograr elevar la calidad en la atención clínica en estos pacientes.

\section{Justificación para el desarrollo de la Guía de Práctica Clínica}

Dado que en México la EPOC es la cuarta causa de muerte y presenta una alta tasa de subdiagnóstico (81.6\%) en el país y en Latinoamérica, la elevada canti- 
dad de otras GPC a nivel mundial y la falta de guías dirigidas al primer nivel de atención, se realiza en esta guía transculturizada un esfuerzo para cubrir dichas necesidades planteadas.

\section{Población}

\subsection{Población a ser considerada}

- Pacientes adultos con el diagnóstico de EPOC incluyendo: 1) pacientes expuestos a humo de tabaco y 2) pacientes expuestas a humo de leña

\subsection{Población excluida}

- Asma

- Bronquiectasias

- Tuberculosis

- Fibrosis quística

\subsection{Tópicos que no serán considerados en la Guía de Práctica Clínica}

- Cirugía

- Deficiencia de alfa-1-antitripsina

5. Escenarios clínicos en donde se aplicarán las recomendaciones de la Guía de Práctica Clínica

- Primero, segundo y tercer nivel de atención

6. Procesos clínicos que serán considerados en la Guía de Práctica Clínica. Estadios clínicos

- EPOC Estable

- Exacerbación de la EPOC

\subsection{Intervenciones y tratamientos que serán considerados}

- Diagnóstico. Cuadro clínico, espirometría y pruebas complementarias; pruebas de laboratorio, oximetría, biometría hemática, pruebas de imagen

- Diagnóstico diferencial

- Medidas generales. Estrategias para evitar la exposición al humo del cigarro (manejo no farmacológico) e inmunizaciones

\section{- Tratamiento para el manejo de mantenimiento de la EPOC estable}

- Tratamientos inhalados

- Broncodilatadores (b2 agonistas, anticolinérgicos)

- Combinaciones de medicamentos

- Metilxantinas

- Tratamientos sistémicos (glucocorticoides)

- Inhibidores de la fosfodiesterasa 4

- Antibióticos

- Rehabilitación pulmonar

- Oxígeno suplementario 
- Tratamiento farmacológico para dejar de fumar

- Cuidados paliativos y apoyo al final de la vida

- Tratamiento para el manejo de la exacerbación de la EPOC

- Manejo ambulatorio

- Antibióticos sistémicos VO

- Glucocorticoides sistémicos

- Broncodilatadores

- Manejo hospitalario

- Antibióticos sistémicos (oral o intravenosos)

- Oxígeno suplementario

- Ventilación mecánica no invasiva

- Ventilación mecánica invasiva

- Programa de manejo domiciliario

- Criterios de referencia al especialista

6.2. Desenlaces clínicos a ser evaluados (GRADE APPROACH)

Desenlace

- Espirometría

- Calidad de Vida

- Escalas de Síntomas

- mMRC y CAT

- Incidencia de exacerbaciones

- Eventos adversos

- Mortalidad

- Costos

\section{Relevancia}

9

9

9

8

7

\section{Aportaciones clínicas que consideramos de relevancia en la GPC}

El objetivo de esta GPC es cerrar la brecha entre la evidencia científica y la toma de decisiones clínicas tanto en médicos de atención primaria como en especialistas. Simplificar la implementación de las recomendaciones de las principales guías internacionales y globales que tienen gran sustento científico inherente a la comunidad médica local/regional. Su aplicación pretende mejorar el manejo de los pacientes con EPOC y disminuir las exacerbaciones y la mortalidad relacionada. Se espera también un incremento en la calidad de vida relacionada a la salud.

\section{Información adicional}

Este es un documento original propuesto y aprobado por el Grupo Nuclear de Desarrollo.

9. Grupo Nuclear de la GPC: un coordinador general, tres metodólogos y ocho expertos clínicos

10. Grupo ampliado de desarrollo

11. Tiempos de entrega 
- Documento de alcances enviado al Grupo Nuclear: 2 de marzo de 2018

- Reuniones presenciales: 16 de marzo de 2018 y 2 de abril de 2019

- Borrador de la GPC revisado por el Grupo Nuclear: 3 de abril de 2019

- Versión final de GPC aprobada por el grupo de desarrollo: septiembre de 2019

- Versión final revisada y aprobada: octubre de 2019

- Presentación oficial de la GPC: 20 de noviembre de 2020 


\begin{tabular}{|c|c|c|c|c|}
\hline Fármaco & Dosis, $\mu g$ & $\begin{array}{c}\text { Posología } \\
\text { (inhalaciones) }\end{array}$ & Presentación & Dispositivo \\
\hline \multicolumn{5}{|l|}{ SABA } \\
\hline Salbutamol & 100 & 2-4 cada 4-6 h & Solución & IDMp \\
\hline \multicolumn{5}{|l|}{ SAMA } \\
\hline Bromuro de ipratropio & 20 & 2-4 cada 4-6 h & Solución & IDMp \\
\hline \multicolumn{5}{|l|}{ SABA + SAMA } \\
\hline Fenoterol + ipratropio & $20 / 50$ & 2-4 cada $4-6$ h & Solución & IDMp \\
\hline Salbutamol + ipratropio & $100 / 20$ & 2-4 cada $4-6$ h & Solución & Respimat \\
\hline \multicolumn{5}{|l|}{ LABA } \\
\hline Formoterol & 12 & 1 cada 12 h & Polvo seco & Aerolizer \\
\hline Indacaterol & 150 & 1 cada 24 h & Polvo seco & Breezhaler \\
\hline Olodaterol & 5 & 2 cada 24 h & Solución & Respimat \\
\hline \multicolumn{5}{|l|}{ LAMA } \\
\hline Aclidinio & 322 & 1 cada 12 h & Polvo seco & Genuair \\
\hline Glicopirronio & 50 & 1 cada 24 h & Polvo Seco & Breezhaler \\
\hline Tiotropio & 5 & 2 cada 24 h & Solución & Respimat \\
\hline Tiotropio & 18 & 1 cada 24 h & Polvo seco & Handihaler \\
\hline Umeclidinio & 62.5 & 1 cada 24 h & Polvo Seco & Ellipta \\
\hline \multicolumn{5}{|l|}{ LABA + LAMA } \\
\hline Formoterol/Aclidinio & $12 / 400$ & 1 cada 12 h & Polvo seco & Genuair \\
\hline Indacaterol/Glicopirronio & $110 / 50$ & 1 cada 24 h & Polvo seco & Breezhaler \\
\hline Olodaterol/Tiotropio & $5 / 5$ & 2 cada 24 h & Solución & Respimat \\
\hline Vilanterol/Umeclidinio & $25 / 62.5$ & 1 cada $24 \mathrm{~h}$ & Polvo seco & Ellipta \\
\hline \multicolumn{5}{|l|}{ CEI } \\
\hline Beclometasona & $100,200,250$ & 1-4 cada 8-12 h & Solución & IDMp \\
\hline Budesonida & 100 y 200 & 1-4 cada 12 h & Solución & IDMp \\
\hline Budesonida & 100 & $1-4$ cada $12 \mathrm{~h}$ & Polvo seco & Turbohaler \\
\hline Budesonida & 200,400 & 1 cada $12 \mathrm{~h}$ & Polvo seco & Breezhaler \\
\hline Ciclesonide & 100,200 & 1 cada $24 \mathrm{~h}$ & Solución & IDMp \\
\hline Fluticasona & 250 & $1-4$ cada $12 \mathrm{~h}$ & Solución & IDMp \\
\hline \multicolumn{5}{|l|}{$\mathrm{LABA}+\mathrm{CEI}$} \\
\hline Formoterol/Beclometasona & $6 / 100$ & 2 cada 12 h & Polvo seco & Nexthaler \\
\hline Formoterol/Beclometasona & $6 / 100$ & 2 cada 12 h & Solución & IDMp \\
\hline Formoterol/Budesonida & $4.5 / 160,9 / 320$ & $1-2$ cada $12 \mathrm{~h}$ & Polvo seco & Turbuhaler \\
\hline Formoterol/Budesonida & $4.5 / 160$ & 2 cada $12 \mathrm{~h}$ & Solución & IDMp \\
\hline Formoterol/Mometasona & $5 / 100$ & 2 cada 12 h & Solución & IDMp \\
\hline Salmeterol/Fluticasona propionato & $50 / 250,50 / 500$ & $1-2$ cada $12 \mathrm{~h}$ & Polvo seco & Diskus \\
\hline Salmeterol/Fluticasona propionato & $25 / 250$ & 2 cada 12 h & Solución & Evohaler \\
\hline Vilanterol/Fluticasona furoato & $25 / 100$ & 1 cada $24 \mathrm{~h}$ & Polvo seco & Ellipta \\
\hline \multicolumn{5}{|l|}{ LABA + LAMA + CEI } \\
\hline Formoterol/Glicopirronio/ Beclometasona & $6 / 12.5 / 100$ & 2 cada 12 h & Solución & IDM \\
\hline Vilanterol/Umeclidinio/Fluticasona Furoato & $25 / 62.5 / 100$ & 1 cada 24 h & Polvo seco & Ellipta \\
\hline
\end{tabular}




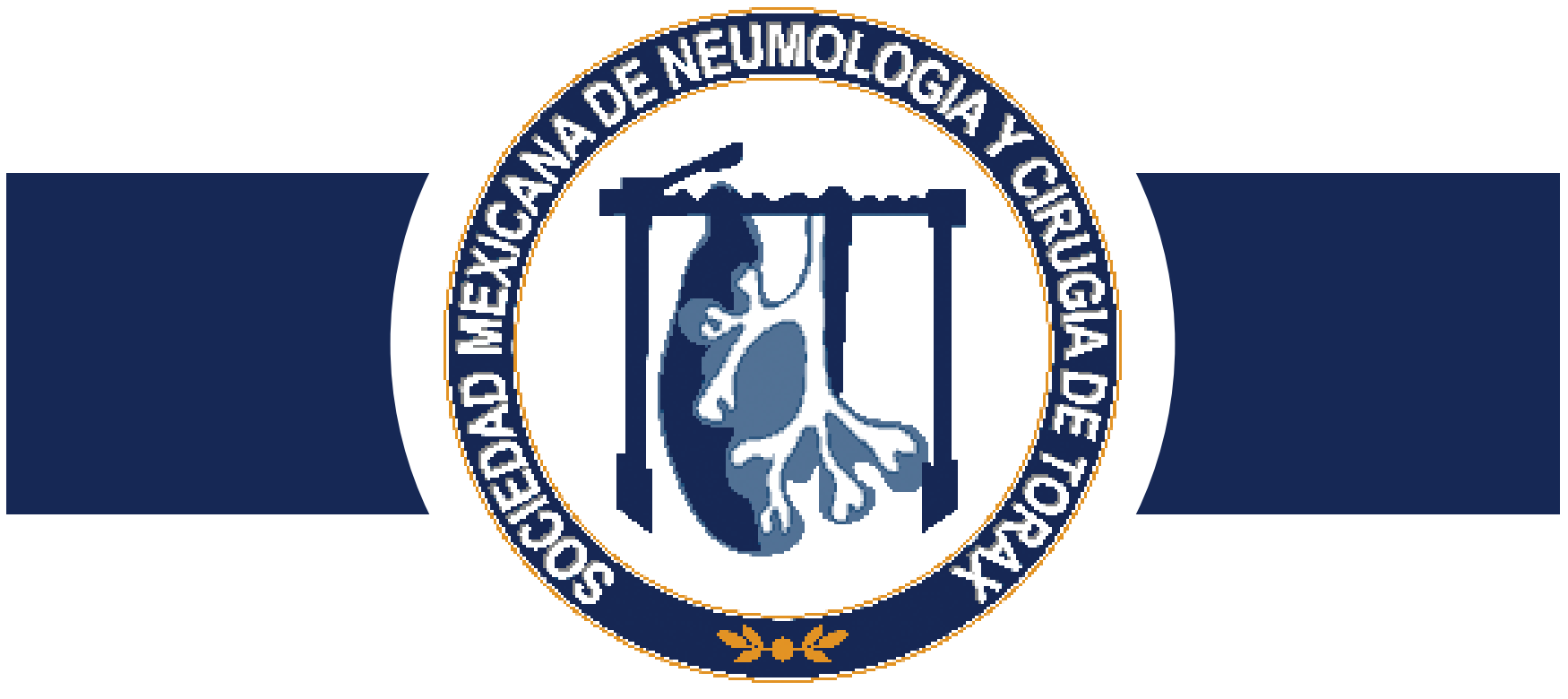

